

\section{DISCLAIMER}

This report was prepared as an account of work sponsored by an agency of the United States Government. Neither the United States Government nor any agency Thereof, nor any of their employees, makes any warranty, express or implied, or assumes any legal liability or responsibility for the accuracy, completeness, or usefulness of any information, apparatus, product, or process disclosed, or represents that its use would not infringe privately owned rights. Reference herein to any specific commercial product, process, or service by trade name, trademark, manufacturer, or otherwise does not necessarily constitute or imply its endorsement, recommendation, or favoring by the United States Government or any agency thereof. The views and opinions of authors expressed herein do not necessarily state or reflect those of the United States Government or any agency thereof. 


\section{DISCLAIMER}

Portions of this document may be illegible in electronic image products. Images are produced from the best available original document. 
SLAC -62

UC-28, Particle Accelerators and High-Voltage Machines

TID -4500 (48th Ed.)

CFSTI ZWRTS

RELEASED FOR ANNOUNCEMENT

IN NUCLEAR. SCIENCE AB́STRACTS
H.c. $\$ 4.00, \mathrm{MN} .75$

\title{
THE STORY OF STANFORD'S TWO-MILE-LONG ACCELERATOR
}

\author{
May 1966
}

by

Douglas Wm. Dupen

\section{LEGAL NOTICE}

This report was prepared as an account of Government sponsored work. Nelther the United States, nor the Commlssion, nor any person acting on behalf of the Commisalon:

A. Makes any warranty or representation, expressed or implled, with respect to the accuracy, completeness, or usefulness of the Information contalned in this report, or that the use of any information, apparatus, method, or process dlsclosed in this report may not infringe privately owned righte; or

B. Assumes any liabllitles with respect to the use of, or for damages resulting from the use of any information, apparatis, method, or process disclosed in this report.

As used in the above, "person acting on behalf of the Commiselon" includes any employee or contractor of the Commission, or employee of such contractor, to the extent that guch employes or contractor of the Commlssion, or employee of such contractor prepares, disseminates or provides access to, any informatlon pureuant to hls employment or contract with the Commission, or hls employment with such contractor.

\section{Technical Report}

Prepared Under

Contract AT(04-3)-400

for the USAEC

San Francisco Operations Office .

Printed in USA. Price \$4.00. Available from the Clcaringhouse for Federal Scientific and Technicial Information (CFSTI), National Bureau of Standards, U. S. Department of Commerce, Springfield, Virginia. 


\section{THIS PAGE WAS INTENTIONALLY LEFT BLANK}




\section{TABLE OF CONTENTS}

Page

I. Introduction ...................... 1

II. The Expansion of Scientific Investigation . . . . . . . . 5

III. Ways and Means of Observation .................. 8

IV. Historical Development of Accelerators . . . . . . . . 11

A. Early Accelerators: Electrostatic Acceleration . . . . . 11

B. The First Big Step: The Cyclotron ............. 13

C. The First High Energy Electrons: The Betatron . . . . . 17

D. Reaching for Higher Energies . . . . . . . . . . 19

E. Higher Energy Electrons: The Electron Synchrotron . . . 20

F. Higher Energy Protons: The Synchrocyclotron ...... 21

G. The Proton Synchrotron . . . . . . . . . . . 23

H. Raising the Limits: The Development of Alternating
Gradient Accelerators . . . . . . . . . 24

I. The Future .................... 26

V. Linear Accelerators . . . . . . . . . . . . . 28

VI. Development of the Electron Linear Accelerator . . . . . . . . 34

A. Resonant Cavity Principle: The "Rhumbatron". . . . . . 34

B. The Traveling Wave Concept .............. 36

C. The First Stanford Machine: The Mark I . . . . . . 37

D. The Klystron Tube . . . . . . . . . . . . 40

E. The Next Machine: The Mark II . . . . . . . . 45

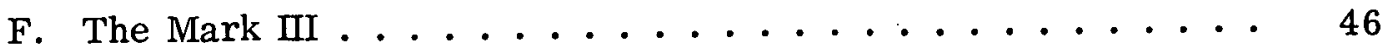

G. Other Stanford Klystron and Accelerator Development . . . . 53

H. The Beginnings of the Two-Mile Machine . . . . . . . 54 
VII. Radiation Shielding for the Accelerator

VII. Radiation Shielding for the Accelerator . . . . . . . . . . 59

VIII. The Site ........................ 66

IX. Accelerator Housing Construction . . . . . . . . . . 70

X. The Acceleration System . . . . . . . . . . . . . 82

XI. Auxiliary Systems ...................... 89

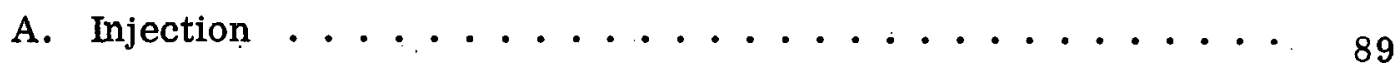

B. The High Power Klystron ............... $9_{1}$

C. The High Voltage Modulator . . . . . . . . . . . 95

D. Trigger System. . . . . . . . . . . . . 95

E. Drive System ........................... 96

F. Phasing System ................... 96

G. Beam Guidance .................. 97

H. Support and Alignment ............... 98

I. Vacuum System ................... 101

J. Temperature Cunlrul Syslem ............. 103

K. Electrical System ................. 105

L. Instrumentation and Control .............. 107

XII. Research With the Beam . . . . . . . . . . . . . 108

Bibliography .............................. 114 


\section{LIST OF FIGURES}

$\underline{\text { Page }}$

1. Aerial view of Stanford's new two-mile-long linear electron accelerator . . . . . . . . . . . . . . . . 1

2. Phantom drawing of the two-mile-long structures comprising the 20-GeV linear accelerator . . . . . . . . . . . . 2

3. Cutaway drawing of the two two-mile-long structures . . . . . 2

1. Sketch of the accelerator site, just west of the campus proper . . . 3

5. The nucleus of the atom appears to be the source of dozens of little-understood "elementary particles" . . . . . . . . . 7

6. Comparison of four "microscopes" . . . . . . . . . . . . 9

7. Negatively charged electrons are repulsed by the like charge from the negative side of a power supply and attracted by the opposite charge of the other side. . . . . . . . . . . . . 12

8. Passing through a magnetic field, a charged particle is made to change direction in a curved path (top) . . . . . . . . . 13

9. The spiral pattern of a particle beam starting in the center of a Cyclotron . . . . . . . . . . . . . . . . .

10. The principle of the Betatron is similar to ordinary transformer action (a) . . . . . . . . . . . . . . . . . 18

11. Principle of operation of a Synchrotron . . . . . . . . . . 21

12. Simplified diagram of the Wideroe type of linear accelerator . . . 29

13. Simplified diagram of the Alvarez type of linear accelerator . . . 32

14. Single resonant cavity accelerator using the Rhumbatron principle . . . . . . . . . . . . . . . . 35

15. Multiple resonant cavity accelerator . . . . . . . . . . 36 


\section{LIST OF FIGURES - Continued}

$\underline{\text { Page }}$

16. Simplified presentation of the traveling wave principle . . . . 38

17. Cutaway drawing showing internal configuration of accelerating waveguide showing three cavity forming disks . . .

18. The original Mark I electron linear accelerator photographed in the Stanford quadrangle and being held by, left to right, S. Kaisel, C. Carlson, W. Kennedy and W. Hansen . . 39

19. Principles of radar operation . . . . . . . . . . . . 41

20. Principle of klystron amplification . . . . . . . . . 43

21. Schematic and plan view of Mark III . . . . . . . . . . 48

22. The first sections of the Mark III accelerator, as seen looking in the opposite direction to beam motion (looking toward the injector) . . . . . . . . . . . . . . . . . . 49

23. The Mark III after replacement of its acceleration sections in 1964 . . . . . . . . . . . . . . . . . .

24. Calculated radiation levels outside the accelerator's earth shield . . . . . . . . . . . . . . . . . 63

25. Location of the Stanford Linear Accelerator Center . • . • • • 67

26. Typical cross sections of Accelerator Housing and earthwork .. . . . . . . . . . . . . . . . 72

27. The two-mile-long cut-and-fill in mid-1964, looking west toward the Pacific Ocean from the initial excavations for the two target buildings . . . . . . . . . . . . . . 73

28. Sketch of the sub-slab laid before Housing construction began . . . 74

29 Sketch of the Housing under construction in the trench _... 75 
30. The first few sections of Accelerator Housing with the pea-gravel back-fill covering the protective Celotex sheets . . .

31. Accelerator Housing construction continued eastward while western portions were being covered with compacted fill ....

32. Sketch of the completed fill over the Housing, showing the top of several of the penetrations leading to the Housing . . . .

33. The western end of the completed Accelerator Housing with 25 feet of compacted earth above it and construction of the Klystron Gallery begun . . . . . . . . . . . . . . 78

34. The framing of the Klystron Gallery . . . . . . . . . . . . . 79

35. Sketch of the Klystron Gallery under construction . . . . . . . 79

36. The complete Klystron Gallery as seen from the injector

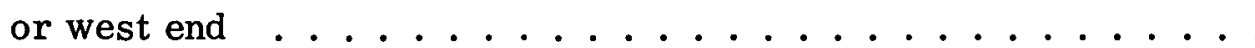

37. Cutaway sketch of the Klystron Gallery and Accelerator Housing showing interconnection penetrations and one of the man accessways ...................

38. Two of the 240 forty-foot-long accelerator stages .......

39. Diagram of the present klystron-to-accelerator configuration (Stage I) and of the possible future configuration (Stage II) . . .

40. Copper cylinders and disks making up the four-inchdiameter, two-mile-long accelerator structure ........

41. One 10-foot section of the accelerator pipe showing the input and output rf couplers at each end and the small center-fed pipes forming the accelerator temperature control jacket .... 


\section{LIST OF FIGURES - Continued}

Page

42. A completed 40-foot module on the transporting rig ready to be taken to the Housing for installation .......... 88

43. The interior of the Accelerator Housing after installation of the accelerator .................... 88

44. Simplified diagram of the injector, showing major components. . 91

45. Cutaway drawing of the SLAC high power klystron amplifier $\quad$. 92

46. Five of the high power klystrons, ready for installation, as manufactured by four different companies and by SLAC itself $\quad . \quad 94$

47. The interior of the Klystron Gallery ........... 94

48. Each 40-foot-long accelerator girder is loosely coupled to the next with a flexible bellows arrangement $\quad \ldots \ldots \ldots$

49. One end of each 40-foot-long girder rests upon three adjustable worm-screw supports ................ . . 99

50. A retractable: Fresnel zone plate target is housed within each 40-foot-long girder to intercept the laser light beam

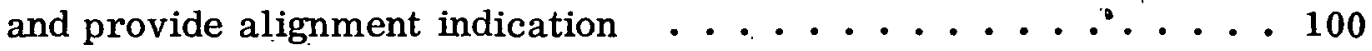

51. Typical block diagram of one of the 70 closed-loop recirculating water systems for the accelerator and its components . . 104

52. One of the pole structures in the SLAC high voltage

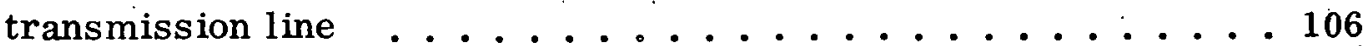

53. The research end of the accelerator .......... 108 


\section{PREFACE}

The two-mile-long electron linear accelerator at Stanford is now a reality. The development of this type of accelerator is barely three decades old and has been carried out primarily at Stanford University. The physical realization of this new machine was done with great dispatch. The details of the story behind this exciting scientific tool exist only in bits and pieces: in specialized professional journals, in government reports, in internal memoranda, in laboratory notebooks, in consultants 'findings, and, in some areas, only in the memories of members of the staff.

The following pages present the story of this accelerator, the background of the development of machines for high energy physics, the appearance and evolvement of traveling wave electron linear accelerators, the design and engineering of this machine, the construction of the facility with particular attention to geological considerations, calculations and planning for radiation containment, and the use of the machine in elementary particle physics research.

Many sources have been drawn from in developing this narrative. Much of this material existed previously but only in widely scattered, often one-of-a-kind, documents. These, which are drawn upon heavily, are listed in the Bibliography and are gratefully acknowledged. 


\section{INTRODUCTION}

Occupying 480 acres of Stanford University's "academic lands, " a 20-GeV electron linear accelerator extends for two miles from west to east (Fig. 1).

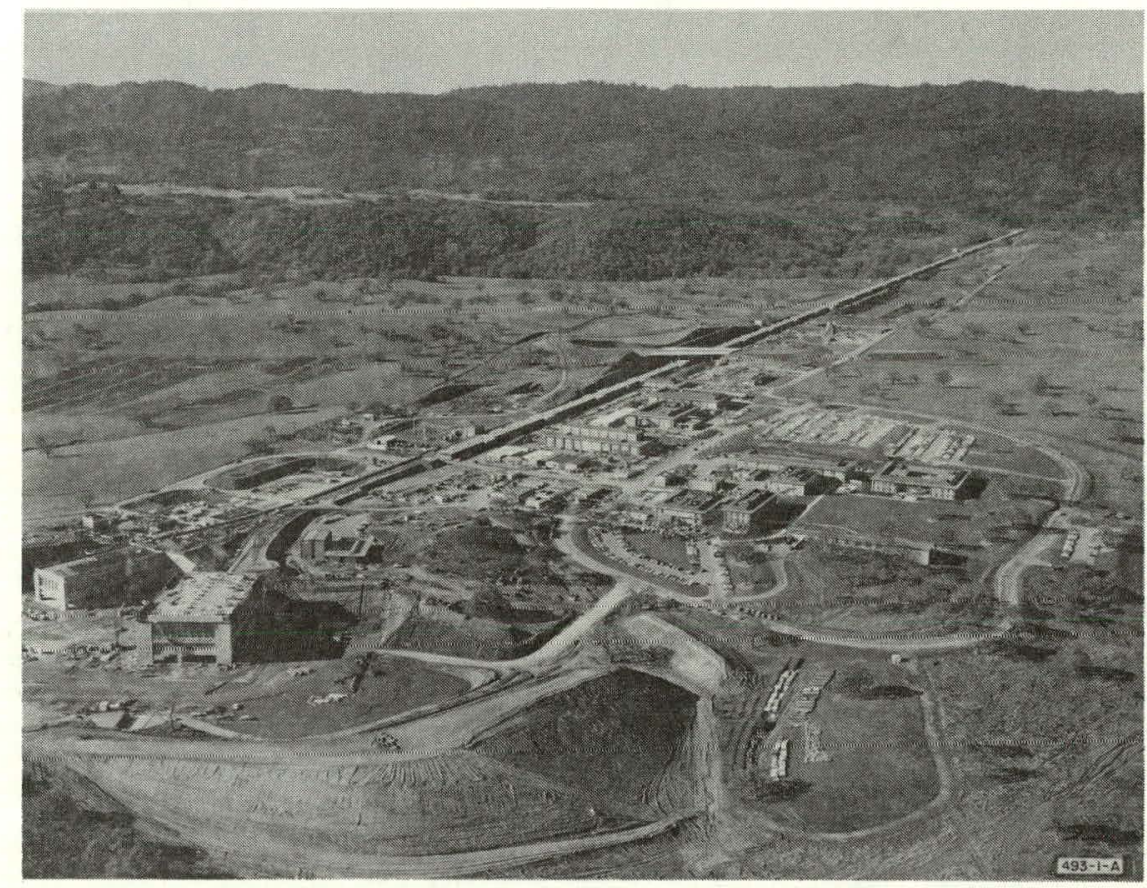

FIG. 1--Aerial view of Stanford's new two-mile-long linear electron accelerator.

On this narrow strip of land, Stanford has constructed a 10,000-foot long concrete tunnel, 25 feet underground. This tunnel, 10 feet by 11 feet in internal cross-section, houses the accelerator proper, a copper cylinder approximately four inches in diameter. Electrons are injected into the west end of this small cylinder and exit from it, after traveling its two-mile length, having been accelerated to as much as 20 billion electron volts of energy.

Parallel to this 10,000-foot tunnel and directly above it at ground level is another 10,000-foot long structure, a 17-foot-high by 30 -foot-wide sheet steel shed. This structure, called the "klystron gallery," contains all the components and devices for providing for the acceleration of the subterranean electron beam. Integration of the functions of these two structures is performed via vertical 
holes ("penetrations") in the separating earth fill. These penetrations, usually 20 feet apart along the entire length, permit interconnection between the equipment in the upper structure and the accelerator tube in the lower structure (Figs. 2 and 3).

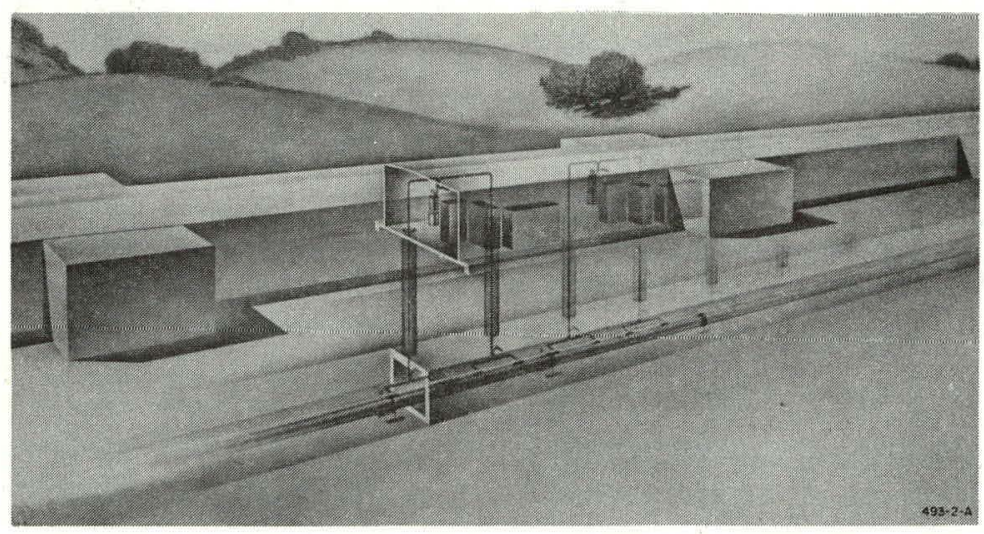

FIG. 2--Phantom drawing of the two 2-mile-long structures comprising the $20-\mathrm{GeV}$ linear accelerator .

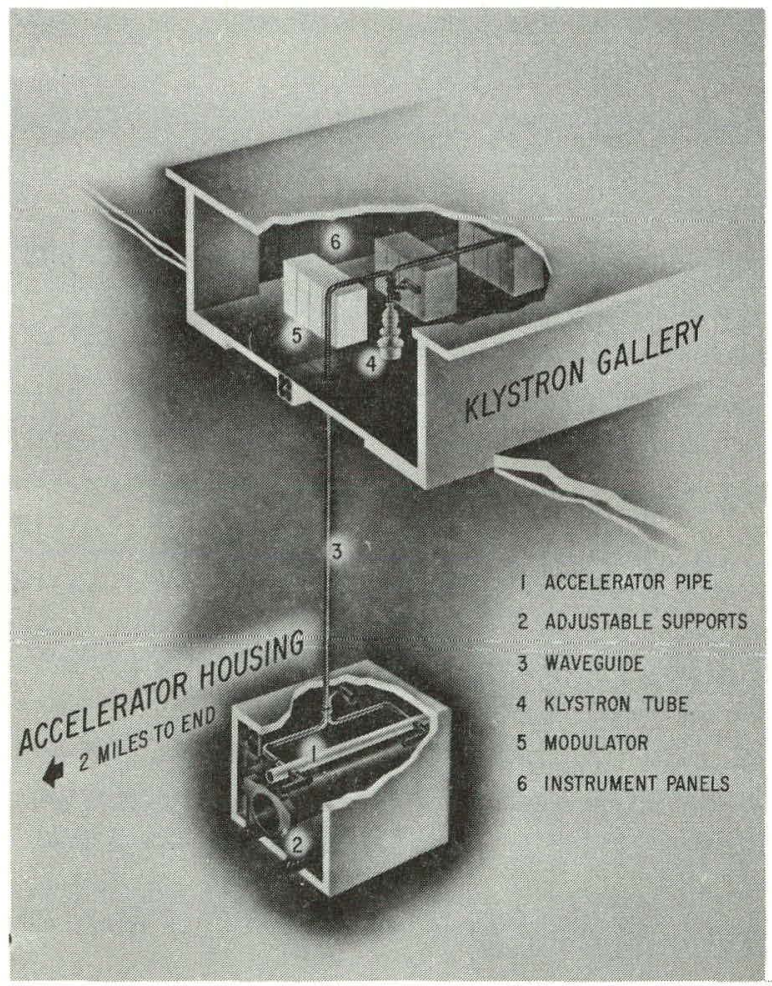

FIG. 3--Cutaway drawing of the two 2-mile-long structures. 
At the exit (east) end of the accelerator, another thousand feet is used up by an underground "beam switchyard" which contains magnets and other devices for bending and directing the accelerated electron beam into selected "target areas" where research with the beam is carried out: 'In this "end station'area" are two very large "target buildings." Two target buildings were planned in order to be able (1) to be preparing one experiment in one target building while the beam is in use in the other, (2) to "share" the beam if desired by directing part of it to one one target building and part of it to the other, and (3) to design and equip the two target buildings differently for the two major classes of experiments performed with this kind of machine.

Also near the east end of the accelerator are the dozen or so large buildings which provide office, laboratory, and shop space for the thousand members of the staff working for Stanford University operating the Stanford Linear Accelerator Center (Fig. 4).

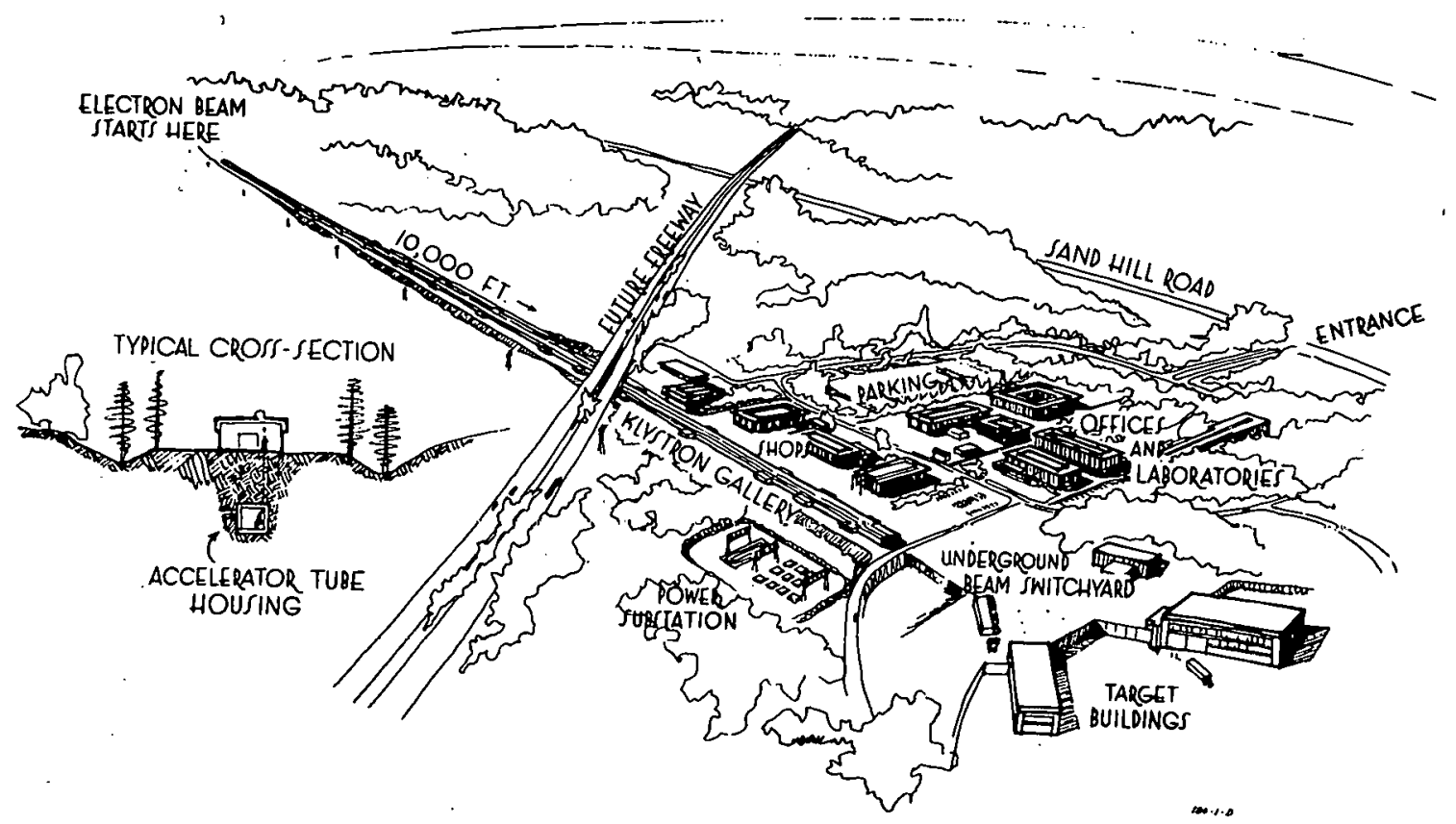

FIG. 4- Sketch of the accelerator site, just west of the campus proper . 
The Stanford Linear Accelerator Center (SLAC) is a national facility designed, constructed, and operated by Stanford University under contract with the U.S. Atomic Energy Commission. The Congress of the United States authorized the project in September 1961. A contract was signed between the Stanford Board of Trustees and the Atomic Energy Commission in April 1962. Ground breaking took place in July 1962. Construction and installation were essentially completed in mid-1966 with research with the beam to begin before the end of that year. This accelerator, costing $\$ 114,000,000$ to design and build, is one of the latest and most esoteric of a continually growing family of gigantic devices to serve the needs of the relatively young new science called "High Energy Physics." 


\section{THE EXPANSION OF SCIENTIFIC INVESTIGATION*}

The exploration of the physical universe has proceeded in two directions, opposite but not unconnected. Our knowledge has expanded to encompass phenomena which take place on a scale vastly different from that of our immediate experience, the astronomically large and the submicroscopically small.

Physicists now comprehend not only the structure of stars, the motion of our own and other galaxies, the curvature of space, the possible ways in which our universe has evolved, but also matter on a smaller and smaller scale: from familiar objects to molecules; then to the atoms of which the molecules are composed; the internal structure of the atom with its electrons orbiting around nuclei; the nucleus itself, made of protons and neutrons and the forces which bind them together; and lately even something of a picture of the inside of the proton itself, complex and containing yet other particles. We are peeling an onion layer by layer, each layer uncovering in a sense another universe; unexpected, complicated, and--as we understand more-- strangely beautiful.

The basic particles out of whose interactions and combinations our whole universe seems to be formed are called "elementary particles." This is a term whose significance has varied enormously as our view of the physical universe has become more detailed and precise; the changes in its meaning mirror the history of modern physics. In the time of Newton and for almost a century thereafter the connection between the structures of different materials was not understood and there were, in this view of our world, as many "elementary particles" as there were kinds of matter: water, salt, oxygen, iron, quartz, etc. ,

\footnotetext{
* Much of the material in this section and the following section appeared in a report originally prepared by a special panel on high energy accelerator phys ics in 1959 for the purpose of acquainting Congressmen with this field of science in preparation for the U.S. Congress' consideration of supporting the construction of the two-mile accelerator.
} 
an immense number. The uncovering of a finer structure to matter, mainly in the nineteenth century, revealed that all matter, with all its different sorts of molecules, was composed of fewer than 100 kinds of atoms; these became the elementary particles of last century's physicists.

Shortly before the first world war we had our first look inside the atom. It appeared as a very small core, the nucleus, surrounded by one or more electrons whose configuration and number determined the chemical properties of the atom. More than three decades ago the tiny nuclei themselves were split open. Observations were difficult, fuzzy, approximate, but clearly showed that all nuclei were composed of combinations of protons and neutrons. And so, as we peeled our onion and looked to more infinitesimal distances, we saw that our approximately 100 atoms were indeed not truly the elementary particles. of our universe, but were themselves made up of a very few kinds: protons, neutrons, electrons.

But the view that these three particles might be the ultimate elementary 、 particles of our universe has been emphatically destroyed. Remarkable ad vances in theoretical understanding and experimental technique have revealed that the appearance of our universe is not nearly so simple. Various elementary particles, when looked, at with instruments which can resolve extrordinarily fine detail, revealed a substructure involving a host of new and strange particles (see Fig. 5). Our onion has more layers.

High Energy Physics is the exploration of this subatomic world. It is concerned with these phenomena, remote from our immediate and familiar surroundings. High Energy Physics research proceeds, not with any view toward specific useful application, but by pursuing discovery for its own sake. It is the very heart of modern physics, and the product of many centuries of effort to understand our universe. 


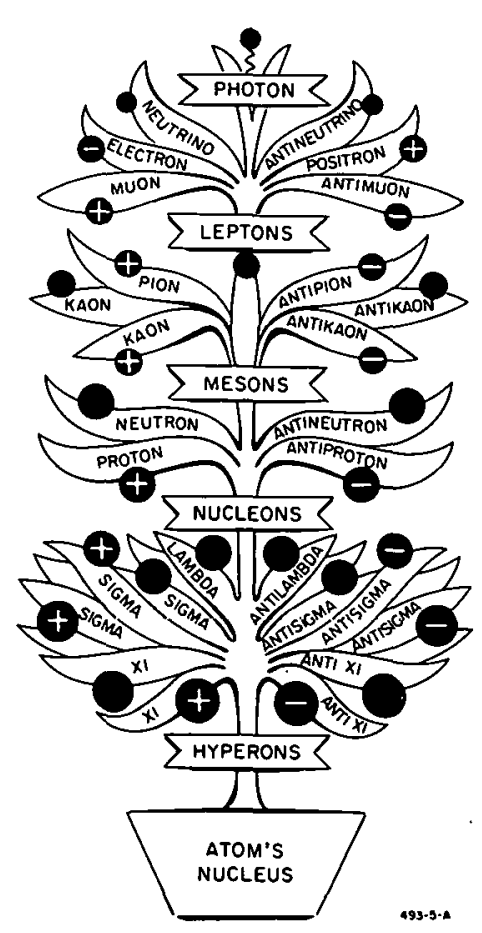

FIG. 5--The nucleus of the atom appears to be the source of dozens of little-understood "elementary particles."

We cannot know what will be discovered from deeper probings of the subatomic world. Our only guide is past experience, and here the lesson is evident that nature often turns out to be remarkably different from any expectation.

Such pure research, stimulated by curiosity and the satisfaction of accomplishment, has given us knowledge and understanding of many of the phenomena of our world. The practical results that must derive from continued exploration with larger accelerators cannot be guessed. If the past is a guide they will.be numerous and fantastic. The one thing that we have learned to expect from nature is to be surprised.

High energy physics is one of the leading intellectual developments of our age. It is not only very exciting but experimentation in this field will probably lead to some of the most important theoretical and perhaps then the most practical developments of our age. ${ }^{1}$

${ }^{1}$ Glenn T. Seaborg, Chariman, U.S. Atomic Energy Commission 


\section{WAYS AND MEANS OF OBSERVATION}

With our eyes we can distinguish objects whose size is as small as threethousandths of an inch. A microscope is used in order to see detail on a much smaller scale than that. But the nature of visible light limits the sharpness of detail that can be observed even with a microscope. Theory predicts and experiment confirms that with even the most perfect optical instrument it is not pos.sible to see anything smaller than about ten-millionths of an inch, a thousand times the radius of an atom, a hundred million times as large as a nucleus. And so in the conventional sense we cannot see an atom or a nucleus, nor can we ever hope to do so. The exploration of atomic and nuclear particles demands a different type of vision, different kinds of instruments.

One way to try to see atomic particles is to use light of wavelength much shorter than that of normal visible light. Such short-wavelength forms of lights are emitted only by sources that can impart a great deal of energy to a. single light wave; the higher the energy, the shorter the wavelength and the more clearly we can see.

However, short-wavelength light is not the only tool used to explore down to nuclear dimensions and below, nor is it even the main one. A beam of subatomic particles itself can be used, like a beam of light, to probe the atom, the nucleus, and beyond. Particles of matter--electrons, protons, and all the rest --behave in many phenomena exactly like light waves. They, too, have associated with their motion a wavelength which decreases as their energy increases.. And, as with light, this wavelength limits the detail that can be examined with a beam of particles. Thus an electron microscope, which uses an electron beam instead of a beam of visible light, defines more detail because it utilizes electrons whose wavelength is smaller than that of visible light. The definition increases with the electron energy (Fig. 6). 


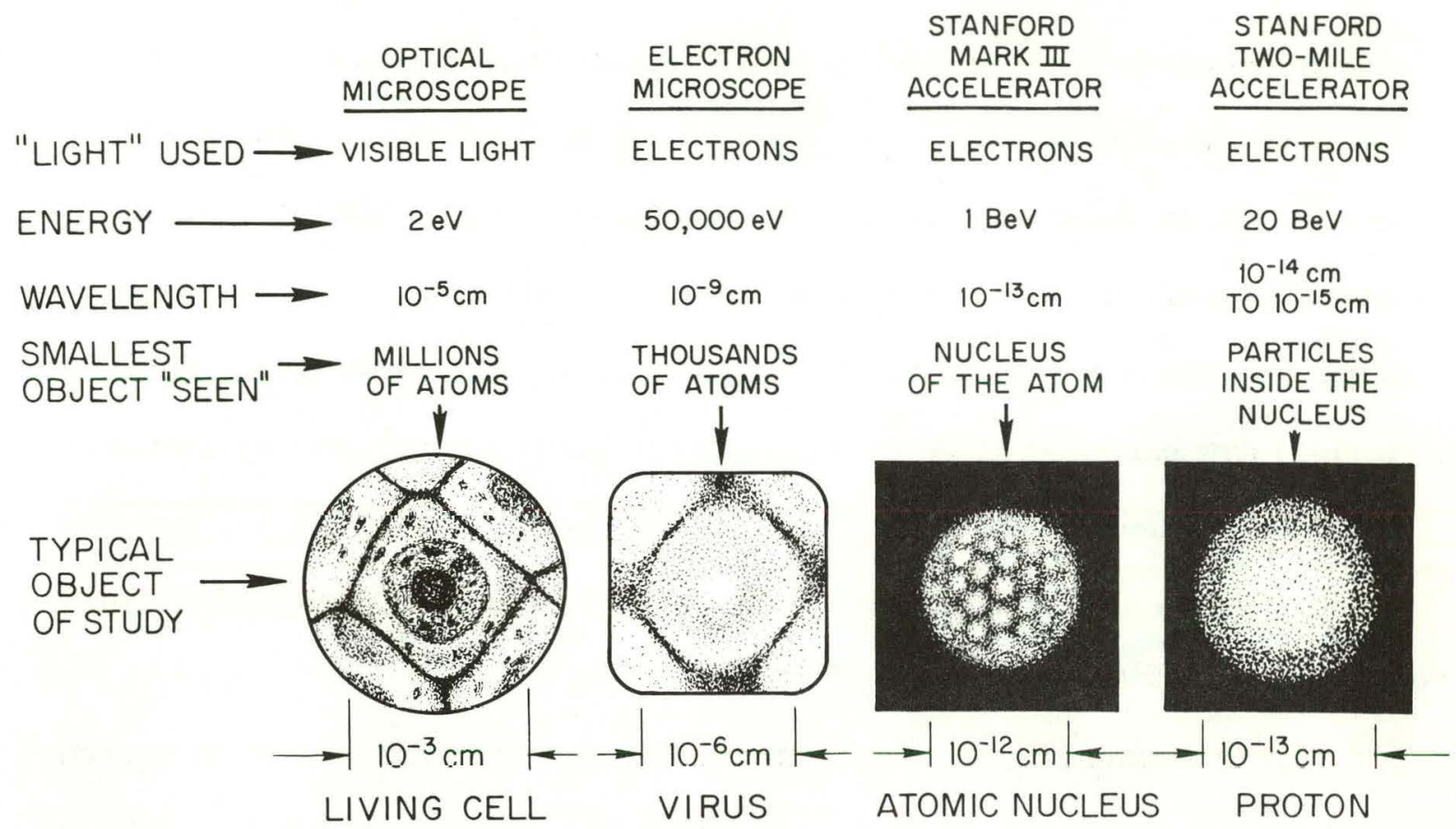

FIG. 6--Comparison of four "microscopes." 473-2-8

Of course, a "look" with a beam of electrons gives a type of picture different from the kinds obtained with visible light. Beams of high-energy protons furnish still another view of our submicroscopic universe. The various views obtained by using different kinds of beams are all equally valid descriptions but differ in the precise information which they give. It is figuratively as if we had photographed our landscape with a variety of cameras, one of which films only the houses, another the trees, a third the streets.

The familiar objects around us are unaltered when we turn on a light in order to see them; the molecules and the atoms of a cube of sugar or a glass of water are not appreciably disturbed by visible light. However, if we increase the energy of the light or particle beam in order to decrease its wavelength and see at atomic dimensions, then the energetic light waves or particles seriously shake up the atoms and often break them up into their constituent electrons and 
nuclei. Beams with a wavelength short enough to probe a nucleus also have high enough energy to split the nucleus apart by knocking out the tightly bound protons and neutrons of which it is made. A detailed observation violently disturbs the system that is observed. In this way a sufficiently high-energy beam of light (particles) striking a proton or neutron or any other target particle has two associated consequences. It offers a partial view of the target's interior, and it frees various new particles which may usually exist only within a struck particle.

Thus the main tools of the physicist who explores the subatomic universe are the beams of high-energy particles which are his light, and the various devices to detect these particles which are his eyes.

Our understanding of the ultimate structure of matter and energy depends upon the great particle accelerators, which take low-energy electrons or protons and impart to them the enormous energy necessary to "see" to distances which are to the thickness of a sheet of paper as the thickness of a sheet of paper is to the distance to the moon. 


\section{HISTORICAL DEVELOPMENT OF ACCELERATORS}

Types of subatomic particles commonly used to form beams in accelerators are electrons, protons, deuterons, and alpha particles. The last three, nuclei of hydrogen, deuterium, and helium atoms respectively, are classed as "heavy particles." and are positively charged. Electrons are negatively charged particles, external to and much lighter than nuclei.

\section{A. Early Accelerators: Electrostatic Acceleration}

Around the middle of the first half of this century, men began to develop devices to accelerate beams of such subatomic particles so that controlled experiments could be performed using the beams as investigatory tools. These early machines caused whatever particles were to be accelerated to pass through a potential field. The higher the voltage of this potential field, the more energy the particle beam acquired and the more useful it became.

Energies of particle beams are measured in units called "electron volts" (eV). Thus if an electron passes through a potential field of 500 volts, it will acquire an energy of 500 electron volts $(500 \mathrm{eV})$. If a proton traverses a 10,000volt potential field, it acquires an energy of 10,000 electron volts (10 keV). Beam energies of these magnitudes were easily achieved in these early "electrostatic"type accelerators (see Fig. 7). Power supplies to provide the necessary voltages for higher energies than this were not feasible to build.

To reach higher energies, several techniques were developed. One was to allow a particle beam to pass through several such potential fields in succession, gaining energy in each step. Another technique is to charge up several high voltage capacitors each to the maximum voltage of the available power supply and then to discharge these capacitors all in series across an accelerator tube while a particle beam is injected at one end. The resultant energy then is proportional 


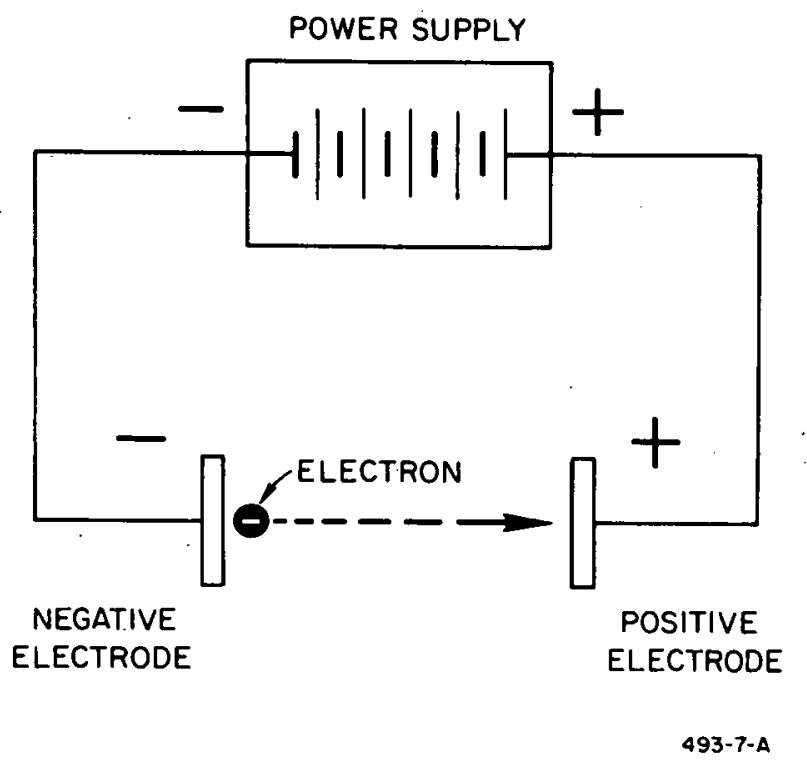

FIG. 7--Negatively charged electrons are repulsed by the like charge from the negative side of a power supply and attracted by the opposite charge of the other side. In moving through the voltage field, the electron gains energy. Elescrostatic accelerator development concentrated on the design of various kinds of power supplies to provide higher and higher voltages and consequently higher and higher energies.

to the sum of the voltages on all the capacitors. This last technique is the basis of the "Cockroft-Walton generator" type of accelerator. Such machines are in use today, generating beam energies as high as several million electron volts (MeV).

Still another technique, developed by R. Van de Graaff in the early thirties, is to take the charge from a power supply and deposit it on a moving pulley which carries the charge to a large sphere, a sphere smooth enough to retain the charge without arcing. By doing this continually for some time, a very huge charge, and consequently high voltage, is built up on the sphere. The particles to form the beam then enter an accelerator tube at one end at ground voltage and are attracted by the high voltage on the sphere a distance away. Beams generated in present Van de Graaff generator type accelerators have reached energies as high as $10 \mathrm{MeV}$. By operating several hydrogen ion Van de Graaffs in tandem and by 
alternating the charge of the accelerated particles by successive addition and. stripping of electrons, even higher energies are achievable.

\section{B. The First Big Step: The Cyclotron}

Again, back in the early thirties, several people were working with the idea of having a beam of particles traverse a row of several relatively low voltage potential fields in succession. Pure physical size and expense limited the possibilities of this technique until E. O. Lawrence at the University of California conceived the idea of causing the beam to move circularly and to return to and re-traverse, over and over again, alternating voltage fields. Thus was born the Cyclotron.

The principle on which this design was based is that any charged particle, passing through the magnetic field between the poles of a magnet, is made to change direction in a curved path (see Fig. 8). With a large electromagnet of

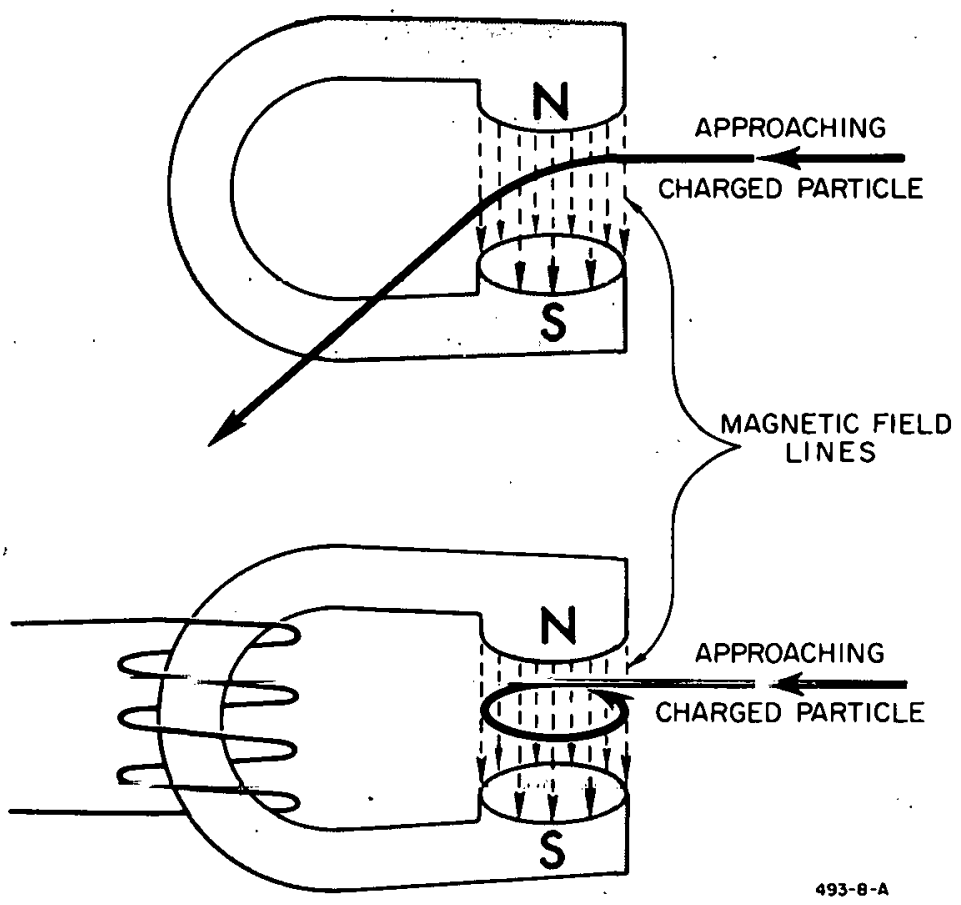

FIG. 8--Passing through a magnetic field, a charged particle is made to change direction in a curved path (top). If the magnetic field is strong enough, the curved path will be tight enough to cause continuous circulation. 
sufficient magnetic strength, particles passing between its poles and into the magnetic field are curved in direction so much that they actually circle back on themselves and continue to circulate, never leaving the field. Lawrence's idea was to have particles do just that but to pass through a pair of alternating high voltage fields with each turn. The total energy the particles would achieve would then be proportional to the number of circular trips the particles took.

In the device that materialized from this thinking, the particles actually pass through two voltage fields, one during each half-turn. One voltage field is set up along a complete diameter of the circle. After the particles pass across this diameter once, acquiring energy, the voltage on the diameter is reversed. Then when the particles have completed a half-turn to cross the diameter at the opposite side, they are again accelerated. So that the particles do not feel the presence of these voltages while they are moving from one crossing point to the other, they are contained during their semi-circular movement in an enclosure shielding them from the accelerating voltage difference.

Practically, this is done by building two devices in the shape of the letter "dee." It is as if an empty tuna fish can were sawed in half from top to bottom, forming two dee-shaped cavities. These two dees are then put back together except that a little space is left between them. This double-dee arrangement is then set between the poles of a magnet. If charged particles are placed inside one of the dees and are started moving, they will move in a curved path until they reach the point of exiting from the dee. A high voltage is placed across the dees of such polarity that as the particles leave one dee and enter the other, they are accelerated and increase in energy. The particles then continue in their path until they have made a half-circle and prepare to exit from the second dee. By this time, the voltage across the dees has been reversed so that on this second inter-dee transit, the particles are again accelerated. Each time the particles 
complete another semi-circle and pass between the dees, the voltage across the dees is reversed so that acceleration continues and energy continually builds up.

The continual reversal of voltage polarity is accomplished by connecting the two dees to the two output terminals of a radio-frequency generator. This $\mathrm{rf}$ generator produces an alternating voltage of a very high, constant frequency. A constant frequency of voltage alternation can be used because of two opposite effects which cancel each other. First, as the particles gain energy they of course increase in velocity, traveling faster in each half-turn. However, this same increase in energy makes it harder for the magnetic field to curve the trajectory of the particles so that each half-turn is a semi-circle of larger radius than the previous one. This longer path the particles must follow, because of the larger semi-circle, is compensated for by the fact that the particles are moving faster. Thus the time to complete each half-turn is always the same, regardless of the amount of energy the particles have been given.

This constant enlarging of the circular path means then that the particles actually follow a course which is much like a spiral (Fig. 9). The particles are

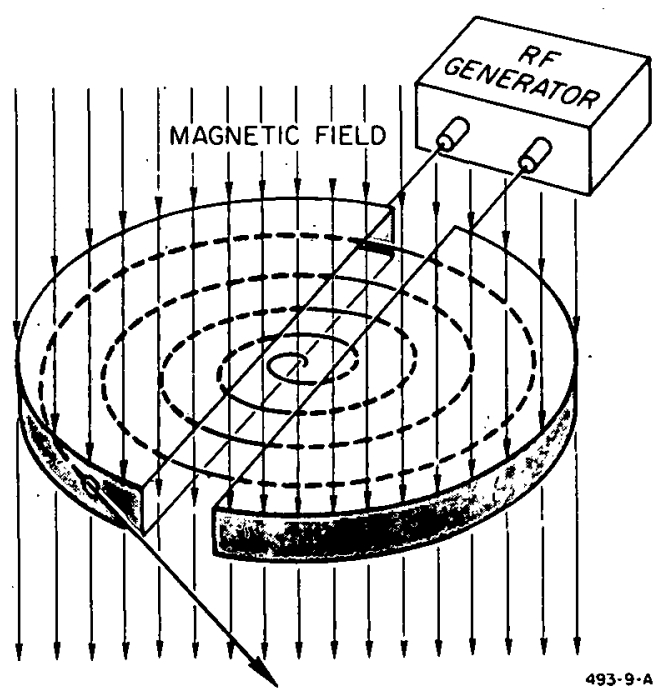

FIG. 9--The spiral pattern of a particle beam starting in the center of a Cyclotron. 
started in the very center of the apparatus and are attracted to whichever dee has the appropriate voltage polarity. In this first dee, the particles begin to turn. Then they cross the gap and enter the other dee, having gained some energy. The turn in the second dee is a wider semi-circle than in the first. Upon reentry into the first dee, the energy has been again increased by the traversal of the gap and the semi-circle is larger again. Finally, when the path has spiraled out to the periphery of the dees, the particles are extracted from the Cyclotron and directed to a target in an experimental area. (This extraction is done by having the magnetic field at a point on the edge of a dee be slightly reduced so that the degree of turn is reduced. Then an electrostatic deflection plate attracts the beam toward the desired target.)

There is a limit, however, to how high an energy can be achieved in a Cyclotron. This limit is set by effects due to relativity. As any moving particle increases in energy, there is also a proportional increase in mass. This mass increase (which takes place at the expense of the desired velocity increase) means that as higher energies are achieved, the rate of increase of velocity is no longer the same as the rate of increase of energy. The increase in velocity with each half-turn is no longer sufficient to compensate for the increased radius of the semi-circular path. Thus the particles begin to fall behind the constant rate of voltage change on the dees so that they no longer cross the gap at the right time. Eventually they would fall so far behind that they would actually be decelerated. In the case of the "heavy particles," this effect is not significant until the accelerated particles reach energies above about $20 \mathrm{MeV}$. This magnitude of beam energy is very useful. Cyclotrons of energies in this range are in use today, accelerating protons, deuterons, alpha pärticles, etc.

But the extremely small mass of the electron and the ease with which electrons can be accelerated to high velocities mean that this effect would limit the 
acceleration of electrons in Cyclotrons to only a few hundred electron volts. For this reason the first attempts at acceleration of electrons to energies higher than those achievable in electrostatic accelerators had to take an entirely different path.

\section{The First High Energy Electrons: The Betatron}

This different path eventually led to the Betatron, a high energy circular electron accelerator, the first one of which was built in 1940 by D. W. Kerst at the University of Illinois. The principle of operation of the Betatron is similar to the action that takes place in an electrical transformer. In a transformer, an electric current is sent through a primary winding or coil. This current sets up lines of force (flux) around the coil. A secondary coil, adjacent to the primary, lies within these flux lines. Now if the current in the primary is caused to vary in intensity, the flux lines also change in strength. This change of flux "induces" a similar current to flow in the secondary coil. If the current in the primary is increased, the flux lines increase, and the electron flow in the secondary increases (Fig. 10).

In the Betatron, much the same thing happens. Electrons are injected into a doughnut-shaped vacuum chamber placed in a magnetic field. As for a Cyclotron, this magnetic field guides the electrons in a circular path so that they move around and around inside the vacuum ring. The windings of this electromagnet can also act as the primary coil of a transformer and the circulating electron beam as the secondary. coil. Increasing the current to the magnet increases the flux to the "secondary and the circulating electron beam is accelerated, gaining energy.

Of course; were nothing else done, the circular path of the accelerating electrons would spiral out and the beam would strike the walls of the vacuum chamber before much energy had been gained. In order for this not to happen, 
the strength of the magnetic field guiding the electrons in the circular orbit is increased as the flux is increased. Thus as the electrons gain energy and try to enlarge their orbit, the magnetic field increases and constrains the orbit to its original radius.
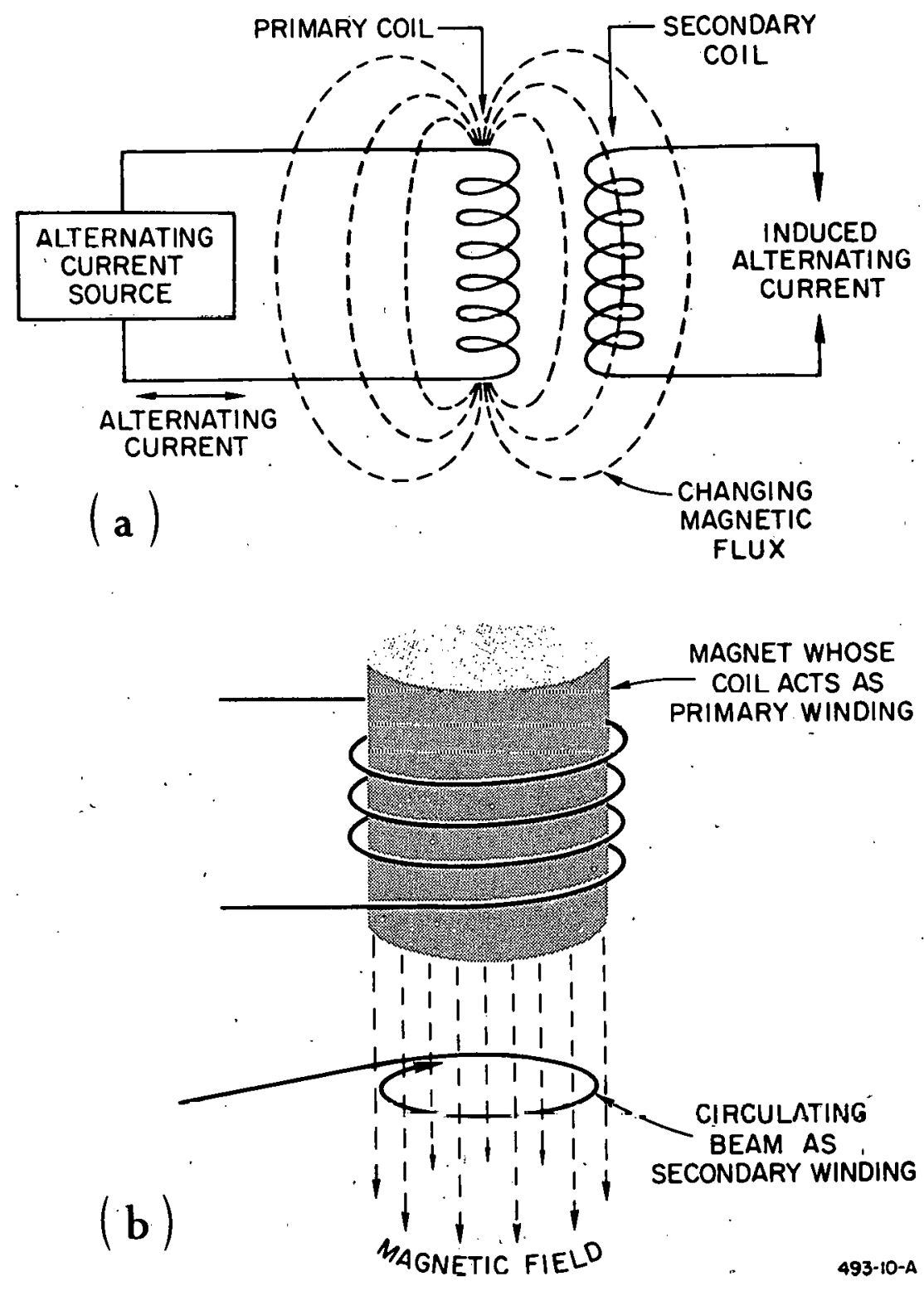

FIG. 10--The principle of the Betatron is similar to ordinary transformer action (a). The electromagnet which sets the curved trajectory of the electron beam also serves as the primary winding inducing energy in the secondary winding, the electron beam itself (b). 
The changing magnetic flux providing acceleration and the increasing magnetic field guiding the electrons can be produced by a properly designed common magnet or by separate magnets. The latter technique provides more flexibility in design and operation.

These changing magnetic parameters mean, of course, that the Betatron has a parameter which a Cyclotron does not, "pulse ratie." In a Cyclotron the protons can be accelerated continuously and can exit from the machine in a steady flow. However, a Betatron must be recycled. When the magnetic flux has increased to produce the desired energy in the circulating electron beam, the accelerated electrons are extracted from the machine, the original conditions must be restored, and the entire procedure must be recommenced.

A new group ("pulse") of electrons is then injected and the cycle is started over again. The new $340-\mathrm{MeV}$ Betatron at the University of Mlinois operates at a pulse rate of six pulses (cycles) per second.

D. Reaching for Higher Energies

With the Cyclotron, proton energies of up to about $20 \mathrm{MeV}$ are achievable. During the late 1040 's, Betatrons were capable of producing electron energies to $70 \mathrm{MeV}$. The aim for higher energies than these was made more practical by the independent but simultaneous work of E. M. McMillan at the University of California and of V. I. Veksler of the U.S. S. R. Their studies of the Cyclotron method of acceleration resulted in two different techniques for overcoming the relativistic limiting of achievable energies caused by the particles in the beam getting out of step.with the alternating voltages providing the energy increases.

To "synchronize". the circular orbital beam traversals with the accelerating alternating voltages, either of two things can be done. Either the accelerating voltages can be slowed down as relativity slows down the beam velocity, or 
the guiding magnetic field can be increased in strength as the beam gains energy, thus constraining the beam from increasing its orbit radius and time of motion.

\section{E. Higher Energy Electrons: The Electron Synchrotron}

The latter of the above two plans was the first to be implemented. To achieve higher electron energies than practical in a Betatron, the Electron Synchrotron was developed. The Electron Synchrotron is an accelerator which combines the Cyclotron method of acceleration with the technique of having the magnetic guide field strength increase as the electron energy increases due to traversals of alternating voltage gaps in the circular path.

The characteristic of an electron which makes this technique practical is the fact that electrons, being so light; are very easily gotten up to a near-maximum constant velocity. Electrons travel at $98 \%$ of the velocity of light, the maximum velocity, with only $2 \mathrm{MeV}$ energy.

The Electron Synchrotron consists of a doughnut-shaped vacuum chamber into which electrons are injected at about this constant-velocity energy by a smaller accelerator such as one of the electrostatic types. The electrons begin their circular motion, passing through alternating voltage gaps in their path. The vacuum chamber is surrounded by a ring magnet whose field makes the electrons follow the circular path defined by the interior of the vacuum ring .

As the electrons gain energy and become harder to turn, the field strength of the surrounding ring magnet is synchronously increased. This keeps the electron trajectory in one single circle of constant radius. Because the electrons are traveling at essentially constant velocity in a constant-length path, the alternating voltages at the gaps can continue to be reversed at constant frequency (Fig. 11). 


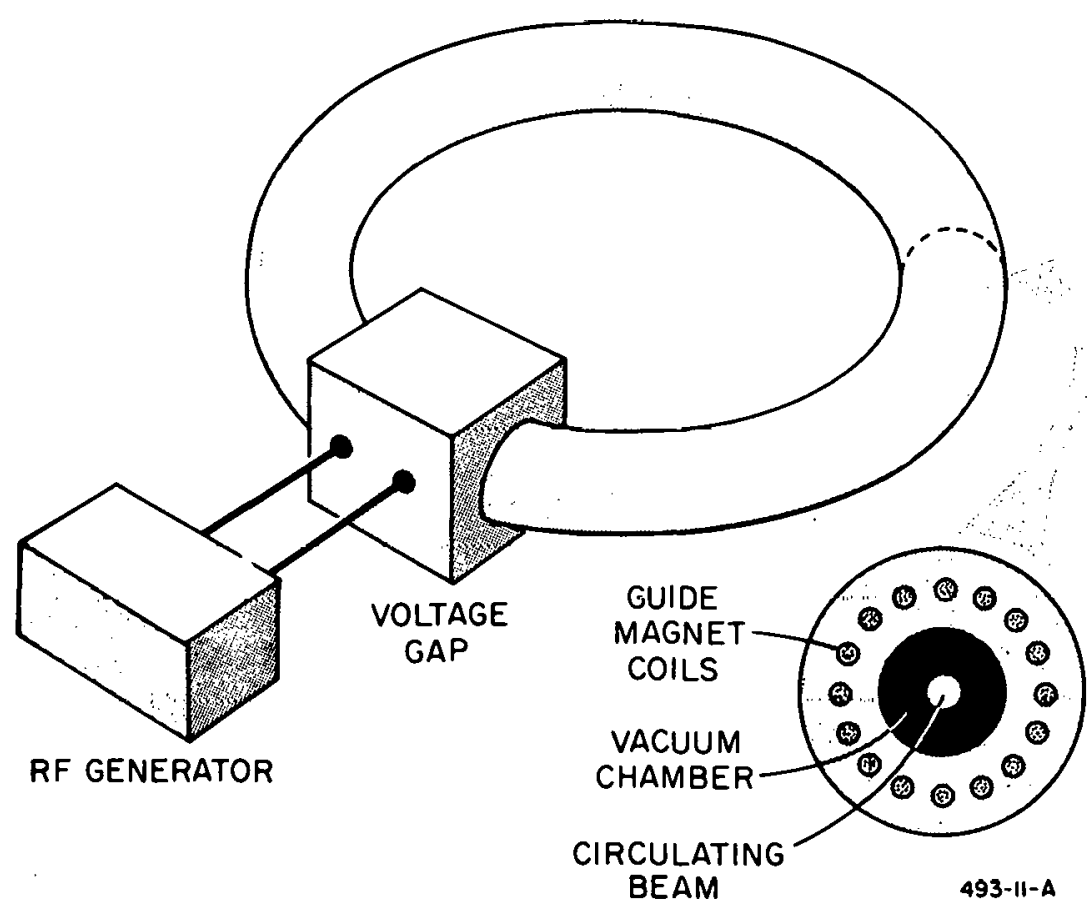

FIG. 11--Principle of operation of a Synchrotron. The entire structure is doughnut shaped. Increasing the magnetic field in the guide magnet keeps the beam in a uniform circle. One of more voltage gaps provide periodic acceleration.

The Mc Millan-Veksler work appeared in 1945. By the end of that decade, several Electron Synchrotrons in the energy range of from 300 to $350 \mathrm{MeV}$ were built. At Frascati, Italy and at the California Institute of Technology, Electron Synchrotrons are now operating at energies well above $1000 \mathrm{MeV}(1 \mathrm{GeV}) .{ }^{1}$ (Even larger ones, using some slightly different principles, have also been built. See Section $\mathrm{H}$ below.) Like the Betatron, synchrotrons must also be "pulses." F. Higher Energy Protons: The Synchrocyclotron

The other McMillan-Veksler alternative was used in the first attempts to reach higher proton energies than achievable in Cyclotrons. Synchronization

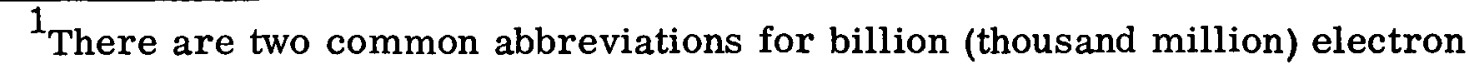
volts. America uses "BeV," Europe uses "GeV." Because "BeV" means something else in Europe and because of the extensive international intercourse in this field, "GeV" is becoming more and more accepted world wide. "GeV" will be used here. 
of beam circulation with the alternating accelerating voltage is achieved by reducing the rate at which the alternating voltage reverses as the particle beam slows down with increased energy. This machine, the Synchrocyclotron, has a constant-strength magnetic guide field so that the beam path remains a spiral from the center to the outer edges. As the spiral radius increases and relativity causes the particles to drop behind the rate of alternation of accelerating voltage, the accelerating rf voltage is "frequency modulated." This means that the rate of alternation of the voltage at the gaps is slowed down at the same rate the particle velocity increase is slowed down due to relativity effects. The polarity of the voltage changes only when the particles traveling in the semi-circle of the dee can manage to get to the gap. The rate of voltage polarity change (the frequency of the rf generator) is the lowest when the particles have reached their highest energies and are at the edge of the Synchrocyclotron dees, ready for ectraction. This technique overcomes the problem caused by the relativity effect; the changing dee voltage remains in step with the cycling of the particles. The rf generator frequency decreases as the rate of increase in velocity becomes less.

The first large Synchrocyclotron was operated at the University of California in 1946. This machine produced proton beams of energies to $350 \mathrm{MeV}$. Rebuilt later, this machine now achieves energies to $740 \mathrm{MeV}$. In Switzerland and in Russia there are Synchrocyclotrons capable of energies to 600 and $680 \mathrm{MeV}$, respectively.

Were Synchrocyclotrons to be built to achieve energies much greater than this, a problem arises in retaining the particles stably in their outer orbits. Even with this problem overcome, there is also a practical limit from the point of view of economics. Synchrocyclotrons are huge machines. For example, the Synchrocyclotron at the University of California uses a magnet which is over 
15 feet across and which weighs over 4000 tons. To build a Synchrocyclotron larger than this is extremely expensive. The cost per MeV of energy increase becomes higher and higher as the magnet becomes larger and larger.

G. The Proton Synchrotron

To reach higher proton energies, it was decided to return to the other McMillan-Veksler alternative. This was the technique used for the Electron Synchrotron, the technique in which the strength of the guiding magnetic field was increased as particle energy was increased during acceleration.

The resulting Proton Synchrotron, like the electron machine, has a doughnutshaped vacuum chamber into which the beam particles are injected. A ring magnet surrounding the vacuum chamber keeps the beam moving circularly along the center of the chamber. As the particles gain energy from traversing the alternating voltage gaps, the strength of the guiding magnetic field is increased. Thus the particles continue to travel in a common single circular path of constant radius.

There is a major difference, however, between Proton and Electron Synchrotrons. As mentioned above, it is easy to get electrons to near the velocity of light, where their velocity remains nearly constant. This means that electrons in a Synchrotron complete each circle in the same amount of time regardless of energy increase.

This is not the case for protons. They do not achieve this convenient nearconstant velocity until they reach energies of about $5 \mathrm{GeV}$ or more. Therefore, as protons gain energy in a Synchrotron, they do continue to increase in velocity. Because the path the protons travel is a constant one, they continually gain on the alternating voltage at the accelerating gaps. So once again, the alternating rf generator must be frequency modulated. In the Synchrocyclotron, the rate 
of voltage alternation is decreased as higher energies are achieved. In the Proton Synchrotron, the opposite is the case: The frequency of the $\mathrm{rf}$ generator must be increased as the particles speed up with increased energy.

Because there is no spiral motion in a Synchrotron, the guide magnet need not cover the entire area of the round machine. Instead the magnet is constructed just around the ring-like vacuum chamber. This cost saving is the big factor making the Proton Synchrotrons preferable to Synchrocyclotrons at high energies.

The first two large Proton Synchrotrons, completed in the early 1950 's, were the Cosmotron at Brookhaven National Laboratory ( $3 \mathrm{GeV})$ and the Bevatron at the University of California (6.2 GeV). Similar to these are several more, including ones in Russia (10 GeV), in France (3 GeV), at Princeton University (3 GeV), in England (8 GeV), and at Argonne National Laboratory (12.5 GeV). High energy Synchrotrons require that the electrons or protons be injected into the accelerator after being previously accelerated to an appreciable energy. This is usuallydone by employing a smaller accelerator such as a linear accelerator, itself fed by an electrostatic injector. These injectors assure that the pulses of particles introduced into the Synchrotron have sufficient energy to enter the designed orbit.

H. Raising the Limits: The Development of Alternating Gradient Accelerators

A new principle of guide magnet design, which was started in 1952 , has led to a series of accelerators capable of much higher energies than were economically practical with any of the above techniques. The accelerators described above all focus their beams using a technique called "weak focusing." To keep the circulating beam from being displaced from the desired orbit, either axially or radially, during acceleration, the instantaneous guiding magnetic field is made to be a little less toward the outside of the circular machine than it is at 
the same time at smaller radii. This slight distortion (a "gradient" field) provides restoring forces to maintain the desired orbit. ${ }^{1}$ However, the solution to magnet design problems made weak focusing more and more expensive as higher energies were reached for.

The innovation which replaced weak focusing at higher energies is called "strong focusing" or "alternating gradient focusing." The technique developed was to divide the guide magnet into sections around the machine. Alternating sections would have a slightly larger instantaneous magnet field at larger radius while the intermediale sections would have a slightly less instantaneous magnetic field at larger radius. Together these alternating gradient fields would comprise a converging lens system which would provide the necessary focusing more practically at higher energies.

This technique has been applied to many kinds of accelerators. Alternating gradient Electron Synchrotrons, using this focusing method, have been built for beam energies to $6 \mathrm{GeV}$ at Cambridge, Massachusetts; at Hamburg, Germany; and at Erevan, Russia.

Alternating gradient Proton Synchrotrons are in operation at Brookhaven National Laboratory, New York ( $33 \mathrm{GeV}$ ) and at Geneva, Switzerland (28 GeV). Being put into operation is a machine in Russia to achieve up to $70 \mathrm{GeV}$. The U.S. Atomic Energy Commission is supporting the establishment of an alternating gradient Proton Synchrotron to reach energies as high as $200 \mathrm{GeV}$. Scientists at various laboratories are making conceptual studies of even larger

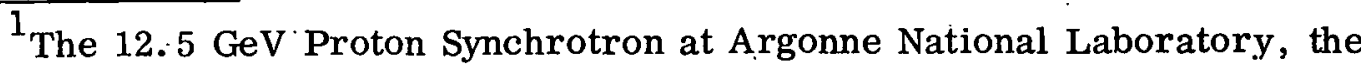
"zero-gradient synchrotron" or ZGS, accomplishes its weak focusing by special shaping of the edge faces of the guide magnet rather than by having the magnetic ficld decrease at larger radii. 
alternating gradient Synchrotrons, perhaps several miles in circumference, to produce proton beams of many hundreds of $\mathrm{GeV}$.

Even the early-appearing Cyclotron has been embellished by a modification of this technique. Using an "azimuthally varying magnetic field" (the magnet looks like a pinwheel of alternating high and low field areas ) to provide focus ing , AVF Cyclotrons are in use today providing beams of several hundred $\mathrm{MeV}$ of energy.

I. The Future

Nothing but economics limits the size of an alternating gradient Proton Synchrotron. New innovations in beam handling and in adapting such machines to higher and higher energies are constantly being developed. Thus this kind of acceleration of protons can continue to higher energies with no theoretical limit.

However, this is not the case for the acceleration of electrons: Any charged particle constrained to move in a circular orbit by a central accelerating force radiates energy away from itself because of this acceleration. This means that as the particles in the beam are given energy to produce acceleration, they must also be given additional energy to compensate for the energy lost because of this "synchrotron radiation."

The higher the energy the particle has been given (the higher its velocity), the greater is this energy loss by radiation. For any type of particle, this phenomenon does not become a nuisance until the particles are traveling at nearly the velocity of light ("relativistic velocities").

The amount of this energy loss at a given energy is much greater for the smaller electrons than for the much more massive protons. For protons, the energy loss is not so large that it cannot continue to be made up for by increasing the energy added at each accelerating gap. For electrons, however, the 
energy loss is so great that before reaching an energy of about $10 \mathrm{GeV}$, the electrons in an Electron Synchrotron begin to lose more energy than practical power supplies can replace. ${ }^{1}$

Therefore, efforts to provide electron beams of energies higher than practical in Electron Synchrotrons had to be confined to extending the development (and size) of linear accelerators where the absence of circular motion removed this relativistic obstacle.

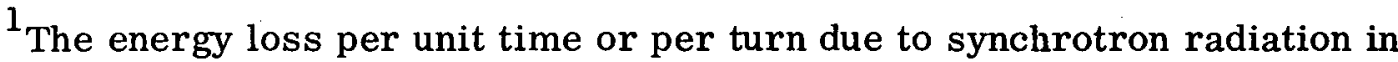
a constant-radius Synchrotron is proportional to the fourth power of the particle's total given energy and thus is a function of the fourth power of its velocity. Conversely (and fortunately) this energy loss is inversely proportional to the fourth power of the particle's rest mass. 


\section{LINEAR ACCELERATORS}

In the previous section, the development of linear accelerators was virtually ignored.' This was done for two reasons: (1) Linear accelerators are somewhat in a class by themselves and were developed in parallel with but separately from the circular accelerators which received much more widespread attention. (2) Because the subject of this writing is a linear accelerator, a more detailed exposition of the techniques involved in linear accelerators is in order.

In the description of electrostatic generators, mention was made of the concept of achieving acceleration by allowing a beam to traverse several voltage gaps in succession in a line. In the earliest and simplest form of the linear accelerator, a series of plates is placed in a line. Holes are bored in these plates to permit the beam particles free passage. Alternate plates (electrodes) are connected together electrically. For instance, all odd-numbered electrodes are connected together and tied to one terminal of a radio frequency generator. All the even-numbered electrodes are connected together and tied to the other terminal of the rf generator. Thus during one-half cycle of the rf generator, half the electrodes are positive and half are negative.

If beam particles are placed between every other pair of electrodes, they are are in a proper voltage gap and are accelerated. As soon as they pass through the hole in the second electrode, the rf generator cycles and the polarities on the electrodes are reversed. The particles are now between the electrodes of the other set of every other pair of electrodes. But because the polarities are reversed, this second set now provides acceleration. This alternation or recycling continues as the beam particles traverse gap after gap and gain energy step by step.

Of course this energy gain means the particles are also gaining in velocity. Because the rf generator is recycling at a constant frequency, the electrodes 
have to be spaced farther and farther apart down the accelerator. The particles are moving faster and must not pass through an electrode before the rf generator has had time to recycle.

To take advantage of the most efficient part of the output of the rf generator, the electrodes are in reality cylinders. While the particles are traversing the cylinders, they see no voltage field and are not accelerated. (These electrodes therefore are often referred to as "drift tubes. ") The length of the successively longer drift tubes is determined so that when the particles leave one drift tube and cross a small gap to the next drift tube, the voltage from the rf generator is just such to provide the most efficient energy gain.

The first beam achieved in an accelerator of this type was in one built about 1928 in Germany by R. Wideröe based upon a 1925 concept of G. Ising. The metal drift tubes were housed in a large glass cylinder. Heavy positive particles were injected at one end and passed through the successive drift tubes and gaps. This successful machine was the direct ancestor of linear or "resonance" accelerators (Fig. 12).

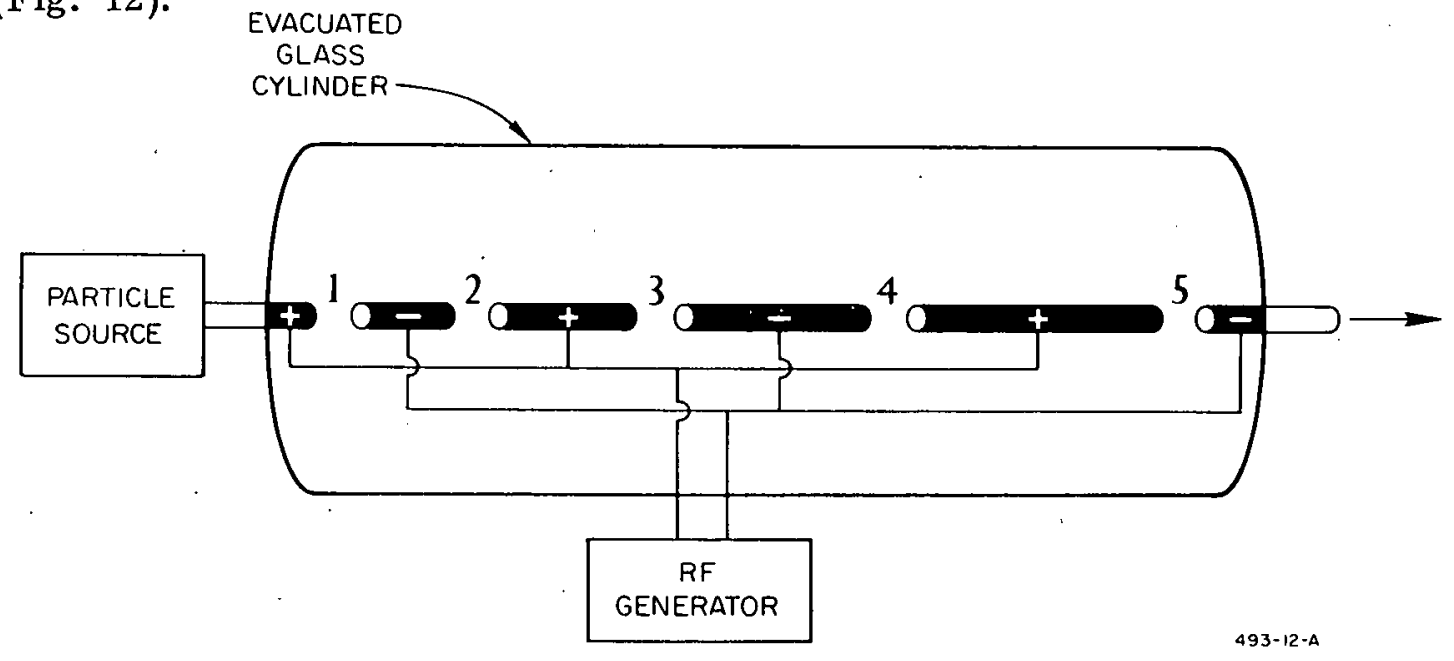

FIG. 12--Simplified diagram of the Wideröe type of linear accelerator. Positive beam particles will be accelerated in gaps 1,3 and 5 . When the $\mathrm{rf}$ generator recycles, the voltages on the drift tubes reverse so that acceleration takes place now in gaps 2 and 4 . 
During the 1930 's, machines of this type were built and successfully operated with as many as thirty drift tubes in the accelerator glass cylinder. These linear accelerators, however, were limited to accelerating only nuclei of relatively heavy atoms ("heavy ions"). This was because only heavy ions remain at low enough velocity as their energy increases. The lighter particles, such as protons and electrons, reach very high velocities at relatively low energies. Because of this, either ridiculously long drift tubes would have been required in order to permit such light particles to continue to move while the rf generator slowly recycles or else it would have been necessary to use rf generators which recycle at extremely rapid rates, on the order of hundreds of millions of times every second. Long drift tubes were not practical and high frequency generators of sufficient power did not exist at that time.

During the late 1930 's, working on the development of high frequency radar system components, the British developed a high frequency oscillator, a microwave tube called the "magnetron." Wartime radar research in America resulted in other types of high frequency oscillators. The appearance of these sources of high frequency power made possible further work on linear accelerators for light particle beams. This post-World War II work was concentrated primarily at two institutions. The development of electron linear accelerators was emphasized at Stanford University. Work on proton linear accelerators was performed at the University of California at Berkeley.

Shortly after World War II, a team at the University of California Radiation Laboratory under the direction of L. Alvarez ${ }^{1}$ developed a $32-\mathrm{MeV}$ proton linear accelerator. This machine used a slightly different principle than that of

${ }^{1}$ An important member of the Alvarez team was W.K. H. Panofsky, now the Director of the Stanford Linear Accelerator Center. 
the heavy ion linear accelerators described above. Rather than housing electrically connected drift tubes in a glass cyliner, Alvarez followed a concept of J. Woodyard and housed isolated drift tubes in a large copper cylinder. High frequency power was coupled into this cylinder by a small loop from a microwave rf generator. The large copper cylinder was thus "excited" and acted as a "resonant cavity."

The dimensions of the copper cylinder, 39 inches in diameter and 40 feet long, were selected so that when rf energy is coupled into it, a high voltage field is set up between the two ends of the copper cylinder. In this machine this resonant microwave field reversed 200 million times per second. This resonant electric field sets up standing radio waves in the cylinder. The alternating magnetic field in the cylinder induces alternating current flow on the drift tubes. At the end of each half-cycle, each drift tube is charged oppositely at each end (no net charge on any tube), and all drift tubes are charged in the same way. With each half-cycle, this charge orientation reverses. Protons are injected when the input drift tube is positive and the closest end of the next drift tube across the gap is negative. The protons cross this gap and are accelerated. While the rf generator reverses, the protons travel along this next drift tube. By the time the protons reach the far end of this drift tube the $\mathrm{rf}$ generator has again reversed, the electric field in the cylinder is reversed, and the far end of the drift tube has a positive charge. Once again the protons traverse a gap toward the negative (nearer) end of the next succeeding drift tube, again achieving energy. So long as the electric field is in the accelerating phase (half-cycle) the protons are crossing a gap. During every other half-cycle, when the field is reversed, the drift tube charge distribution is reversed, and the field is "decelerating," the protons are in a drift tube. Each succeeding drift tube is of course longer than the preceding one because the protons are then traveling at a higher velocity. 


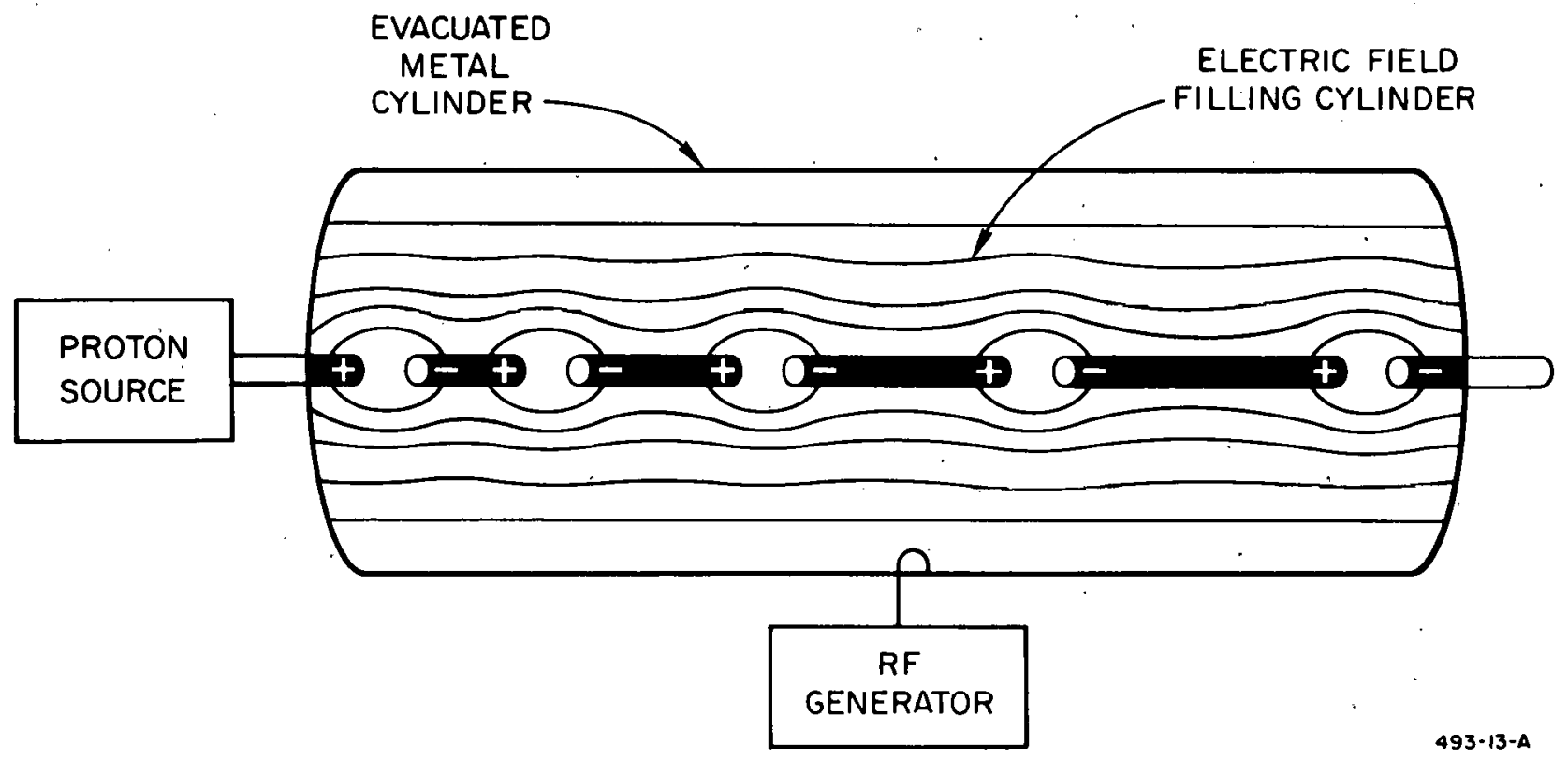

FIG. 13--Simplified diagram of the Alvarez type of linear accelerator. Protons in the gaps are accelerated. When the rf generator reverses the field so that the charge distribution on the drift tubes is reversed, the protons "hide" in the drift tubes through which they are moving. On the next field reversal, the polarities are again as shown, the protons have reached the next gaps, and further acceleration takes place.

In this 40-foot-long cylinder there are $46 \mathrm{drift}$ tubes of increasing length.

The protons are injected at $4 \mathrm{MeV}$ with a Van de Graaff machine, The rf generator is actually nine vacuum-tube self-excited oscillators, each coupled into the cylinder and each providing 250 kilowatts of power.

The high power output of these oscillators requires this accelerator to be "pulsed" in order to keep the average power output of the oscillators within their operating range. Thus the oscillators are on for less than a thousandth of a second 15 times each second.

This historic machine was dismantled in 1958, moved to the University of Southern California, and put back into operation there.

At the University of Minnesota, J. H. Williams has built a proton linear accelerator which provides $70-\mathrm{MeV}$ protons. This machine is built in three sections, 
each much like the University of California machine, and each powered by an $\mathrm{rf}$ generator called a "resnatron" especially developed just for this accelerator. The British Atomic Energy Research Establishment has a proton linear accelerator at Harwell, designed for even higher energies.

Proton linear accelerators are also used extensively as injectors for large circular proton machines, The injectors for the Bevatron at the University of California and for the Synchrophasatron at Moscow are 10-MeV proton linear accelerators. The injectors for the Alternating Gradient Proton Synchrotrons at Brookhaven and at CERN are $50-\mathrm{MeV}$ proton linear accelerators.

This kind of accelerator is eclipsed by the capabilities of proton synchrotrons and so probably will not be much extended for the purpose of achieving high energy protons. However, developments in this area have diverged with related aims in mind. For instance, by not requiring high energies the $\mathrm{rf}$ generators can be on for longer periods of time and thus proton beams of very high current (protons per second ) can be produced. High current beams have particularly useful applications in nuclear research.

Again, developments have continued in the field of heavy ion linear accelerators to achieve higher energies for such particles. Although not directly applicable to elementary particle physics, such machines find great use in nuclear physics and nuclear chemistry. Energies and intensities of heavy ion beams produced in cyclotrons are too low for these experiments. The heavy ion linear accelerator is ideal for this application.

Meanwhile, back at the Farm, the development of electron linear accelerators was preceding and proceeding along with the above development of proton linear accelerators. 


\section{DEVELOPMENT OF THE ELECTRON LINEAR ACCELERATOR}

Two things took place at Stanford during the 1930 's which made possible the University's later specialization and success in the field of high energy electron linear accelerators. One was the development of practical resonant cavities for electron acceleration. The other was the invention of the high frequency amplifier, the "klystron" tube.

For a while in 1934, Stanford Physics Professor William W. Hansen and graduate student Russell Varian roomed together. Hansen was interested in finding a way of producing high energy $x$-rays by electron bombardment of a target, without involving the expense of building a huge electrostatic electron accelerator. Hansen and Varian discussed several techniques, discarding each because of impracticality or cost.

\section{A. The Resonant Cavity Principle: The "Rhumbatron"}

Hansen conceived of the idea of passing electrons through a high voltage which oscillated at such a high frequency that there would be no time for high voltage breakdown and a large vacuum chamber would not be required. His idea was to couple some high frequency power into a small, copper cavity about the size of a small box or can in such a way that the cavity would oscillate. First one end would be positive and the other negative, then the situation would reverse. Small holes were bored in the center of each end of the cavity so that electrons could pass through. If the electrons enter the cavintÿ just as the near end is negative and the far end positive, the electrons are accelerated through the cavity, leaving the far end with higher energy than that with which they entered. This device became known as the "rhumbatron." (Fig. 14).

The power feeding the cavity came from a high frequency rf generator and was coupled into the resonant cavity with a small coupling wire. In 1936 and 


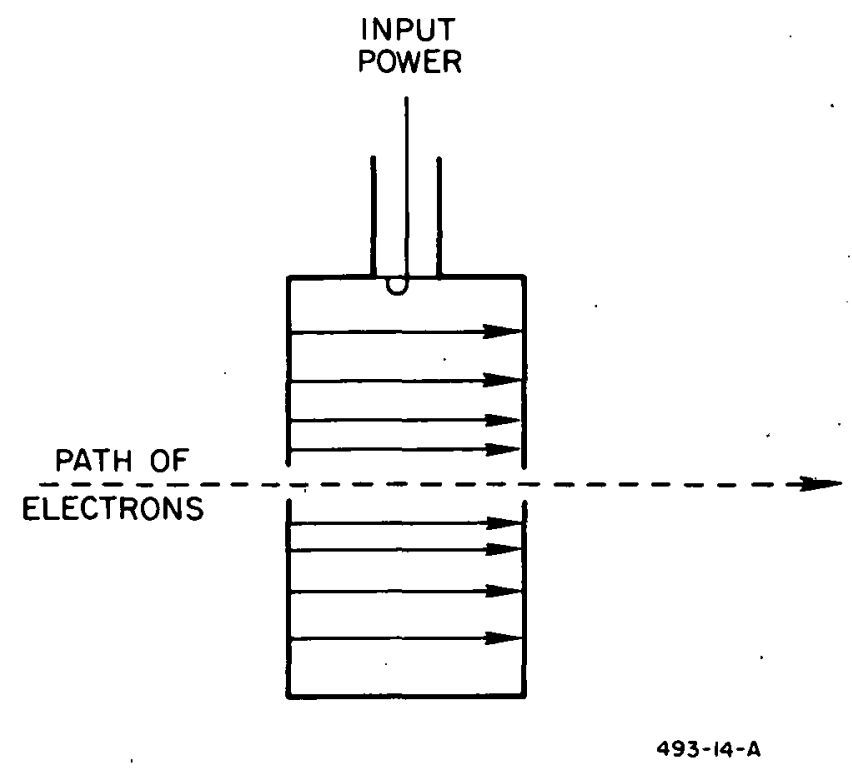

FIG. 14-- Single resonant cavity accelerator using the Rhumbatron principle. The input power is a high frequency oscillating radio (microwave) signal which reverses polarity many millions of times per second. In the diagram, the halfcycle of the field, when it is in the accelerating phase, is shown.

1937, Hansen built several different rhumbatrons of different sizes and shapes, striving to obtain the most efficient resonant cavity.

The natural extension to such a device is of course to place several resonant cavities in a long line, end-to-end (Fig. 15). Each successive cavity would then add more and more energy to the moving beam of electrons. However, it would be impractical to try to "excite" each resonant cavity with an individual rf generator. It would be much simpler to connect together electrically each of the power input coupling wires and to feed them with the output of a common rf generator. Of course, the excitation of each cavity must be properly timed so that the voltage reversals (oscillations) take place properly as the electrons leave one cavity and enter the next. To do this, the signal from the rf generator would start at the same end of the device as the electrons would, and travel down the line 
connecting the coupling wires at the same speed the electrons would travel through the center of the in-line resonant cavities.

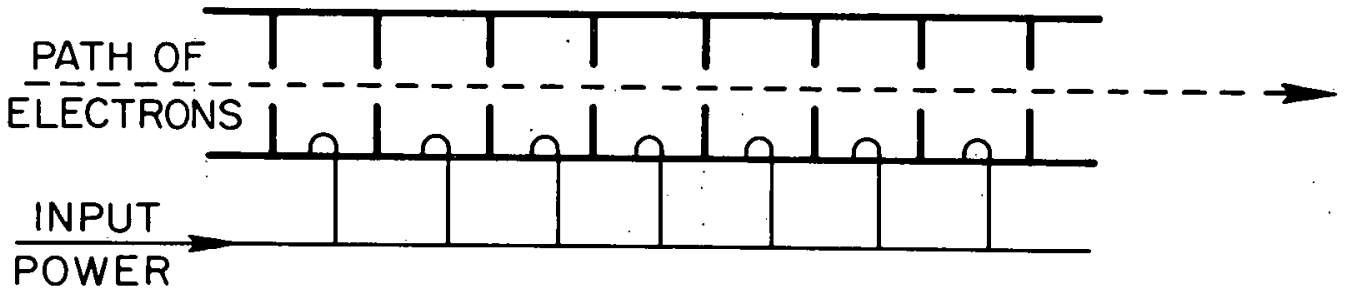

$493-15-A$

FIG. 15-- Multiple resonant cavity accelerator. In this scheme each cavity is excited. with input power in succession from a single source, using individual couplers.

\section{B. The Traveling Wave Concept}

Such a complex distribution scheme is possible and has been used. But the design: and construction of a multiple feed system to achieve the desired timing relationships between cavities is difficult in execution. Instead, Hansen resorted to another technique, the utilization of a traveling radio wave.

Into one end of his string of resonant cavities, Hansen decided to introduce a radio wave which would travel down the length of the device. A radio wave has successive crests alternating between negative and positive. If such a radio wave could be caused to flow down the cylinder (made up of the cavity string) the pos.tive wave crests and negative wave crests in motion would create a moving electric field delivering energy to each cavity. Electrons could than be introduced into the cylinder, coicident with the appropriate wave crests. ${ }^{1}$

1 The essential principles of the design of a traveling wave linear accelerator were established independently and nearly simultaneously at Stanford and at the Telecommunications Research Establishment at Malvern, England. 
Hansen wrote, "Now if a particle be introduced onto the leftmost wave crest with a velocity equal to that of the wave, the particle will feel a steady force to the right and will, therefore, be accelerated. We have assumed that the wave velocity is controllable; let it be adjusted in such a manner that as the particle is accelerated, the wave is also, and at just the same rate, so that the particle will always ride the crest of the wave and will always feel an accelerating force. The particle will then gain energy at the expense of the field, and, if all the above can be made to happen as assumed and the numbers are favorable, we may have a practical means of accelerating charged particles. " 1

To draw an analogy: Just as a surf-board rider is accelerated onto the beach by riding the crests of ocean waves, Hansen believed electrons could be accelerated through a string of resonant cavities by riding the crests of radio waves (see Figs. 16 and 17).

\section{The First Stanford Machine: The Mark I}

Prior to World War II, Hansen was never able to put together a working model of such an accelerator with the high energies of interest to the physicist. One of the things which held back the effort was the lack of a suitable high frequency, high power source of the traveling radio wave.

During the war, the demands of radar resulted in the development of several kinds of such microwave power tubes. One of these, developed by the British, was a high power microwave oscillator tube called the "magnetron." The magnetron saw extensive use in the war effort as a power tube for radar sets.

After the war, Hansen together with Professors E. L. Ginzton and J. R. Woodyard examined former conclusions regarding the feasibility of electron linear accelerators. This group, among several others, recognized that the

\footnotetext{
${ }^{1}$ Ginzton, Hansen, and Kennedy, Rev. Sci. Instr. 19, 89 (1948).
} 

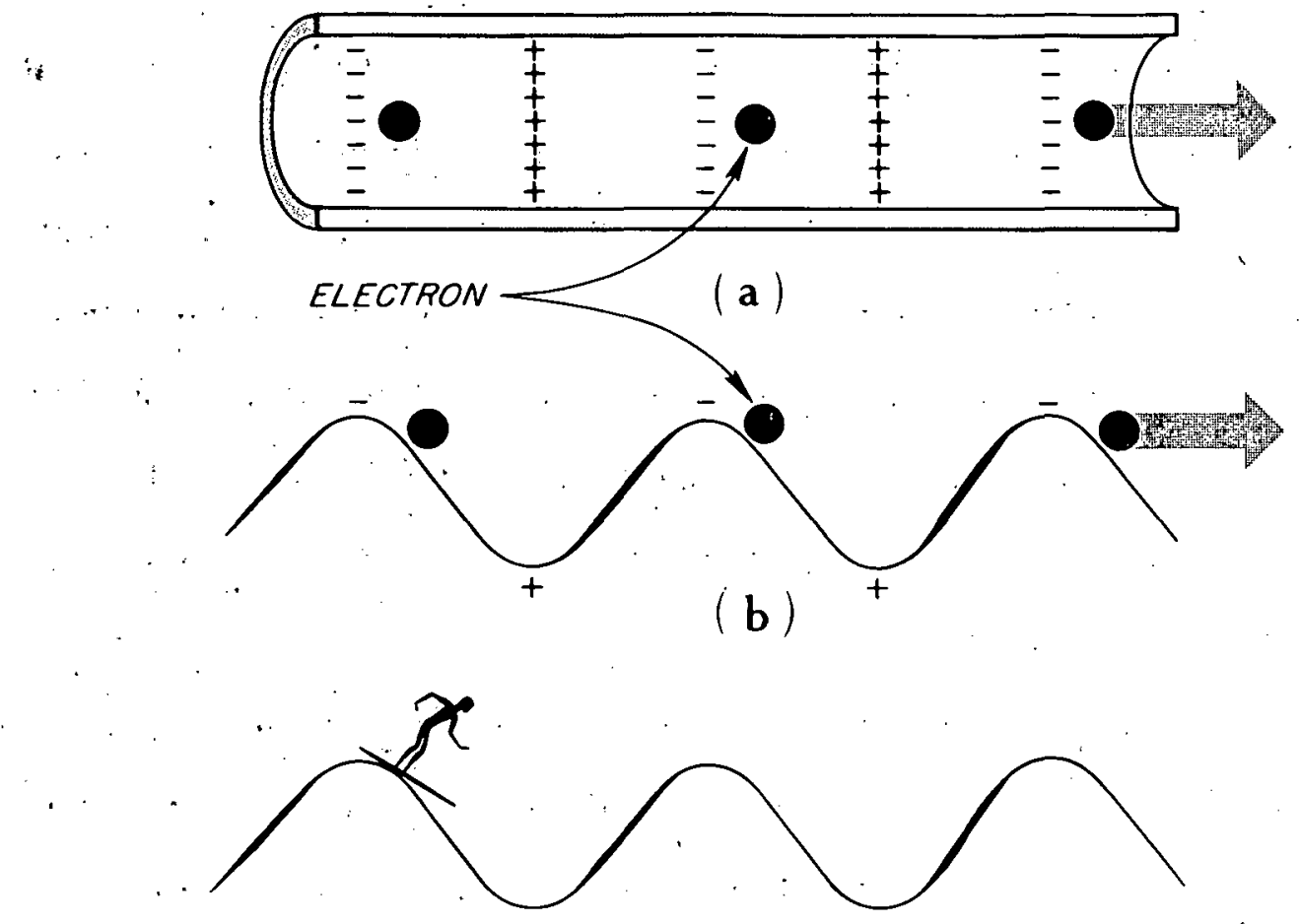

(c)

FIG. 16--Simplified presentation of the traveling, wave principle. A high frequency radio wave is caused to flow down an electrical waveguide (a). Negatively charged electrons are pushed by the negative wavecrests and pulled by the positive wavecrests to cause motion to the right (b). This is not unlike the horizontal accel-. . eration of a surf-board rider on ocean beach waves.

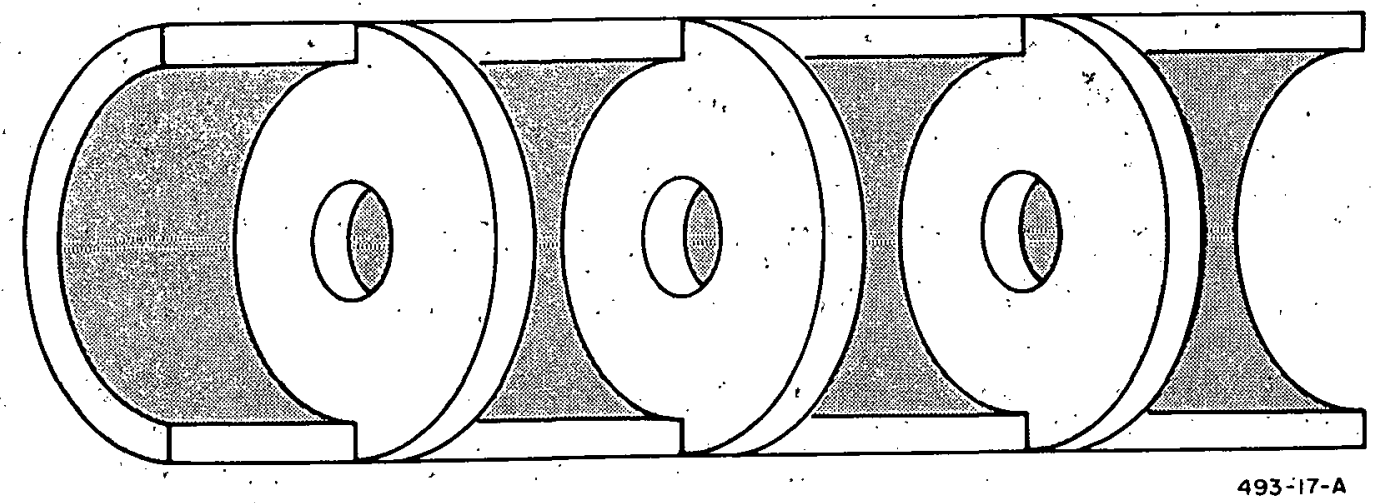

FIG. 17 -Cutaway drawing showing internal configuration of accelerating waveguide showing three cavity-forming disks. The dimensioning and spacing of these disks control the velocity of the traveling wave so that the "surf-board riding" electrons can remain in step with the wave crests. 
war-developed magnetron made it practical to build electron linear accelerators in the range of several $\mathrm{MeV}$ with available magnetrons. (It was also apparent that any higher magnitude of energies would require further development of power sources in order to obtain a total power of several hundred megawatts. ) In 1947, the first Stanford traveling wave electron linear accelerator was operated. This machine, later known as the Mark I, was 3-1/2 inches in diameter and three feet long (see Fig. 18). It contained 38 cavities in its length. Using a 0.9megawatt magnetron oscillator for the source of the traveling radio wave, the Mark I generated a 1.5-MeV electron beam. Development of the Mark I was carried out under the sponsorship of the U.S. Office of Research and Inventions, later the Office of Naval Research (ONR). For a Quarterly Status Report on the

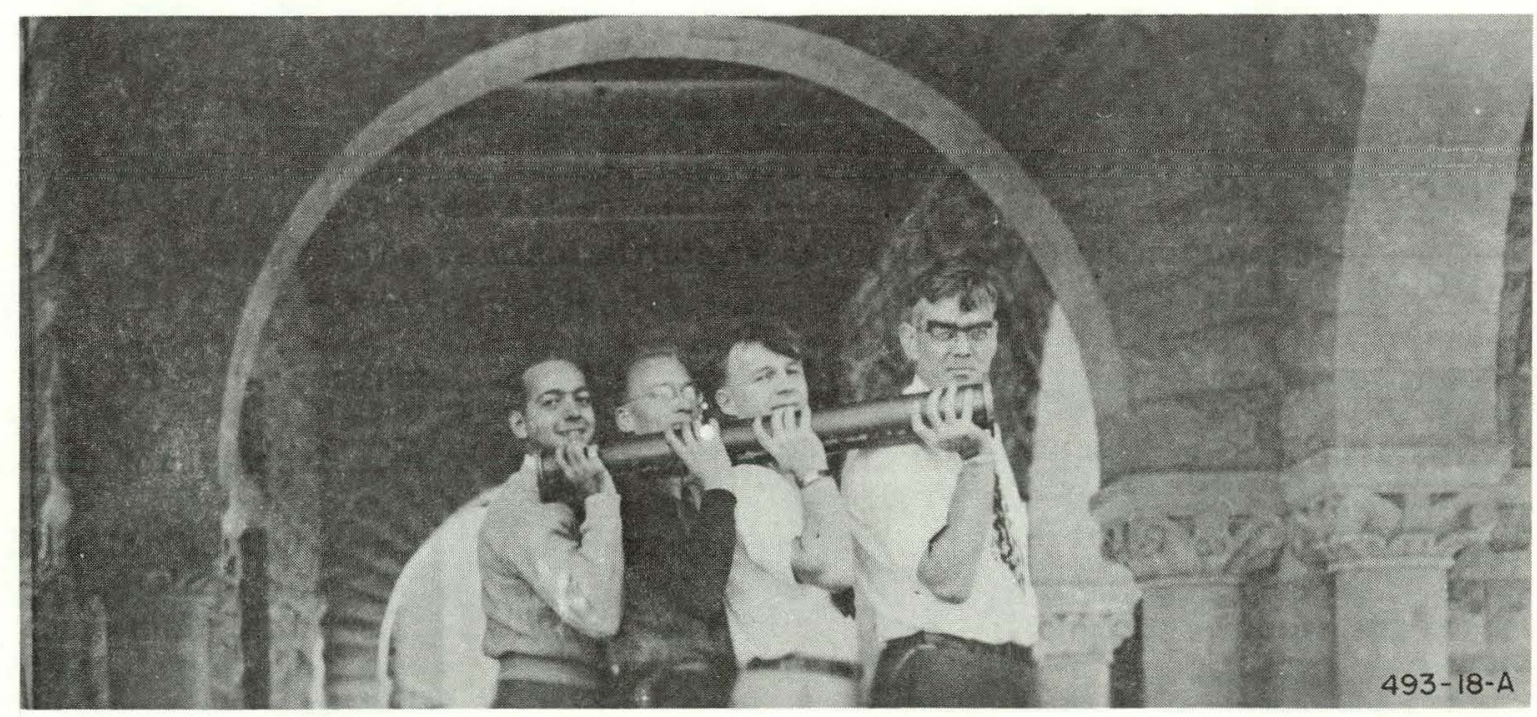

FIG. 18-- The original Mark I electron linear accelerator photographed in the Stanford quadrangle and being held by, left-to-right, S. Kaisel, C. Carlson, W. Kennedy, and W. Hansen. 
project at this time, Hansen submitted a one-sentence report: "We have accelerated electrons." Eventually the Mark I was extended to a total of 14 feet and provided 6-MeV electrons. ${ }^{1}$

To build an even higher energy accelerator, Hansen recognized that rf sources would be required of power higher even than available with magnetrons . To achieve such a device, Hansen decided to turn to the development of a high power amplifier to increase the power available from existing rf oscillators. This led him back to the second, parallel Stanford story: the development of the klystron tube.

\section{The Klystron Tube.}

Radio detection and ranging ("radar") is based on the transmission and reception of high frequency radio signals. The ability to move and point the antennas requires them to be as small as possible. This in turn requires the radio signals to have as short a wavelength (high a frequency) as possible. In addition, the transmitted radio signals must be of very high average power so that reflected signals can be received from distant objects.

The approach of World War II accelerated research and development of os cillating and amplifying radio tubes to provide these high frequency (microwave) radio transmissions. The British magnetron, mentioned above, was one of the results of this work. But similar activity was being carried out at Stanford.

Russell Varian's brother Sigurd was an airline pilot, concerned with bad weather navigation. In 1936, the brothers sent a suggestion to the Civil Aeronautics Administration for determining the height of cloud layers by timing the reflection of light signals aimed at the clouds. This led them to consider using

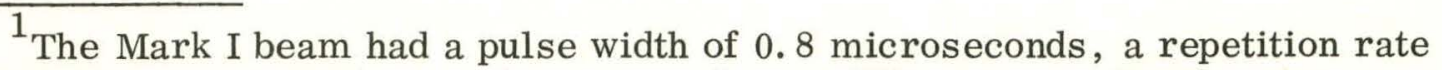
of 60 pulses per second, a peak current of one milliampere and an average current of 0.05 microamperes. 
microwave radio signals, which would penetrate clouds but which would be reflected by solid objects (see Fig. 19).
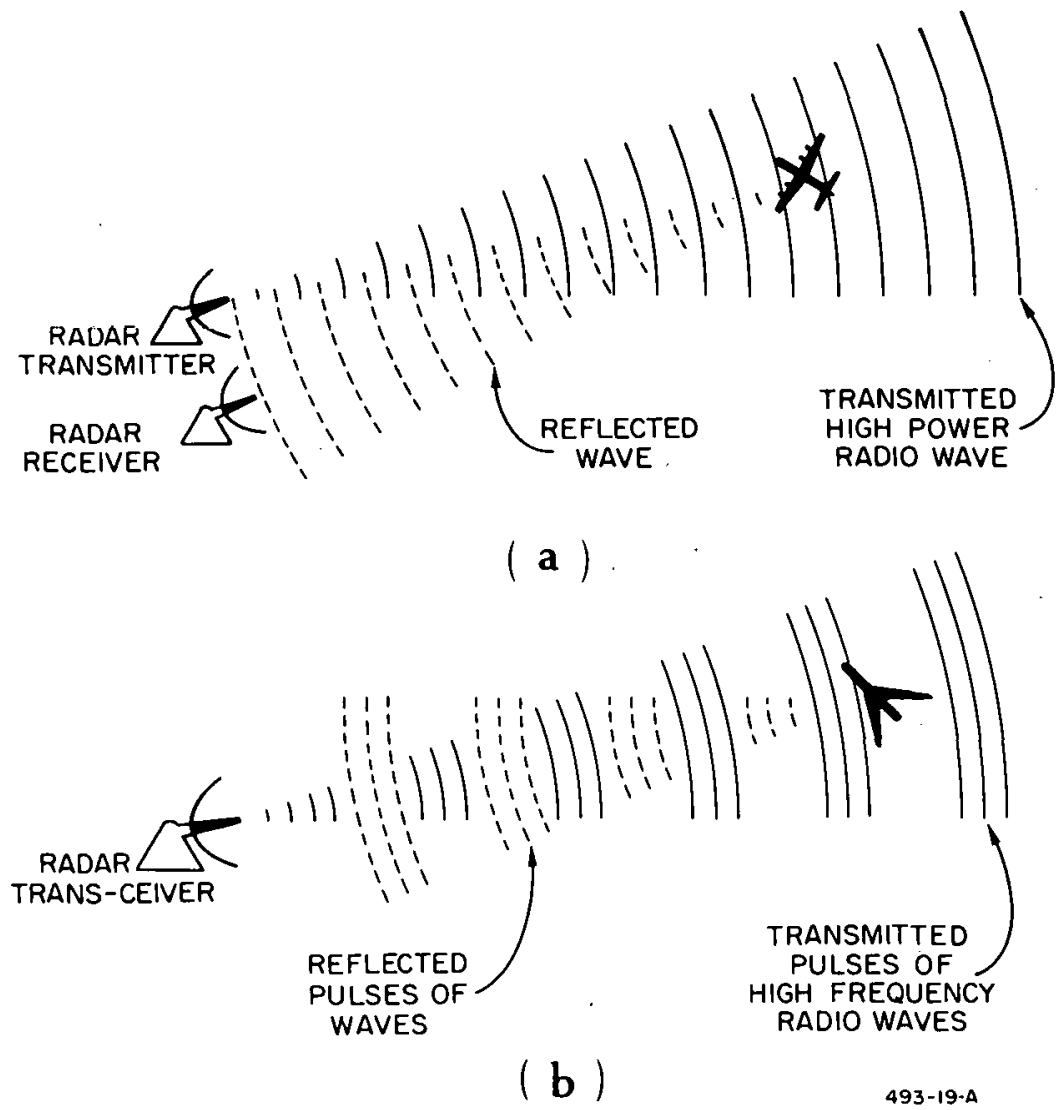

FIG 19-- Principles of radar operation. High power microwaves are transmitted toward an object. Some of this is reflected from the object and returned to the radar set. Analysis of the two waves provides information about the position of the object. High power transmission is required so that the small part of the small reflected wave can be detected. Early designs used continuous waves (a). Later developments permitted pulsed transmission (b).

By early 1937, the Varian brothers were both research associates at Stanford working with Professor Hansen both on the rhumbatron and other microwave devices. Russell Varian dedicated himself to trying to conceive of a technique for amplifying microwave signals to powers useful in radar-type 
applications. After the team having designed and built several kinds of devices, on. June 5, 1937,Russell Varian conceived of the klystron principle.

The klystron is a microwave amplifying tube based on Hansen's rhumbatron and Russell Varian's principle of velocity modulation. As described above, the rhumbatron was a resonant cavity which transferred energy from an rf generator to electrons passing through. Varian's velocity modulation principle was based on his recognition of the fact that the accelerated electrons, leaving the rhumbatron cavity, would not be in a steady stream but would appear in "bunches."

If a steady stream of electrons is introduced into one side of an oscillating resonant cavity, the velocity of each electron will be affected by the status of the oscillating electric field in the cavity. Electrons arriving just as the electric field is maximum in the accelerating phase will receive the greatest increase in velocity. Electrons arriving a little before or after this time will be speeded up a little less. Those electrons appearing at other times will be slowed down.

Now if all these electrons are allowed to pass down a drift tube after they leave the cavity, the faster ones will begin to catch up with the slower ones so that eventually bunches of electrons are formed. Varian's idea was to use these bunched electrons to excite another resonant cavity in reverse. In the first cavity, a small microwave radio signal caused the cavity to oscillate and these oscillations affected the velocity of a traversing electron beam. Varian placed a second cavity in the path of the bunchedelectrons. The bunched electrons passing through the second cavity caused this cavity to go into oscillation just as the microwave signal did the first cavity. The oscillating magnetic field in the "excited" second cavity then induced a current in a small coupling loop inside the cavity to couple out the microwave signal generated by the bunched electron beam (Fig. 20). 


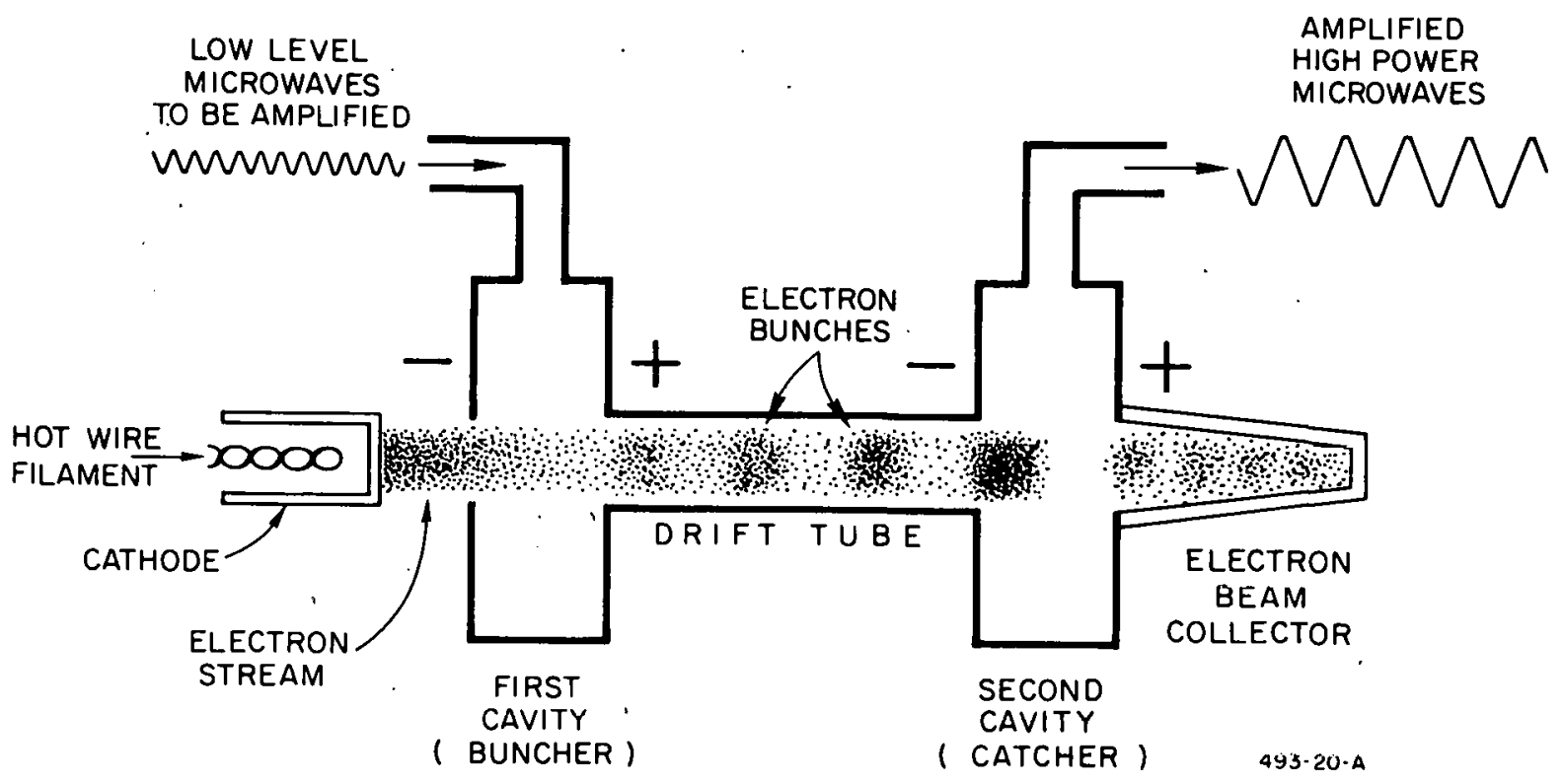

FIG. 20-- Principle of klystron amplification. Low level microwaves excite the first cavity to oscillate. The electron stream enters from the left and is bunched by the oscillations. The bunches in turn excite the second cavity to oscillate. The oscillating energy in the second cavity is taken off as amplified microwaves.

The microwave radio energy coupled out of the second cavity will have the same frequency as the microwave radio signal driving the first cavity because the second cavity has been excited by electrons bunched by the first cavity. However, the microwave signal coupled out of the second cavity will be of much higher power than the microwave signal coupled into the first cavity. This is because the power given to the second cavity comes from the bunched electrons themselves which can be given high power before injection into the first cavity. Thus amplification has taken place. A microwave radio signal has been amplified, being given increased power at the expense of the electron stream. The first cavity in the klystron is called the "buncher," the second cavity is called the "catcher." 
In August 1937, the first such klystron amplifier was constructed and operated by the Varian brothers at Stanford.

For the next two years, the Varians and Hansen concentrated on improving their klystron in order to achieve better amplification and higher power. These early tubes provided a continuous output signal useful in early types of special purpose radar systems. However, in England the concept of pulsed radar was becoming well advanced. This kind of radar uses only short bursts of microwave power spaced out in time. Measuring the time between transmission and reception of pulses was a more feasible technique for obtaining range information. In the early $1940^{\prime}$ 's the British were able to develop klystrons, based on the early work of Hansen and the Varians, capable of producing up to 20 kilowatts of pulsed microwave power.

In the meantime, the British had also been actively working on magnetron development, and by late 1940 and early 1941 they had achieved considerably greater power than the klystron's 20 kilowatts--perhaps as much as 150 kilowatts. Because of this earlier success, the British put all their emphasis on the further development of the magnetron, and did not continue any additional development work on the pulsed klystron.

In 1944, Ginzton went to England and investigated the British work on pulsed klystrons. After his later return to Stanford, Ginzton together with Professor M. Chodorow began a study of the possibilities of the generation of high pulsed power by means of the klystron. Although the principal aim of their study was to demonstrate the feasibility of very high powers and to determine ultimate limitations, the specific work was directed towards trying to achieve characteristics required for klystrons. to drive a very high energy linear electron accelerator then being investigated by Hansen. 
So two parallel endeavors were begun at Stanford. One was to design an electron linear accelerator to develop energies in the $\mathrm{BeV}$ range. The other was to develop klystrons capable of producing the high power traveling waves necessary to power such an accelerator. In 1948, Stanford submitted a proposal to the U.S. Office of Naval Research, presenting in considerable detail arguments in favor of a billion-volt electron linear accelerator. Under sponsorship of ONR, work on the project was started in 1948. This ONR-sponsored research and development was known as "Task 16."

Extensive work was also started on the development of the high power pulsed klystron. This part of the ONR-sponsored activity was known as "Task 23." In March 1949, the first such high power klystron tube operated successfully. This tube operated at a frequency of 3000 megacycles and delivered a power output in. the vicinity of 20 megawatts.

E. The Next Machine: The Mark II

Beginning in 1948, several projects were underway, Stanford began to construct a building ${ }^{1}$ to house a $1-\mathrm{BeV}$ electron linear accelerator. With ONR support, design work was begun on the $1-\mathrm{BeV}$ machine, research and development of the high power klystron were intensified, and construction was begun on a prototype machine.

This last machine, meant to provide an intermediate milepost on the way toward the eventual construction of the $1-\mathrm{BeV}$ machine and to act as a prototype of one of the many sections of the larger accelerator, was known as the "Mark $\Pi$."

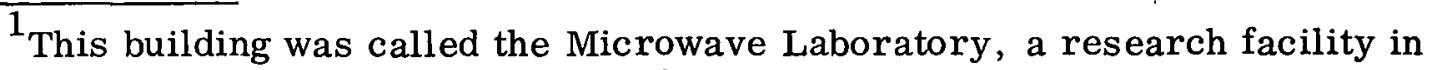
Stanford's Graduate Division, with Professor Hansen of the Physics Department as Director. When Professor Hansen died in 1949, Professor Ginzton became Director. Four years later another building was built to become the Microwave Laboratory. The original building housing the accelerator became the High Energy Physics Laboratory. 
Built under the direction of R. F. Post, the Mark II was first successfully operated in October 1949, using the first klystron tube built under this program. The high power klystron provides the accelerating traveling wave by amplifying a microwave signal provided by a magnetron. The Mark $\Pi, 3-1 / 2$ inches in diameter, was built in seven two-foot-long subsections for a total of 14 feet. Each of the seven subsections contained 23 cavities. Operating at 2855 megacycles, electron energies of up to nearly $40 \mathrm{MeV}$ were obtained with peak beam currents of about 10 milliamperes in one-microsecond pulses at 60-pulse-per-second repetition rate.

The Mark $\amalg$, sometimes modified and rebuilt, has been in use for experimentation in electron physics since 1950.

\section{F. The Mark III}

The contract between the Office of Naval Research and Stanford University, calling for work leading to a billion-volt electron linear accelerator, went into effect in June 1948. An organization named the Microwave Laboratory was set up to carry out the work. The Laboratory work began in the "physics corner" of Stanford's main quadrangle, but in early 1949 , the building to house the large accelerator was completed and the work of the Laboratory was transferred to the new building.

During the early years of the contract, work was carried out in several areas. The theory of microwave electron linear accelerators was studied and advanced. Investigation was carried out of various accelerator structures to determine which were most suitable for electron acceleration. (The linear arrangement of resonant cavities forming the accelerator structure is more properly called "waveguide," referring to the fact that the structure is designed for transmission of traveling radio waves.) Microwave measuring techniques 
were developed for testing accelerator components. Further research into the accelerator principle was carried out on the magnetron-powered Mark I 6-MeV accelerator. Design, development, and construction of the high-power klystron amplifier were intensified in order to be able to provide the necessary traveling waves for the large accelerator. The modulating devices for pulsing the klystrons on and off were developed. Components for the large accelerator were designed and fabricated. The prototype Mark II accelerator was operated with the new components, including the new high power klystron. Construction of the large . accelerator, now known as the Mark III, was begun.

The accelerating waveguide for the Mark III was constructed in two-foot-long subsections, each containing 22 cavities assembled with extreme care from annular disks and four-inch-diameter tubing of selenium-copper. Five such subsections were then clamped together to form the ten-foot-long accelerating waveguide sections. Each ten-foot section in the machine was to be fed by one klystron amplifier, all the klystron amplifiers to be driven by a common magnetron oscillator.

The Mark III first operated on the night of November 30, 1950. At that time, a length of 30 feet of accelerator was assembled, supplied by three klystrons. With each klystron providing an average of eight megawatts of microwave power, this operation delivered an electron beam of about $75 \mathrm{MeV}$.

In the following months, the accelerator grew in ten-foot steps. The fourinch-diameter accelerator was mounted on 20-foot-long I-beams for support. These units were mounted on the floor of the long accelerator building. Concrete shielding blocks were piled along each side and across the top. The klystrons and their pulse-control modulators were housed in oil baths and high voltage cages, respectively, along one side of the resulting concrete bunker. 
On January $8,1951,134 \mathrm{MeV}$ of beam energy was achieved using five klystrons feeding 50 feet of accelerator. On-March 23, 1951, seven klystrons and 70 feet of accelerator were in place and provided a beam of $160 \mathrm{MeV}$. By April 6 , 1951, the Mark III reached 80 feet in length and eight klystrons had been installed . On that date this arrangement delivered a beam of $180 \mathrm{MeV}$. During this time the klystrons were operating at no more than half their design value of 18.5 megawatts. The highest energy obtained with the 80 -foot Mark III was about $200 \mathrm{MeV}$ on January 14,1952 .

The accelerator was operated at the 80-foot length until May 8, 1952. At that date, the machine was disassembled. The used subsections were cleaned and assembly of the final 220-foot machine was begun (Figs. 21 and 22).

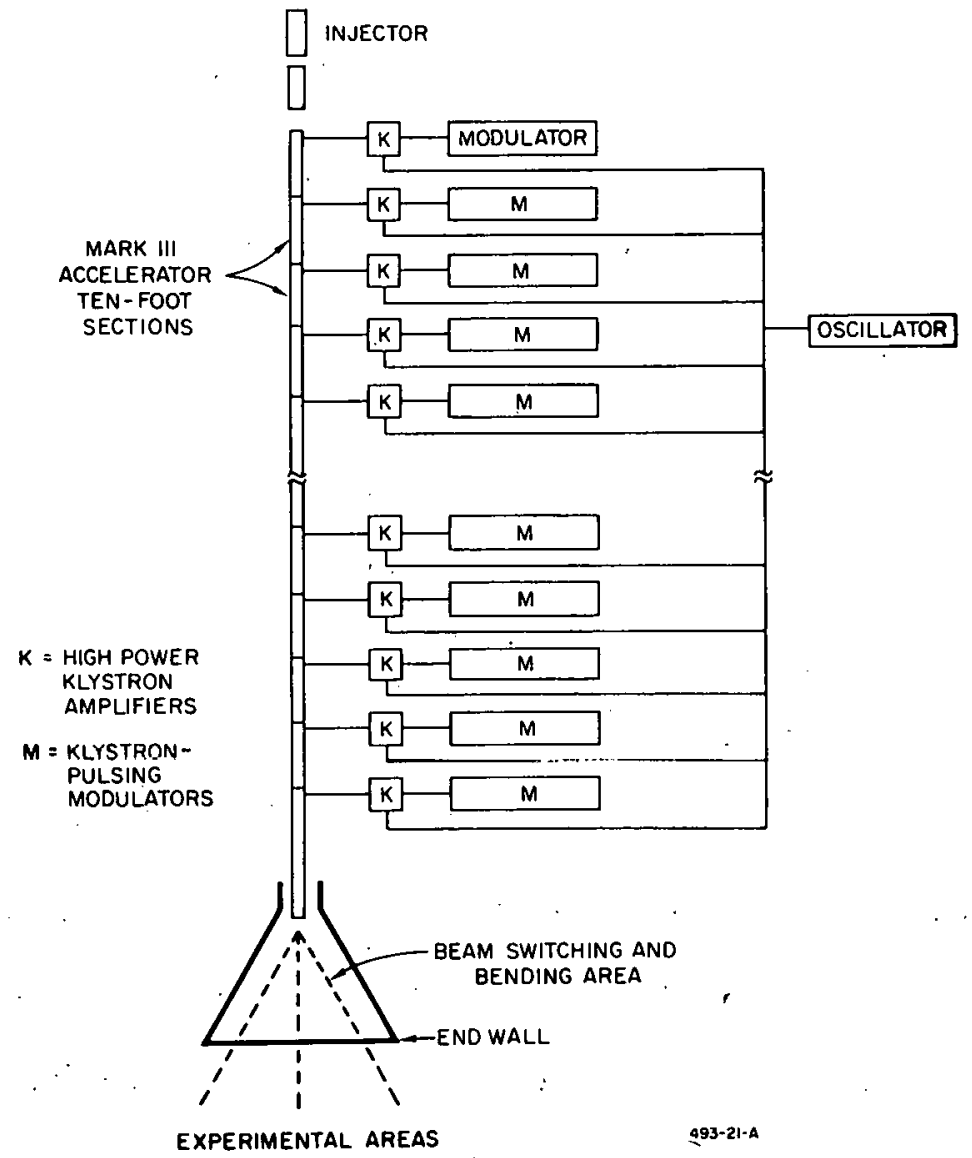

FIG. 21--Schematic and plan view of Mark III. 


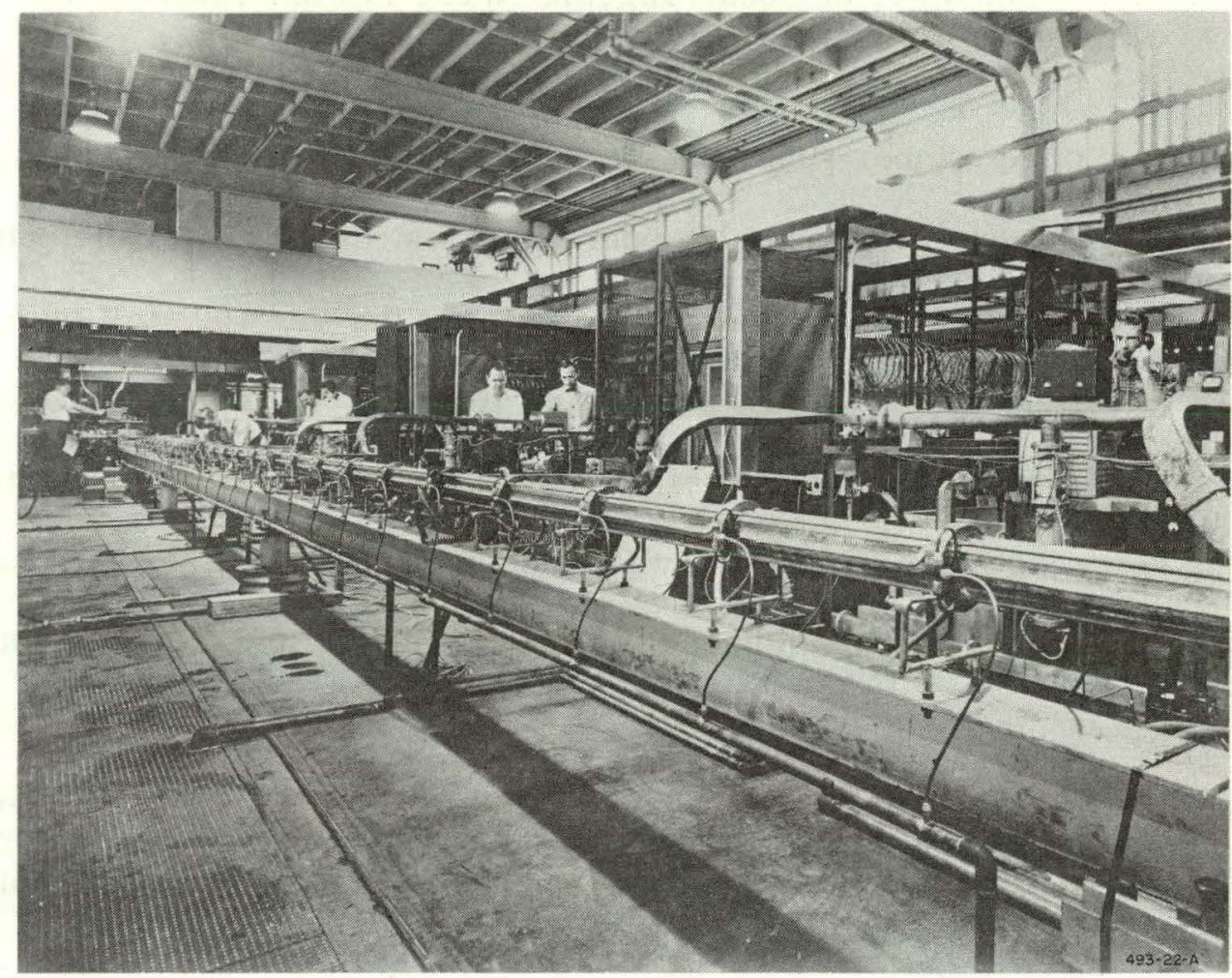

FIG. 22--The first sections of the Mark III accelerator, as seen looking in the opposite direction to beam motion (looking toward the injector). The twisted waveguide delivers power from the klystrons to the accelerator tube which is supported by the I-beams. After construction, the accelerator and I-beams were surrounded by concrete shielding.

In June 1953, what had been called the Microwave Laboratory was divided into two parts, the High Energy Physics Laboratory and the Microwave Laboratory. The High Energy Physics Laboratory, under the direction of Professor W.K.H. Panofsky, ${ }^{1}$ was to be concerned with operation of the Mark II and the Mark III accelerators. The Microwave Laboratory, under the direction of Professor Ginzton, occupied a new building and continued development work on

${ }^{1}$ Panofsky had first come to the Stanford Physics Department from the University of California at Berkeley in July 1952 to participate in planning for research with the Mark III. 
the new klystrons and other devices. Together these two laboratories were called the "W. W. Hansen Laboratories of Physics." 1

By the end of November 1953, the Mark III had 21 ten-foot sections in place, but there were not yet enough reliably operating klystrons to power the entire machine. The maximum electron energy up to that time was $400 \mathrm{MeV}$ with 14 klystrons operating. At this time, Stanford Professor R. Hofstadter and his collaborators began their investigation of nuclear structure by means of electron scattering using the Mark III beam. By December 1955, the accelerator was operating routinely with a full complement of 21 klystrons to yield an energy of about $600 \mathrm{MeV}$.

The injector, the source of the electrons, is located at the north end of the Mark III. Injection into an electron linear accelerator can be a very simple process. In the Mark II the injector consists of very little more than a hot tungsten spiral cathode arranged to emit electrons with energies of about $80 \mathrm{keV}$. Although $80-\mathrm{keV}$ electrons have a velocity of only half the velocity of light, it still proved possible to inject them into a section of accelerating waveguide in which the phase velocity of the accelerating traveling wave has a phase velocity equal to the speed of light. This does not seem so mysterious when it is realized that the high accelerating fields in the machine bring electrons very rapidly to almost the speed of light.

A high energy electron linear accelerator is essentially a constant-velocity device where the electrons travel at almost the speed of light throughout the entire machine. (The traveling waves from the klystrons travel down the entire

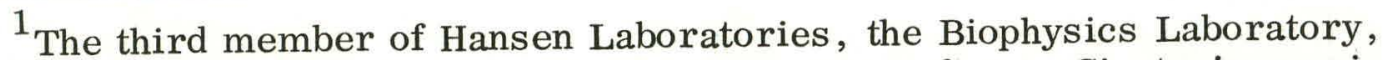
was to come a few years later as an outgrowth of Professor Ginzton's growing interest in adapting electron linear accelerators for medical applications, radiology, and therapy. 
accelerator at the velocity of light.) The increase in velocity of the electrons from near the input end to the output end is extremely small. The electron energy increase however is linear along the machine. Energy can be thought of as being dependent upon both velocity and mass. ${ }^{1}$ Increases of energy at low velocities are almost entirely in the form of velocity increases. At high velocities, using this relationship, increases of energy more and more take on the form of mass increase. However, the significant factor in accelerator physics is the beam energy . Whether this is thought of as velocity or mass does not matter.

In the Mark II the electrons are injected at about half the speed of light. The traveling radio wave, moving at the speed of light, "captures" most of these and the electrons very quickly are accelerating in energy at a velocity close to the speed of light. Thus the "captured" electrons can continue to ride the crests of the traveling wave in near-synchronism.

But in this process, many electrons which do not enter the accelerator at the proper time are lost. So in the Mark III, a "bunching section" is included which pregroups the electrons for more efficient capture. This buncher is just another piece of accelerator waveguide, but one in which the internal dimensions vary along the length. The internal dimensions of the accelerator waveguide are what establish the velocity of the traveling radio wave. By changing the inside diameter of the tubing and the size and spacing of the annular disks, the velocity of the traveling wave can be controlled. In the Mark III buncher, the internal dimensions are such that the traveling wave is less than the speed of light at the input end and near the speed of light at the output end. Thus at the input end, traveling more slowly, the radio wave can capture more electrons, bunch them

${ }^{1} \mathrm{~A}$ more accurate statement of electron beam energy is $E=m c^{2} /\left[1-\left(v^{2} / c^{2}\right)\right]^{\frac{1}{2}}$ where $\mathrm{m}$ is the mass of the electron, $\mathrm{c}$ the velocity of light, and $\mathrm{v}$ the elect tron's velocity. At low energies, this relativistic equation expands to the classical kinetic energy equation $\mathrm{E}=\frac{1}{2} \mathrm{mv} 2$, plus the electron's equivalent rest energy. 
properly on the wave crests, increase their energy, and deliver them to the first uniform accelerator section ready for acceleration at near the velocity of light.

After leaving the machine at the south end, the accelerated high energy beam passes into a beam-switching area where it can be displaced either to the right or to the left by deflecting magnets or it can be allowed to proceed undeflected. It then enters the experimental areas through holes in a wall of heavy concrete. Then on the far side of these experimental areas, a large earth mound serves as a "backstop" to reduce the radiation level in the surrounding campus area. Professor Hofstadter's electron scattering program was one of many kinds of nuclear research programs carried out in the experimental areas of the Mark III during this time. A high point for the Laboratory was the awarding of the 1961 Nobel prize in physics to Professor Hofstadter "for his pioneering studies of electron scattering in atomic nuclei, and for his thereby achieved discoveries concerning the structure of the nucleons."

By December 1957, a ninety-foot extension of the Mark III accelerator was under construction. This extension was completed by July 1960 and from this time on routine operation at energies of $900 \mathrm{Mev}$ was possible. One GeV was obtainable if all 30 klystrons along the 300-foot machine were effective and well processed.

During the last half of 1963 , the Mark III was dismantled. New accelerator sections, produced to the improved design of those to go into the two-mile machine, replaced the original Mark III sections. By March 1964, the Mark III was back on the air producing electron beams to $1.2 \mathrm{GeV}$. Under the direction of Professor W. C. Barber, the High Energy Physics Laboratory continues to operate the Mark II and Mark III on a busy and significant schedule (Fig. 23). 


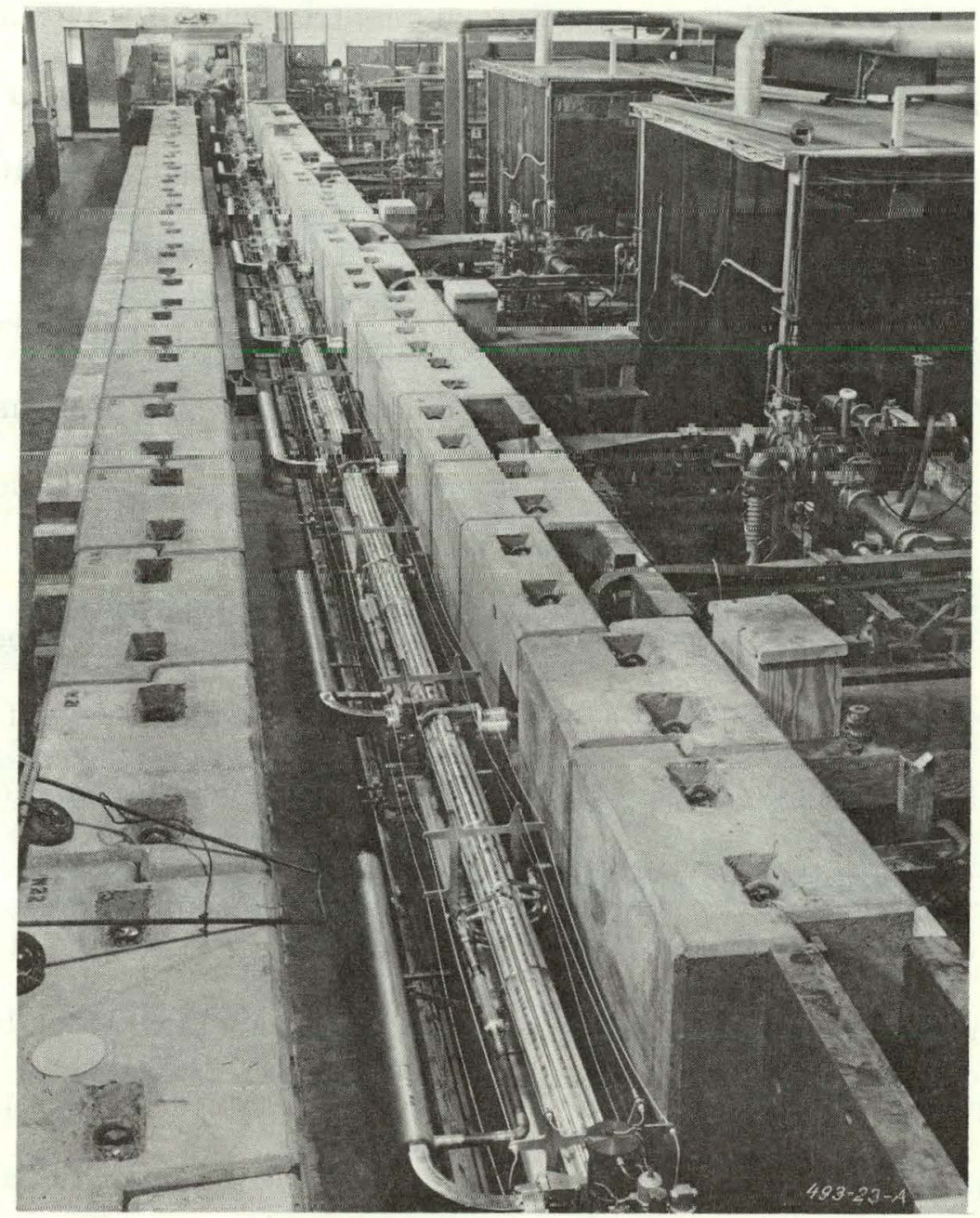

FIG. 23-- The Mark III after replacement of its accelerator sections in 1964. In this photograph, all that remained was to replace the concrete shielding blocks on top of the concrete shielding walls.

\section{G. Other Stanford Klystron and Accelerator Development}

The development of the electron linear accelerator and its klystrons at Stanford led to a number of important by-products. The high-power klystrons have now been built for a number of different operating radio frequencies and different sizes for defense applications, including for distant early warning radar networkis. 
A number of electron accelerators have also been built for medical and other applications. During the mid-1950's Stanford constructed a 10-foot, 35-MeV accelerator for cancer therapy at Michael Reese Hospital in Chicago, a 20-foot, 60-MeV accelerator for cancer research at Argonne National Laboratory, and a 6-foot, 5-MeV accelerator for cancer therapy at Stanford University Hospital. These machines, powered by Stanford klystrons, are used to generate beta-rays and $\mathrm{x}$-rays by electron beam target bombardment. Many private industrial firms now specialize in building small accelerators of the Stanford design for medical research.

During the same time period, Stanford built several research accelerators including two 3-foot, 2-MeV machines for radiation research, one of which was put into use at Oxford University, and a 6-foot, 5-MeV accelerator for experimental medical research by the General Electric Company.

In 1954, with U.S Atomic Energy Commission support, Stanford started to build a 20-foot, $80-\mathrm{MeV}$ research accelerator. This machine which became known as the Mark IV, was designed in order to be able to study methods of improving accelerator components. The Mark IV, under the operational direction of R. B. Neal, was invaluable in establishing many improved methods of design and construction of linear accelerators. Later for a time the Mark IV was used for beta-ray cancer therapy. In the early 1960 's, the Mark IV was used extensively as a prototype for the two-mile accelerator and for testing some of its components. After the two-mile machine was well along in construction, in 1964 the Mark IV was dismantled.

\section{H. The Beginnings of the Two-Mile Machine}

The immediate and resounding success of the Mark III in the early 1950's , both in operation and in application, started Stanford thinking about a really big accelerator. Beginning in 1955, Stanford Professors L. Schiff, R. Hofstadter, 
W. Panofsky, F. Bloch and E. Ginzton met together informally several times to discuss the possibilities of a"Multi-GeV"electron linear accelerator. This group popularly referred to as the"SHPBG group, "decided that such a machine had good scientific justification and that the possibilities should be further investigated.

To this end, the first"Project M Meeting"1 was held in the home of Professor Panofsky at 8:00 p.m. on April 10, 1956. In attendance; in addition to members of the SHPBG group, were K. Mallory, W. Barber, K. Brown, R. Debs, R. Neal, R. Mozley, F. Pindar, S. Sonkin, and J. Jasberg. From the minutes of this meeting,

"The purpose of this gathering, the first in a series of weekly meetings, was to discuss plans and form objectives which will ultimately lead to a proposal for the construction of a multi-GeV linear electron accelerator. The participation of the members of this group is entirely voluntary and on their own time as there are no funds available to support this program... should such a program materialize, it should be administratively distinct from the Hansen Laboratories and the Physics Department. Professor Ginzton has agreed to serve as Director of the proposed accelerator activity during the design and construction phases, and Professor Panofsky as Assistand Director for at least one year. ${ }^{2}$ Professors Schiff and Hofstadter would act as consultants. The primary objective of the proposed large accelerator was declared to be basic physics research. There should be no security measures except to protect personnel and property, no classification and freely publishable results; the facilities should be available to qualified research visitors... The following possible accelerator characteristics were listed to orient future thought: Length, two miles; energy, $15 \mathrm{GeV}$, expandable to $50 \mathrm{GeV}$..."

During the following year, extensive activity was carried out by this study group $^{3}$ with the assistance of several other organizations. Detailed studies were

${ }^{1}$ Opinion is equally divided as to whether the letter M. in this early unofficial name of the project stands for Multi-GeV or for Monster.

2 As things turned out, Professor Panofsky soon becam Deputy Director of Project M, a post he held until assuming the Directorship late in 1961, after Professor Ginzton became chairman of the Board of Varian Associates following the death of Russell Varian, the last surviving Varian brother.

${ }^{3}$ During the year, the Project M Study Group was augmented by the addition of the names of F. Bunker, M. Chodorow, E. Chu, D. Dedrick, L. Franklin, C. Jones, J. McIntyre, C. Olson, and H. Suderstrom. 
made of the general problems that would be involved in the construction of such

a machine. ${ }^{1}$ Several special studies were carried out on beam dynamics, accelerator structures, etc. The Utah Construction Company and the Bechtel Corporation made voluntary independent studies of the site and tunnel problems, and submitted complete reports on their respective solutions. Cost and specification information was generated. Planning and cost estimates were made for the construction and operation of a facility to design: and build the huge number of klystrons which would be required. The University of California Radiation Laboratory (later the Lawrence Radiation Laboratory) provided financial and administrative information based on its operating experience. At Stanford, Professors C. Oglesby of Civil Engineering and B. Page of Geology provided site; geological, civil engineering, and other information.

From all this endeavor, a formal proposal was published. On April 18, 1957 this proposal was submitted by President Sterling to the U.S. Atomic Energy Commission, to the National Science Foundation, and to the Office of the Secretary of Defense for Research and Engineering.

The proposal had consistent and impressive scientific support from almost the very beginning. The first formal endorsement of national significance came in 1958 when a panel convened by the National Science Foundation recommended that the project be initiated. Later in 1958 , the joint panel drawn from the General Advisory Committee of the U.S. Atomic Energy Commission and from the President's Science Advisory Committee recommended the project. In 1960 , the same joint panel, after updating its review of high energy physics, strongly reiterated its support of the Stanford proposal. Represented on these panels were many of the most eminent physical scientists in the nation. Hearings before

${ }^{1}$ Funds to support some of these studies were supplied variously by the AEC and by Stanford University. 
the Joint Committee on Atomic Energy of the Congress were held in July and August 1959, and in April 1960.

A high point in the activity during this period was a speech in May 1959 in New York by President Eisenhower, in which he announced,

I am recommending that the Congress of the Federal Government finance the construction, as a national facility, of a large, new, electron linear accelerator. Physicists consider the project--which has been sponsored by Stanford University--to be of vital importance. Because of the cost, such a project must become a Federal responsibility.

In late 1960 , under congressional authorization, a contract was negotiated between the U.S. Atomic Energy Commission and the Board of Trustees of Stanford University. This contract, known as "Contract 363," called for Stanford to perform initial engineering and design of Project $M$, at an estimated cost of $\$ 3,000,000$. Under this contract, activity was accelerated. A building on the campus to house the initial Project M staff was planned. Further studies and design work were carried out. Stanford entered into contract to acquire architectengineer-management services for the project. The contractor selected for this work was a joint venture known as Aetron-Blume-Atkinson (ABA). This joint venture comprised people from the Aetron Division of Aerojet-General Corpora-tion, John A. Blume and Associates, Engineers, and the Guy F. Atkinson Construction Company. ABA began work on architectural design and planning for site and building construction.

After more correspondence, meetings, and hearings, the Congress on September 15, 1961 authorized the AEC to enter into negotiations with Stanford University for the ultimate realization of the two-mile accelerator In this authorization, the total design and construction cost was estimated at $\$ 114,000,000$. While work on the project continued, there followed six months of negotiation between the AEC and Stanford. Finally, in April 1962, a contract had 
been executed. In general terms, the contract (known as "Contract $400^{\prime \prime}$ ) called for the University to design and construct the machine. Costs were to be borne by the AEC. The 480 acres of University land on which the machine was to be built were leased to the government for one dollar per year for fifty years with options for extension.

Contract 400 also included provisions for spending up to $\$ 18,000,000$ in pre-construction research and development. Besides being used for investigation of alternative methods of various design and fabrication techniques, some of this latter sum was used for component testing and development on the small Mark IV accelerator.

Ground breaking took place in July 1962, and the big job was begun. 


\section{RADIATION SHIELDING FOR THE ACCELERATOR}

Biological radiation damage results from radiant charged particles, such as electrons, ionizing matter. Whenever moving electrons strike matter, they may cause ionization or they may cause $\mathrm{x}$-rays to be produced. These $\mathrm{x}$-rays move on and can themselves result in the production of more moving electrons making possible more ionization.

If every electron in the SLAC electron beam were to move in an absolutely straight line and if it were to pass through a perfect vacuum, it would never strike matter and there would be no resultant radiation at all. However, such a perfect situation is not realizable in a practical electron linear accelerator. First of all, the injection of the electrons into the four-inch-diameter copper accelerator tube is a complex operation; not all the injected electrons can be introduced in a parallel direction. Then, too, a perfect vacuum is never quite achievable, although in the SLAC accelerator the vacuum is better than $10^{-6} \mathrm{~mm}$ $\mathrm{Hg}$; there are always some residual air and gas molecules for some electrons to collide with. It must also be admitted that mis-steering and malfunctions can occur to result in at least portions of the beam colliding with the copper walls of the accelerator tube. Finally, special devices are located at intervals along the accelerator purposely to stop electrons moving too far from the axis of the beam.

$\mathrm{X}$-rays produced by stray electrons striking gases in the accelerator or striking the copper walls can induce residual radioactivity ${ }^{1}$ in the Housing, particularly in the copper of the accelerator, the nitrogen in the air in the Housing, and the sodium in the concrete walls. This induced residual radioactivity

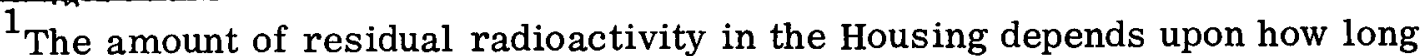
the beam has been on. This residual radioactivity will cause a delay between beam turn-off and entry to the Housing of between a few hours to several days depending upon local radiation levels and necessity of entry.
} 
remains in the Housing even after the beam is turned off, although with only relatively short half-lines.

So radiation does exist in the accelerator and must be carefully considered and shielded. At the Mark III, the 300-foot-long accelerator is installed within a bunker made of concrete blocks averaging three feet thick. It was known all along, of course, that the situation would be much more severe in the two-mile machine. The amount of radiation produced by an electron beam is: proportional both to the number of electrons accelerated per second (the beam current) and to the energy of each electron undergoing collisions with matter. On both these counts, the two-mile machine exceeds the Mark III by an order of magnitude. Some of the earliest design studies for the SLAC machine involved calculations for planning the radiation shielding of its high-energy, high-current beam.

A common unit to measure radiation exposure is the "milliroentgen equivalent man" or "mrem:" This is a complex unit dependent both upon the ratio of the amount of absorbed radiant energy to the mass of absorbing matter and upon the relative biological effectiveness of the radiation (the chemistry of the matter receiving radiation and the susceptibility of this matter to sustaining a biological effect).

Although in biological systems some radiation damage is subject to repair, most radiation damage is cumulative. The measure of the effect of radiation must be related to time. Thus standards of acceptable exposure are usually rated in mrem per year.

There is no radiation level (other than zero) at which it is impossible for radiation damage to occur. Because of the difficulties in experimentation, there is as yet no good evidence showing whether very low doses are harmful or not. There may even be some kind of threshold below which radiation is not damaging. Radiation damage is statistical in nature. Most radiation received passes through 
the receiver with no effect. But there is a probability that some of the radiation will cause biological harm. If the amount of radiation exposure is relatively small, this probability reduces to "almost" zero.

In fact, man is subject to natural radiation throughout his entire life, and it is possible that this has played an important part in evolution of the species through radiation-induced mutations. Cosmic rays from outer space continually bombard our atmosphere, producing radiation. Natural radioactive elements in the rocks of the earth's crust (radium uranium, etc.) also contribute to our radiation environment. A study by the U.S. Federal Radiation Council ${ }^{1}$ concluded that the average background radiation from such natural sources is about 80 to 170 mrem per year. The same study also found that the average background radiation from such man-made sources as medical and dental $\mathrm{x}$-rays is about 80 to 280 mrem per year in the United States. Thus man is continually subjected to radiation in his normal environment of between 160 and $450^{\circ}$ mrem per year. This amount of radiation is small enough so that the amount of genetic damage caused by it is experimentally unmeasurable in the individual. (Before radiation damage can be detected and measured in an individual, he must receive a dose of at least 25,000 mrem.)

With the growth of modern science's activity in the field of atomic and nuclear physics, installations have been established which are concentrated sources of radiation. In order to protect the citizenry, the Federal Government and other organizations have studied radiation exposure and its effects. Such studies have resulted in the setting of acceptable standards or, more accurately, recommended guide levels fur maximum exposurès, taking into account that any exposure must be justified in terms of the benefits derived from the radiation activity.

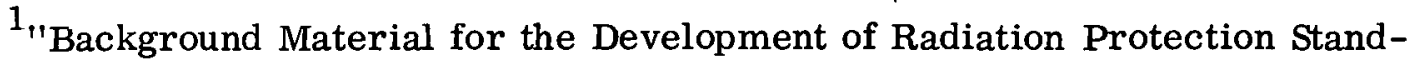
ards," Staff Report No. 1 of the Federal Radiation Council, May 13, 1960, Government Printing Office, Washington, D. C.
} 
These studies have made recommendations at two levels. First there is the general populace to be considered, the people not associated with radiationinvolved activity but who happen to live near such an installation. For these people, most studies recommend as maximum exposure an amount approximating what is called the "doubling dose." This is the amount of radiation exposure from special installations which would double the amount a person receives from normal sources. During initial planning stages, SLAC set its own standard of maximum exposure to the general public at only one-half the doubling dose.

For radiation workers directly involved in the operation of an installation, most federal studies have recommended a maximum exposure about ten times that recommended for the general public. This takes into account the value and benefits of the work the man is doing while still retaining a low exposure level where the statistical probability of damage remains miniscule. During initial planning stages, SLAC set its own maximum permissible exposures for its workers at only one-third of the federally recommended maximum level.

Having set its policy of maximum levels below those recommended by the federal studies, SLAC carried out calculations for a suitable shielding system. To allow for uncertainties in the calculations and to assure that additional shielding would not be called for, SLAC selected calculated shielding data that indicated radiation exposures through the shield of only one percent of the permissible maxima, both for its radiation workers and for the general public.

The cost of a suitable concrete shield for the two-mile machine would have been astronomical, so studies were made of the radiation shielding capabilities of compacted earth fill. Using two different methods of calculation, utilizing measurements of radiation taken at the Mark III during operation, and allowing for uncertainties in estimations, SLAC arrived at the curve shown in Fig. 24. 


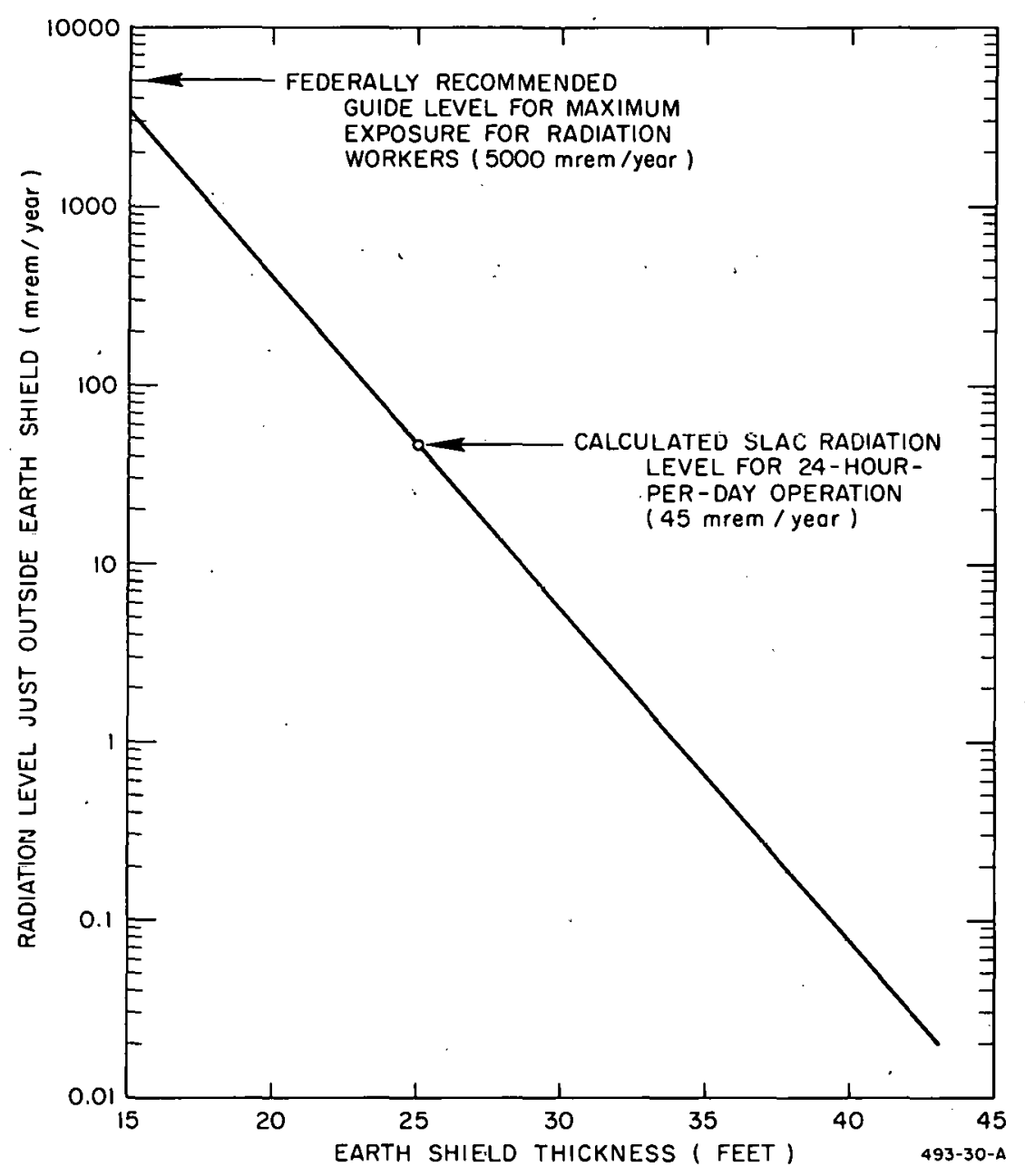

FIG. 24--Calculated radiation levels outside the accelerator's earth shield.

As the curve shows, the calculated radiation level at the surface on a $25-$ foot-deep earth shield around the accelerator would be less than one percent of the recommended maximum exposures. The fact that a full-time radiation worker would only be on the site for less than one-third of the time (a 40 -hour week) reduces the exposure even more.

The placing of a fence around the accelerator 500 feet from the radiation shield takes advantage of the natural reduction of radiation with distance. This results in an exposure for the general public of less than one percent of the 
doubling dose (even if the general public spent its entire life leaning against this fence).

None of the above calculations took into account the fact that the accelerator is inside a housing made of concrete walls between 18 inches and two feet thick. The extra shielding provided by this concrete is an added bonus above and beyond that calculated for the solid earth shield. Measurements of radiation made after beam turn -on confirmed the general accuracy of the calculations.

Table I summarizes these figures and shows the various recommendations and standards. 
TABLE I

\section{ANNUAL RADIATION DOSES}

Per Capita

(mrem per year)

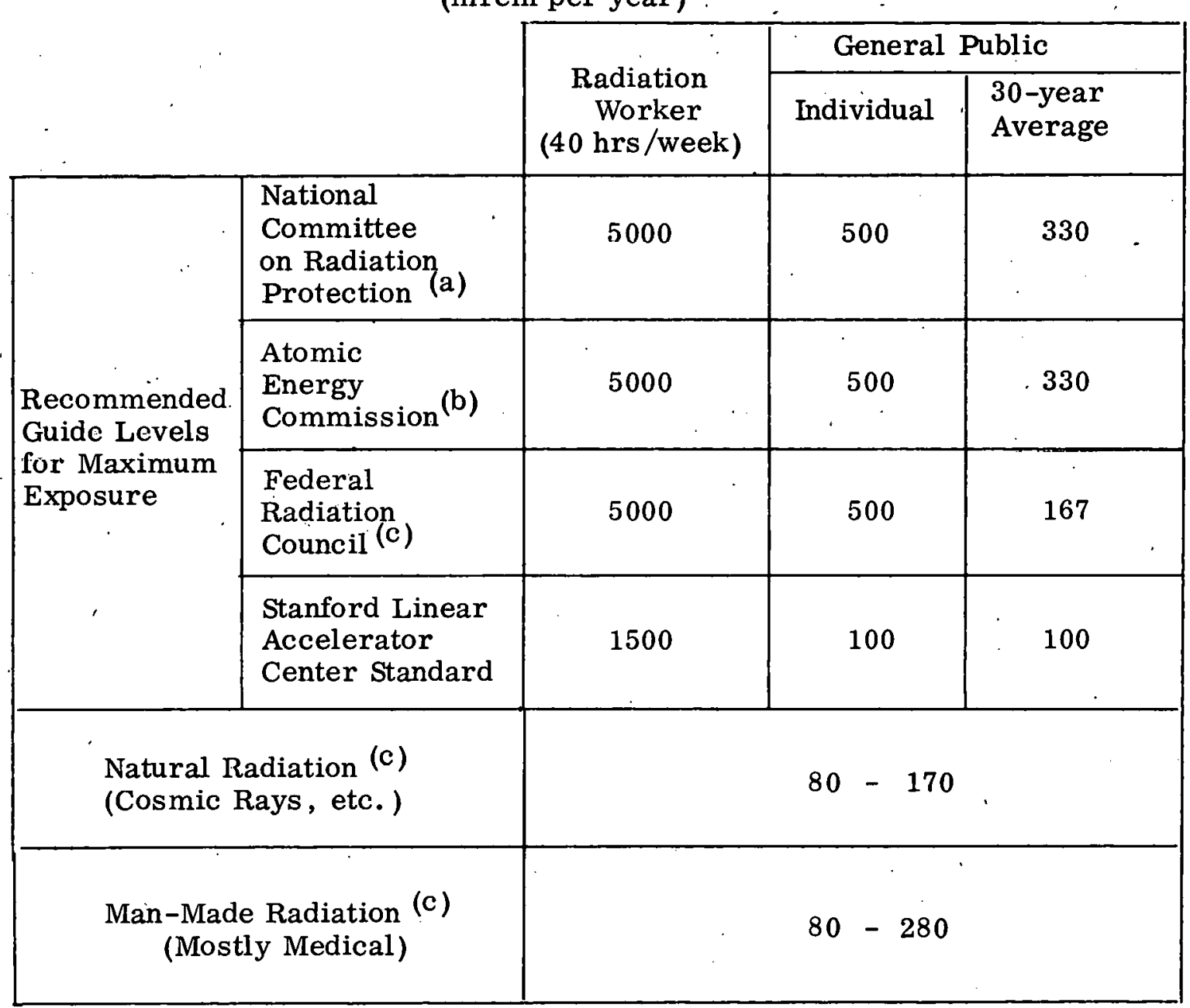

(a) "Permissible Dose From External Sources of Ionizing Radiation," National Bureau of Standards Handbook 59, September 1954.

(b) AEC Manual 0524-02-F.

(c) "Background Material for the Development of Radiation Protection Standards," Staff Report No: 1 of the Federal Radiation Council, May 13, 1960, Government Printing Office, Washington, D. C. 


\section{THE SITE}

Two related investigations were carried out during the early planning days. One was for the selection of a suitable site. The other was for a construction configuration to result in an Accelerator Housing under 25 feet of earth.

Several methods of construction of a-Housing were considered. The general requirement was for two 2 -mile-long structures, one to house the accelerator itself and one to contain the klystrons and associated auxiliary equipment. The two structures were to be separated from each other by 25 feet of earth shielding. This double configuration was required so that equipment could be operated, maintained, serviced, repaired, and adjusted by personnel in the one structure while the beam was on in the accelerator in the other structure. Connections between all the equipment in the one structure and the accelerator proper in the other were to be made via interconnecting penetrations in the earth shield at somewhat regular intervals along the entire machine.

Two parallel tunnels bored through a hilly area was one method considered. Another was the boring of one tunnel for the Accelerator Housing with the construction of a parallel building on the surface of the ground. A third plan, the one finally adopted, was to excavate a trench to the elevation of the floor of the proposed Accelerator Housing and to construct that Housing in the open trench. Then some of the excavated earth was to be dumped back into the trench after the Housing was constructed. 'Ihis fill was then to be compacted, layer by layer, until a 25-foot-deep shield existed. Finally, the second structure was to be built on top of this fill, parallel to and directly over the buried Accelerator Housing.

Several sites were investigated, including three on Stanford University property and three on shore lands around San Francisco Bay. Because of the requirement for a bedrock foundation, the selection narrowed to the Stanford 
sites. Economic construction considerations eventually led to the final selection of the "Sand Hill" site.

The site of the Stanford Linear Accelerator Center occupies 480 acres of University land, leased to the Federal Government, in the Stanford foothills area (Fig. 25). The site is connected with the San Francisco Bay Area by several major highways. The future Junipero Serra Freeway between San Francisco and San Jose crosses the accelerator at about mid-length.

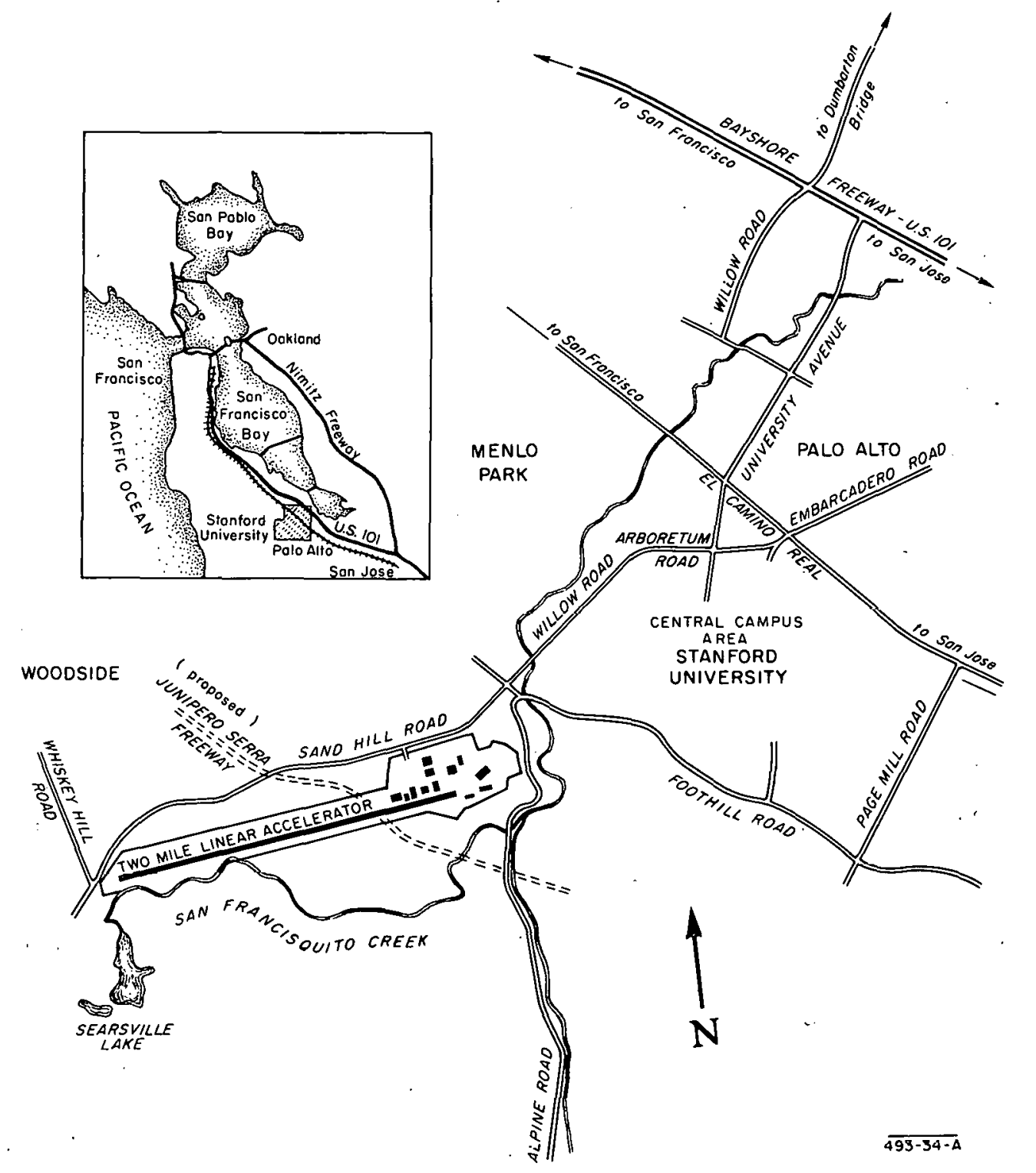

FIG. 25--Location of the Stanford Linear Accelerator Center. 
The Stanford foothill area is a belt of low, rolling foothills, lying between the alluvial plain bordering San Francisco Bay on the east and the Santa.Cruz Mountains on the west. The accelerator site varies in elevation from 200 to 375 feet above sea level, whereas the alluvial plain is less than 150 feet above sea level and the mountains to the west rise abruptly to over 2000 feet.

The site is bordered in part on the south by San Francisquito Creek, a major watercourse draining the foothill belt. The headwater area of the creek is dammed to form Searsville Lake.

The entire Sand Hill site is underlain bÿ sandstone and claystone. The bed rock on which the western half of the accelerator sits is of Eocene age (over $50,000,000$ years. old) and that under the eastern half is of Miocene age (over $10,000,000$ years old). On top of this bedrock at various places along the accelerator alignment are found alluvial deposits of sand and gravel of generally Pleistocene age $(1,000,000$ years old). At the surface is a soil overburden of unconsolidated earth materials averaging from three to five feet in depth.

The trench for the Accelerator Housing was made deep enough so that the Housing would rest on bedrock except in a few places where the Pleistocene alluvium was unusually deep. One of two things was done at each of these locations. In some cases, the alluvium was over-excavated and replaced with compacted earth. In other cases the alluvium was mechanically preconsolidated.

In three other places, existing open valley floors lay beneath the level of the excavated trench. Here too, specially selected earth was placed and compacted to the necessary density.

There are no historically active earth faults crossing the accelerator site. Several faults cut the Eocene and Miocene beds and at least one cuts the Pleisto-cene alluvium, but there is no evidence of movement on any of the faults for nearly a million years. 
The nearest large active fault is the well known San Andreas Fault, whose movement in 1906 resulted in the catastrophic San Francisco earthquake and fire. This fault zone runs nearly perpendicular to the accelerator site, and its eastern boundary is about a half mile away from the accelerator's western end. During the 1906 temblor, structural damage to inadequately constructed buildings in the area occurred. However, the Searsville Dam, which is within a few hundred yards of the accelerator, suffered no damage at all.

Earth strain is known to be accumulating along the San Andreas Fault. Because this elastic deflection along the fault could be causing strain accumulation on the accelerator site, field investigations of possible earth movement were made on the site.

To measure vertical movement, bench marks were established along the alignment, located at depths of 30 feet. Observations were made over an 18-month period. Total differences in vertical movement of the site earth amounted to less than one-eighth inch.

To measure horizontal movement, twelve alignment stations were located parallel to the accelerator alignment. The maximum horizontal deviation noted over an 18-month observation period was at one of the stations which moved in a cyclic way, first $1 / 4$ inch north, then $1 / 4$ inch south of its original position. All other stations exhibited less movement. The eastern half of the site showed the least movement, in the order of less than 1/8-inch departure from the reference line.

These extremely minor earth movements, together with the predominant rock foundation, made the site suitable for construction of the accelerator. The next step was to build an extremely strong reinforced concrete structure in the excavated trench to house the machine. 


\section{ACCELERATOR HOUSING CONSTRUCTION}

The extreme requirements for strength and linearity of the structure housing the accelerator resulted in the accomplishment of one of the most exacting large construction projects ever undertaken.

The electron beam itself, which passes through the 4 -inch-diameter, 10,000-foot-long accelerator tube, is less than a half inch in diameter. Unimpeded and undeflected, this beam will travel in an absolutely exactly straight line. The hole through which the beam passes on its two-mile trip is barely $7 / 8$ inch in diameter. So that no part of the linear beam will brush against the edges of the passage holes, the specification was made that the accelerator pipe over its entire length must have no more than \pm 0.04 inch total deviation from a theoretically straight line.

It would be impossible to build a single rigid structure of this length to such a stringent linearity requirement. Therefore, the accelerator has been built in separate 40-foot-long modules. Each of the 240 such modules is connected to its two neighbors via flexible couplings, much like accordian bellows. Beneath each coupling point, adjustable worm-screw jacks permit that point to be raised, lowered, or moved to one side or the other. This adjustment mechanism per mitted the accelerator to be initially aligned after installation and permits later alignment if necessary. To keep these jacks from having to be readjusted very often and to permit them to be of uniform size and of realistic adjustment range, it was necessary to build the Accelerator Housing very straight. It was also necessary to build it very strong in order to retain the initial straightness for years to come.

The contractor was given the initial alignment specification that when the accelerator was first aligned, the floor of the Housing must be absolutely straight, 
permitting no point to be more than four inches above a perfectly straight theoretical reference line and no point more than two inches below. He was given the long-time strength requirement that no point along the two-mile housing move more than one-quarter inch in any 90-day period throughout the life of the. accelerator.

These requirements meant that the trench floor had to be extremely straight and extremely compact so that it would not sag during and after construction. They meant that the Housing had to be a single rigid concrete structure permitting no points of permissible bending. They meant that the Housing had to be very strong so that as 25 feet of earth was compacted above it, it would withstand the resultant forces and remain straight. They meant that the earth fill, in the three places along the alignment where the trench floor had to be built up from valley bottoms, had to be compacted to a high density to transmit the Housing load effectively to the bedrock supporting the majority of the Housing in order to minimize Housing settlement.

All these considerations had to be applied to all the different configurations resulting from the cut-and-fill technique of construction (Figs. 26 and 27).

In some places, the Housing was placed in the excavated trench and filled over to the original ground level where the Klystron Gallery was built.

When a portion of the alignment crossed a valley floor, that floor had to be over-excavated so that a hill could be man-made of select fill. This man-made hill was allowed to settle under its own weight until it was compacted to bedrock density. Then the trench was excavated through the man-made hill and the Housing constructed therein. The final fill on top of the Housing brought ground level back to the top of the man-made hill for construction of the Klystron Gallery. 


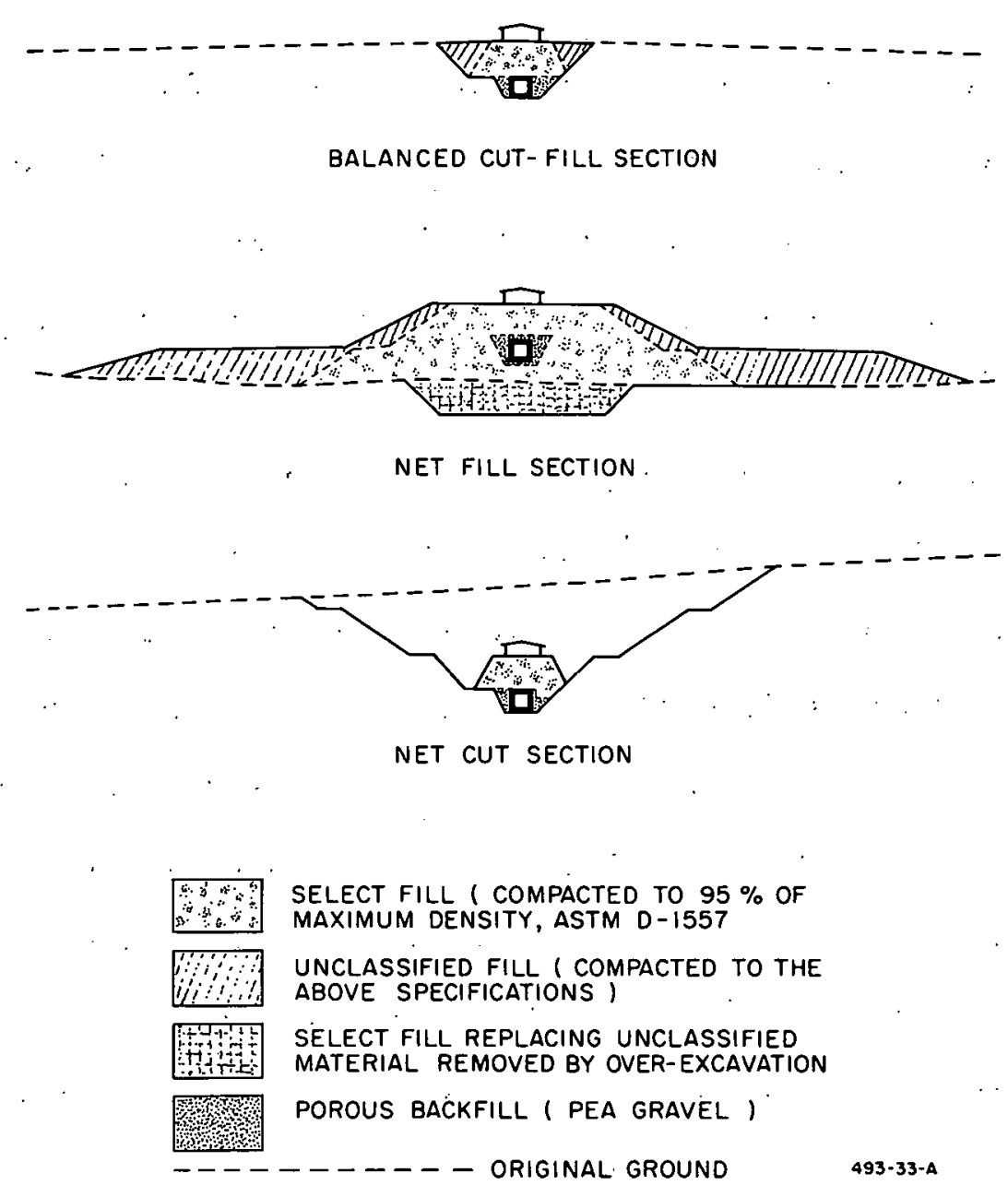

FIG. 26--Typical cross sections of Accelerator Housing and earthwork.

In many places, the original ground level was at a very high elevation so that a very dəep cut had to be made. The Housing was built at the bottom of the deep cut and again filled over with 25 feet of compacted earth. The Klystron Gallery in these places is below the original ground level.

All construction started at the west end of the site. As soon as several thousand feet of bedrock floor had been opened, and while more cut-and-fill work proceeded eastward, construction of the Housing began.

The Accelerator Housing is a 10,000-foot-long concrete box with 1-1/2foot-thick walls and 2- to 2-1/2-foot-thick roof and floor slabs. The interior of 


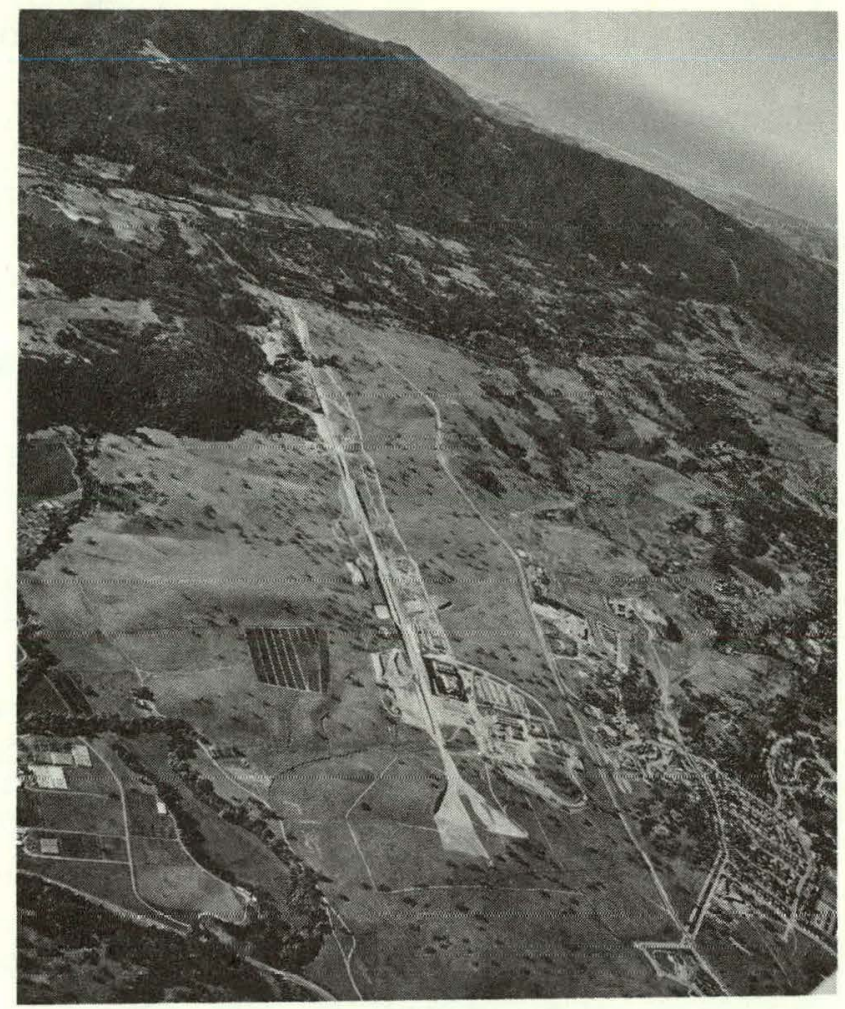

FIG. 27--The two-mile-long cut-and-fill in mid-1964, looking west toward the Pacific Ocean from the initial excavations for the two target buildings.

the long box is 10 feet wide and 11 feet high. Imbedded in the concrete is nearly 4000 tons of reinforcing steel. The Housing is a monolithic concrete structure from end to end, containing no expansion and contraction joints.

The Housing was built in 80 -foot-long sections. Alternate sections were poured first. The intermediate sections were poured later between pairs of already cured sections. This permitted the concrete of the later sections to flow and bond to the existing sections, resulting in an overall continuous Housing.

The first big problem in the construction of the structure was the shrinkage cracking inherent in the curing and drying of concrete. In normal concrete work, much of this cracking tendency is absorbed by expansion and contraction joints. In this jointless structure, the most effective way to reduce the cracking was to reduce the shrinkage factor. To achieve low shrinkage, the concrete mix was 
carefully designed and mixed and the pouring and curing were closely controlled.

It was found that the use of crushed, high quality limestone or granite aggregates, with samples pretested to insure low shrinkage characteristics, was essential for a low shrinkage mix. To reduce the effect of temperature changes, the temperature of the concrete poured was maintained between 40 and 60 degrees Fahrenheit. During summer night-time pouring, ambient temperatures met this specification. For daytime summer pouring, ice often had to be added to the concrete mix. Adjacent to the on-site concrete plant was a 20-ton-per-day ice plant which produced 150 pounds of ice per cubic yard of concrete on hot days.

The first step in making ready for a pour was to lay a 0.02 -inch-thick polyvinyl chloride membrane in the floor of the trench. Then a 3 -inch sub-slab was poured over the membrane to protect it during construction (Fig. 28). Next the steel forms for the Housing were put in place and set to a tolerance of $1 / 8$ inch.

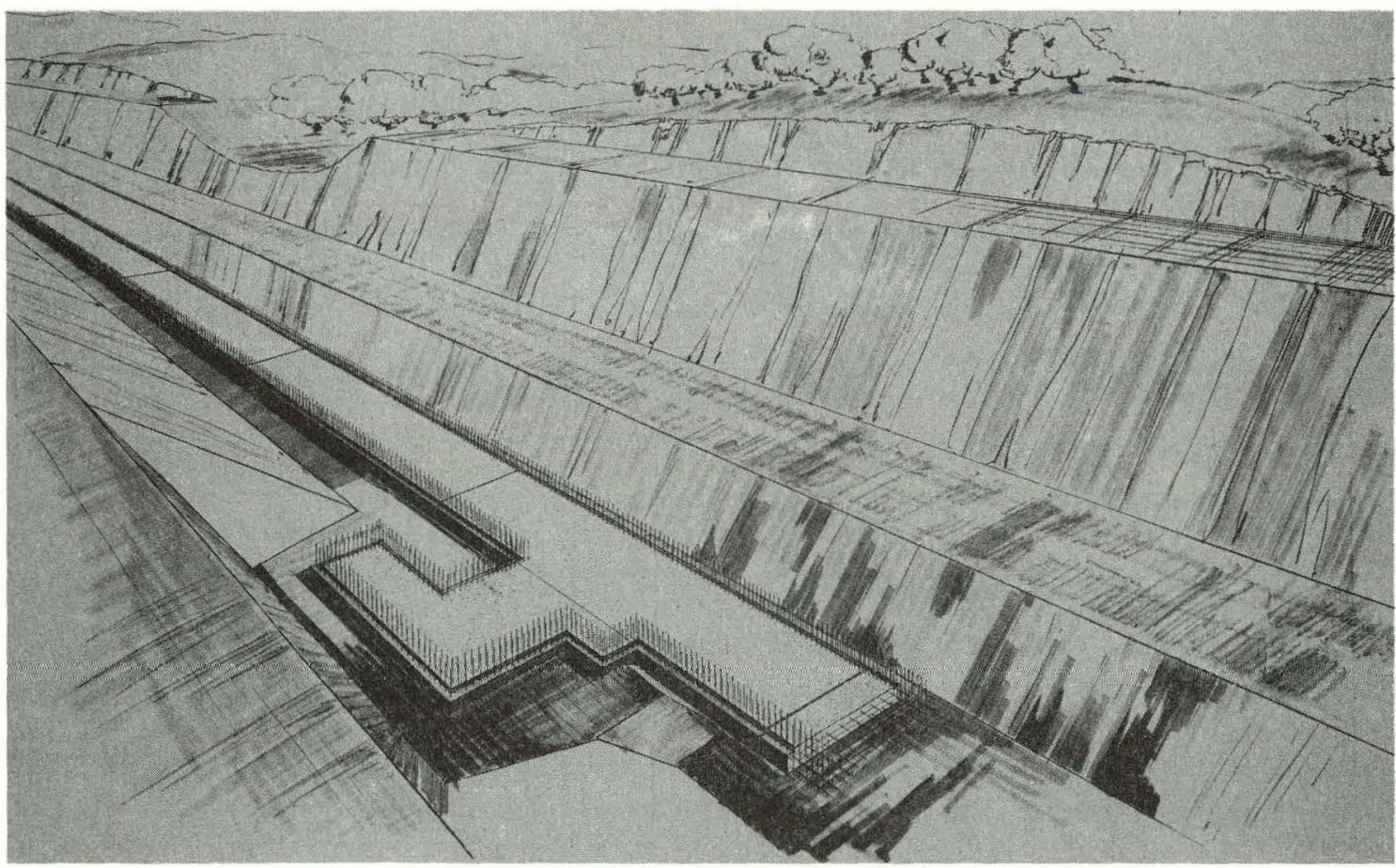

FIG. 28--Sketch of the sub-slab laid before Housing construction began. 
With the forms in place, the walls, floor and ceiling of the 80 -foot section of Housing were monolithically poured around preconstructed reinforcing steel bars (Fig. 29).

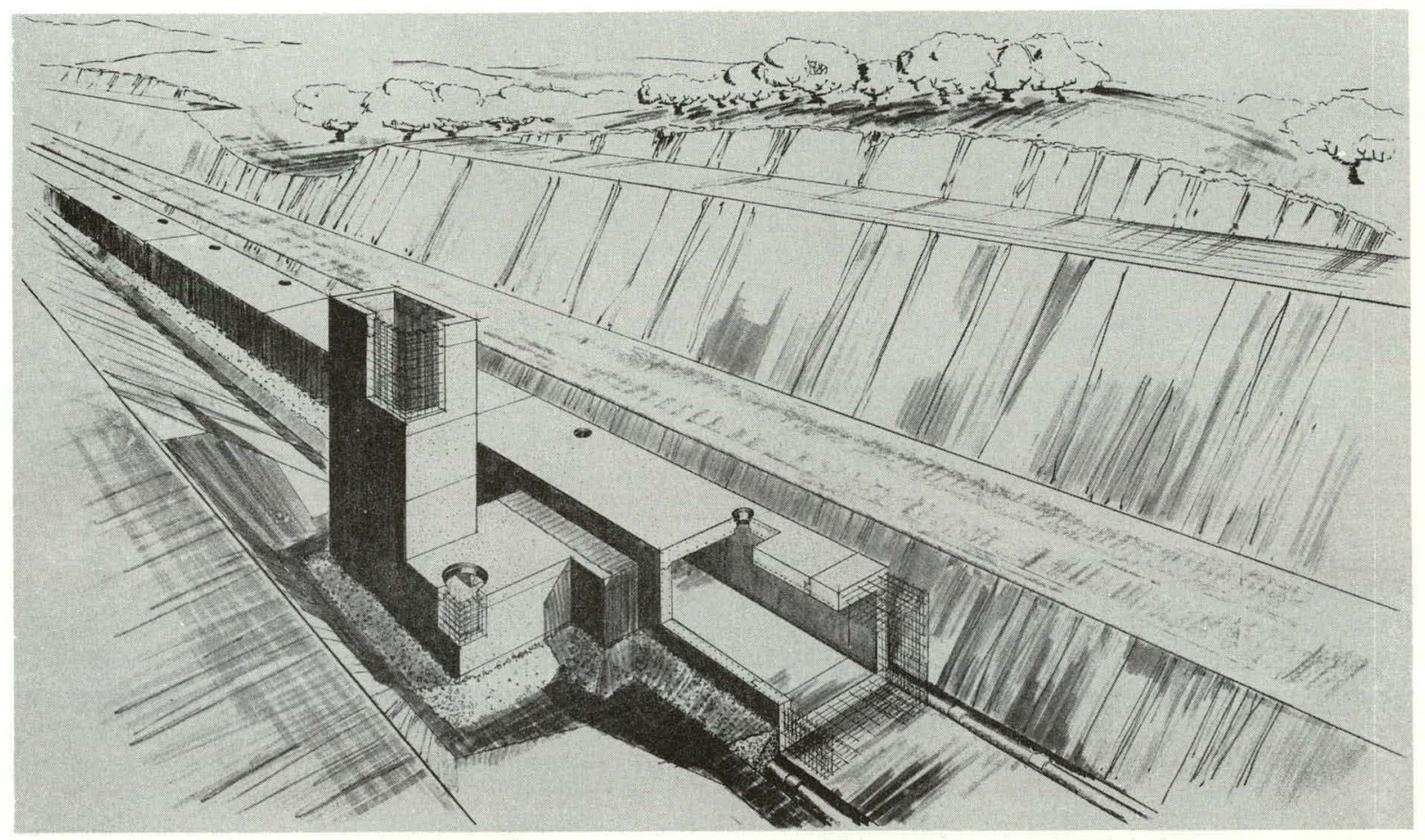

FIG. 29--Sketch of the Housing under construction in the trench. The vertical structure is one of several equipment accessways.

After the concrete had set, the forms were stripped away and water pipes with spray nozzles were placed on the sides and top of the new Housing section. For the next fourteen days, the green concrete was subjected to a "fog" cure. Once the curing was completed, the fog spray was used as an evaporating type coolant to keep the temperature of the Housing low until the embankment fill material could be placed upon it.

When the concrete was cured, an adhesive sealer was applied directly to the concrete surfaces and more plastic membrane was sealed to the top and around the sides of the structure. The top and side pieces overlapped the sheets 
placed beneath the sub-slab to make a watertight seal around the entire Housing. In order to reflect heat away from the black polyvinyl chloride until the embankment fill had been placed and to protect the membrane during backfilling, sheets of white fiberboard insulation were placed around the top and sides.

To permit moisture drainage, a porous back-fill of pea gravel was laid along both sides of the Housing in the remainder of the trench (Fig. 30). Then began the job of placing layer after layer of earth around the sides and back on top of the Housing, each layer compacted to bedrock density (Fig. 31).

When the 25-foot-deep fill had been completed and compacted (Fig. 32), cracks were searched out. These cracks, which occurred mainly at the construction joints between sections, were pumped full of an epoxy grouting. This epoxy formed joints as strong as the concrete itself.

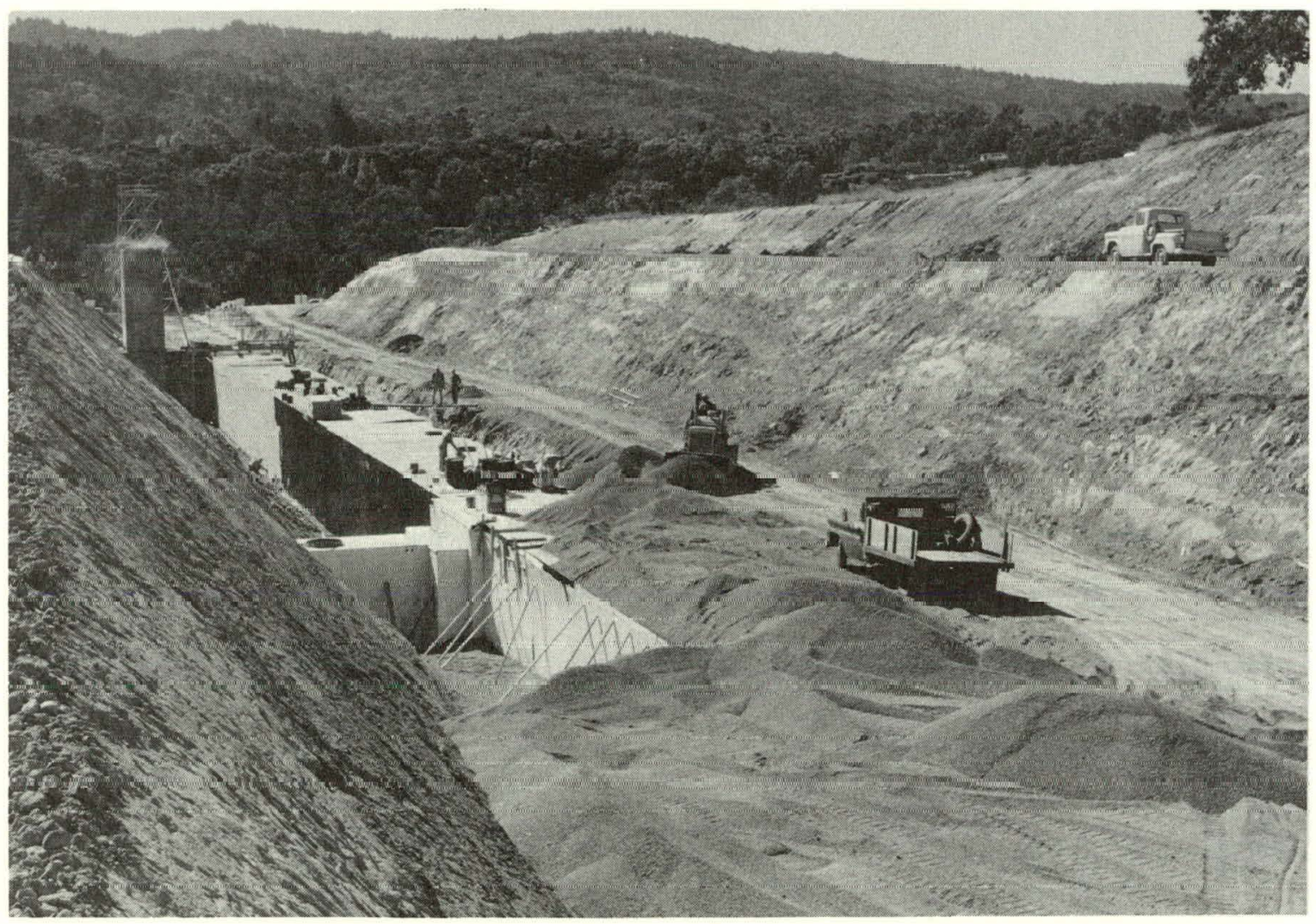

FIG. 30--The first few sections of Accelerator Housing with the pea-gravel back-fill covering the protective Celotex sheets. 


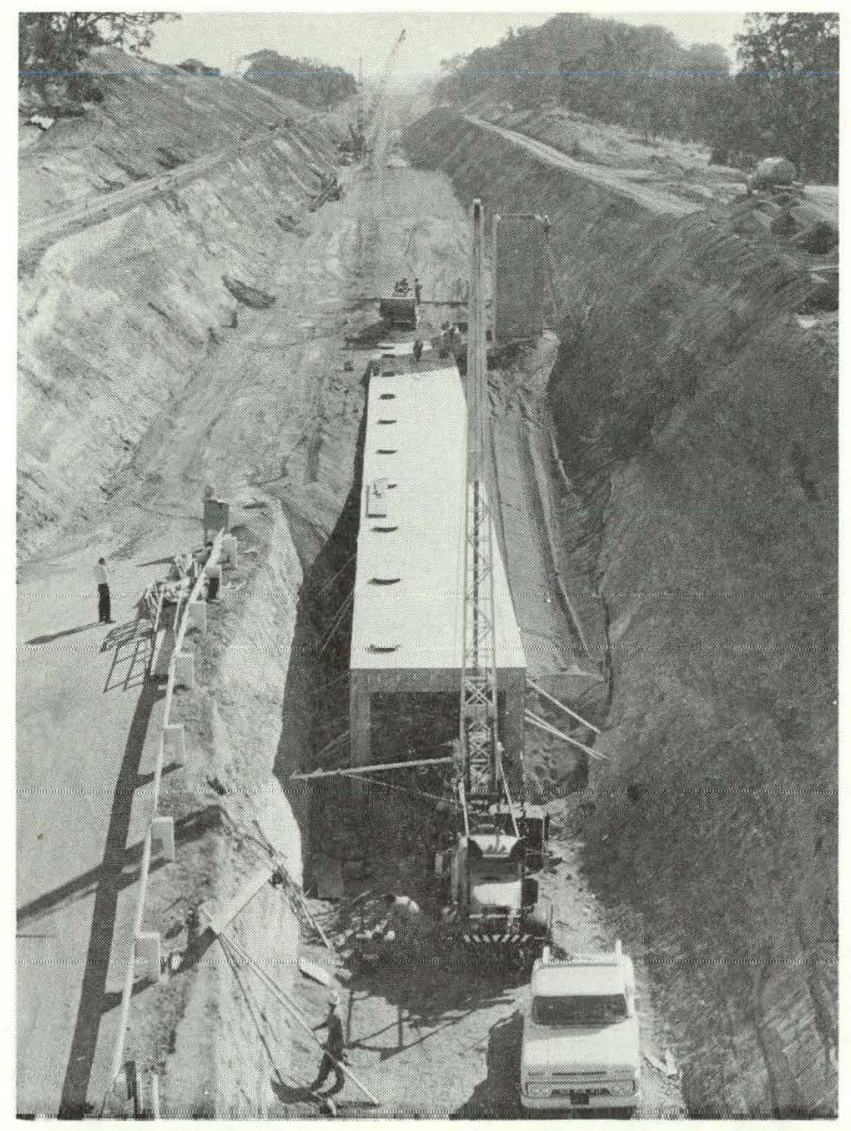

FIG. 31--Accelerator Housing construction continued eastward while western portions were being covered with compacted fill.

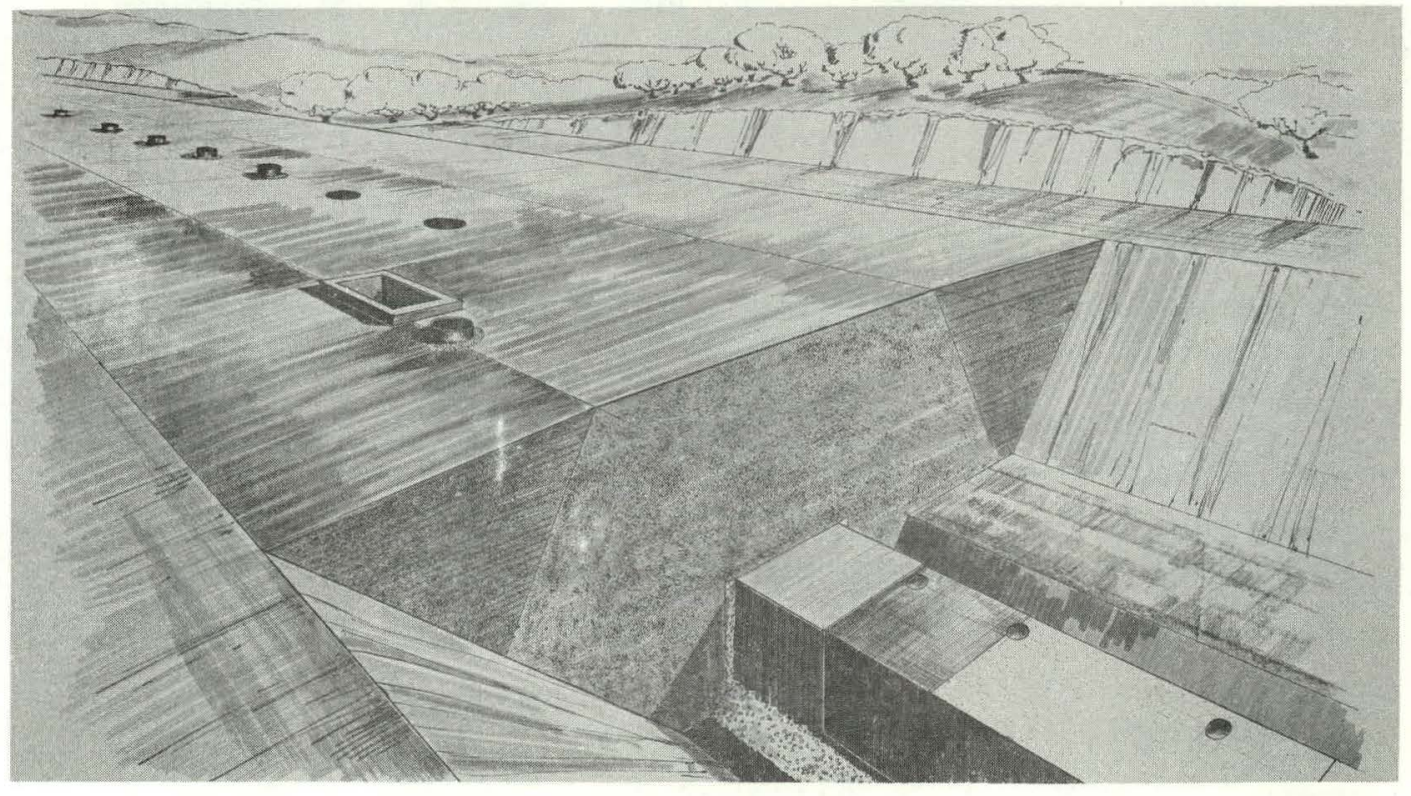

FIG. 32--Sketch of the completed fill over the Housing, showing the top of several of the penetrations leading to the Housing. 
During accelerator operation, the Housing is at a temperature well above 90 degrees Fahrenheit due to the energy dissipated in the machine. This causes the concrete to tend to expand. The epoxy grouting resists this expansion and thus enhances the structural integrity of the Housing and pre-stresses the concrete.

Finally, the on-the-surface Klystron Gallery was constructed above the Housing (Fig. 33). The Klystron Gallery is a single-story structural-steel-framed building, divided into thirty "sectors" separate from each other to allow for thermal expansion. The structure consists of a rigid steel frame every ten feet with transverse frames (Fig. 34). A structural steel longitudinal bracing system provides for resistance to longitudinal seismic forces. Further such resistance is provided by concrete shear wall panels in each sector. Seismic forces in the transverse direction are resisted by the structural rigid frames. The walls and roof are noninsulated fluted metal panels with no windows or skylights (Fig. 35).

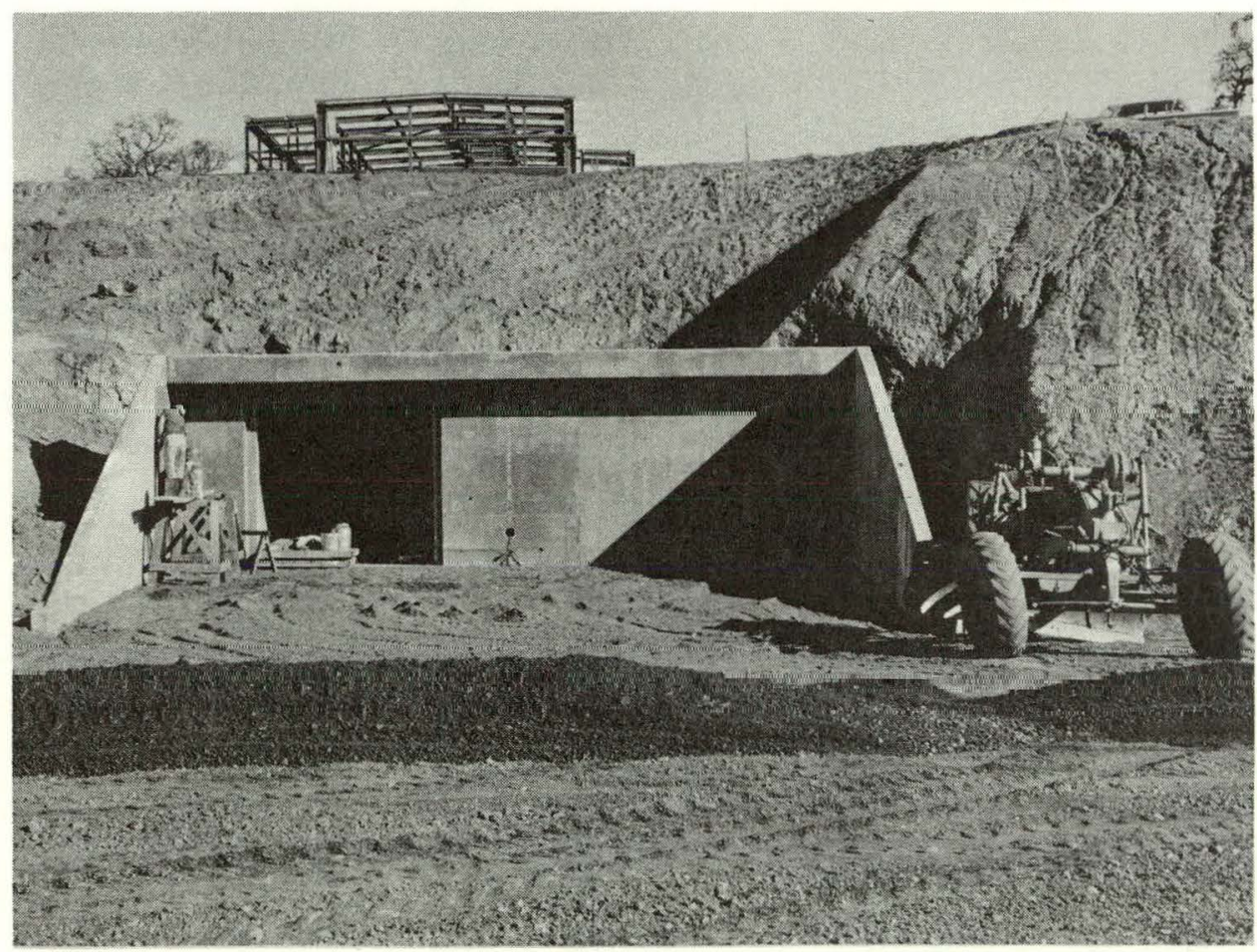

FIG. 33--The western end of the completed Accelerator Housing with 25 feet of compacted earth above it and construction of the Klystron Gallery begun. 


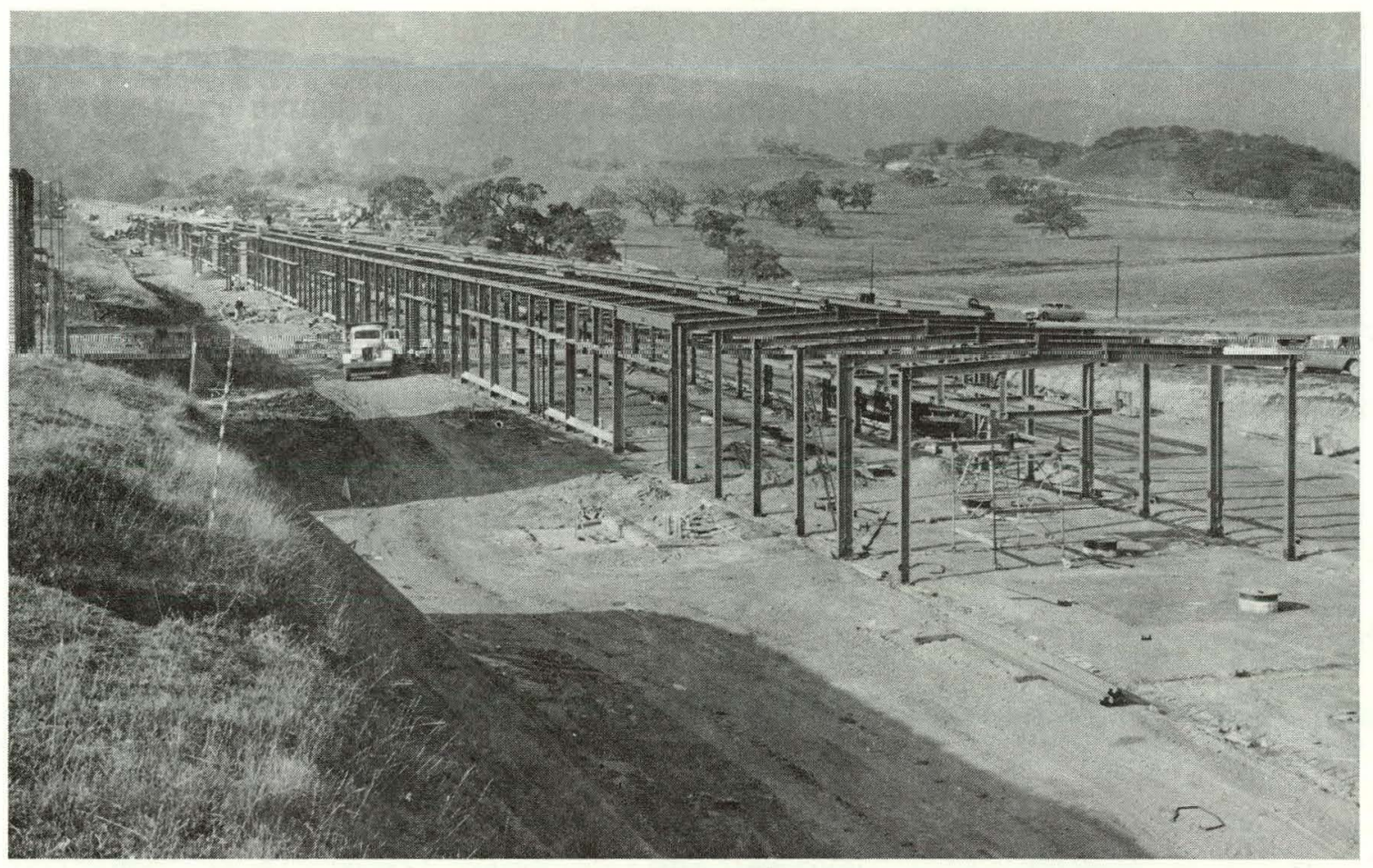

FIG. 34--The framing of the Klystron Gallery .

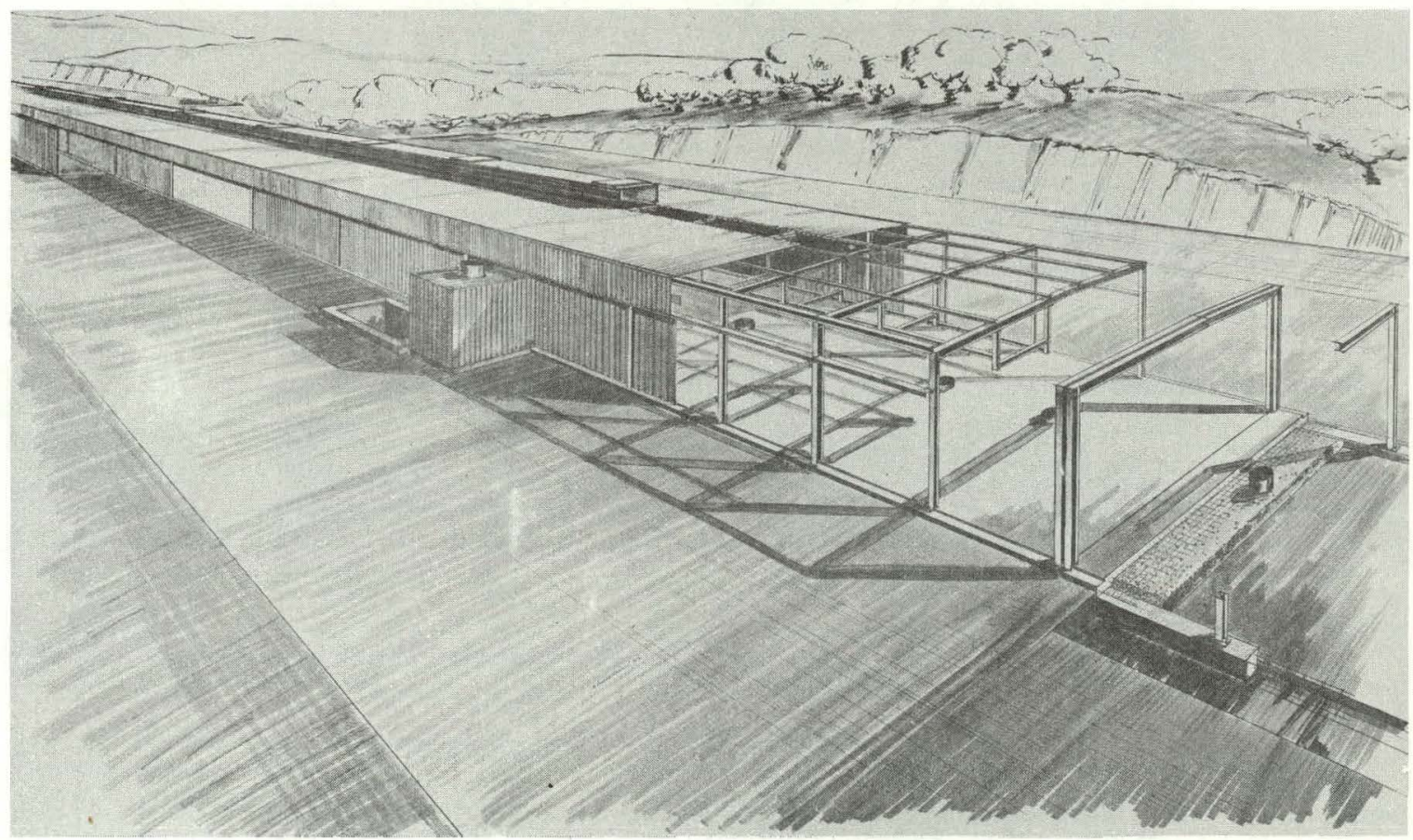

FIG. 35--Sketch of the Klystron Gallery under construction. 
Removable roof sections provide access to the rigid structures connecting the equipment in the Gallery to the accelerator in the Housing via the penetrations in the ground.

Alcoves along the north side of the Gallery contain instrumentation and control equipment for each sector. Alcoves along the south side of the Gallery house other periodic mechanical and electrical equipment (Fig. 36).

Besides the approximately 2-feet-in-diameter penetrations in the ground, spaced usually 20 feet apart, there are several accessways from the Gallery to the Housing. At one place in each sector, on the south side, a vertical man accessway has been constructed. These are 3-foot-wide manholes, 25 feet deep,

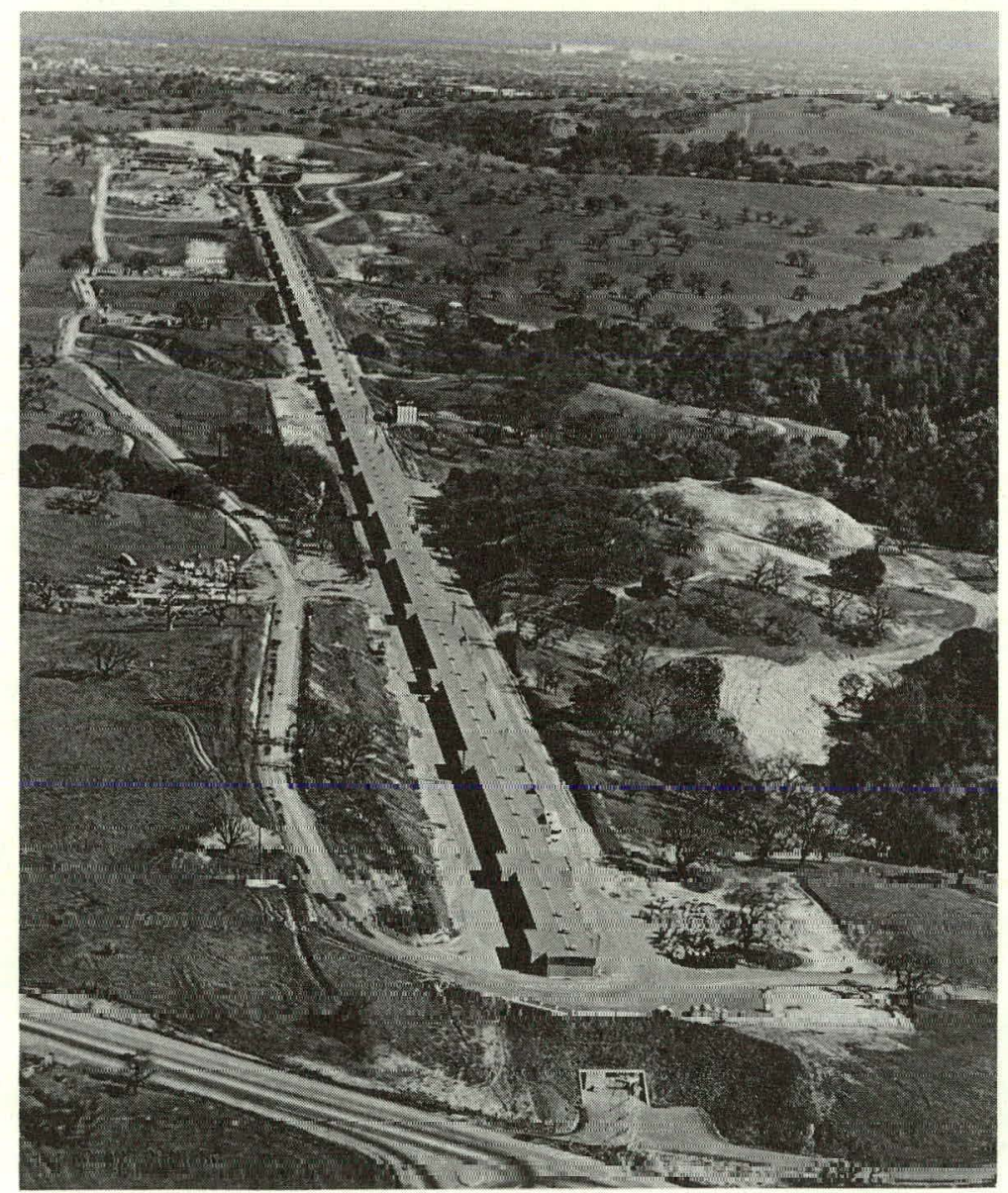

FIG. 36--The complete Klystron Gallery as seen from the injector or west end. 
equipped with wall ladders (Fig. 37). In addition, at a half-dozen places along the machine, larger accessways have been constructed to permit equipment and apparatus to be raised and lowered into and out of the Housing. All these penetrations and accessways are capped and are offset from the accelerator in order not to act as passageways for straight-line radiation from the accelerator.

As construction of the two 2-mile-long structures proceeded, installation of the accelerator and auxiliary equipment was begun.

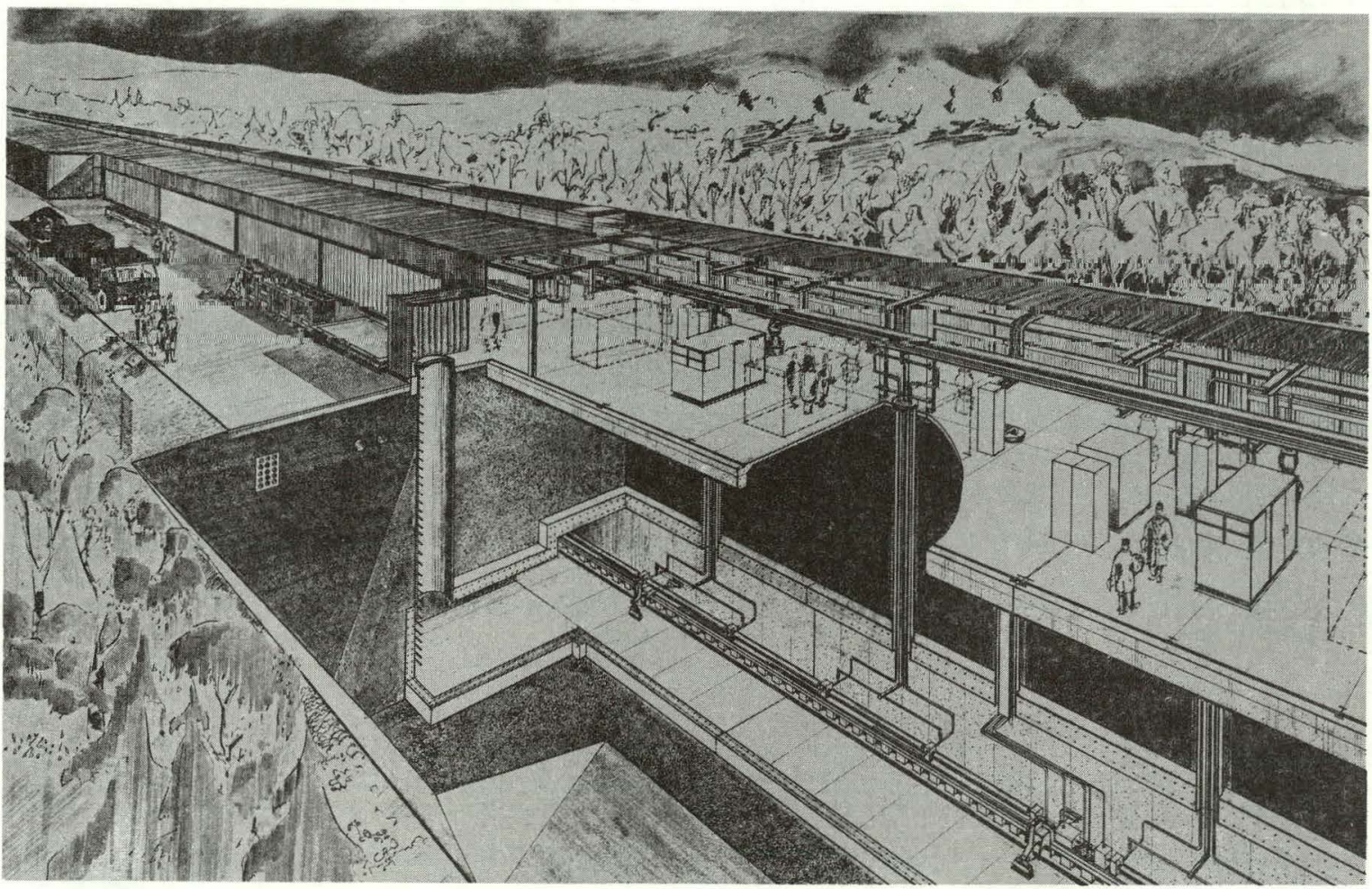

FIG. 37--Cutaway sketch of the Klystron Gallery and Accelerator Housing showing interconnection penetrations and one of the man accessways. 


\section{THE ACCELERATION SYSTEM}

The basic unit of the accelerator proper is a 40-foot-long "module" divided into four 10-foot-long "sections." There are 240 such modules installed in the underground Housing. Radiofrequency power to each 40-foot module is supplied by one high-power klystron amplifier tube (Fig. 38). The klystron produces short pulses of up to 24 megawatts of radio power at the microwave frequency of 2856 megacycles per second. Directly above the klystron, in the Klystron Gallery, this output power is divided into two halves. Thus 12-megawatt pulses of $\mathrm{rf}$ power are carried down through the 25 -foot-deep earth shield via rectangular waveguide piping in each of the two penetrations associated with each klystron.

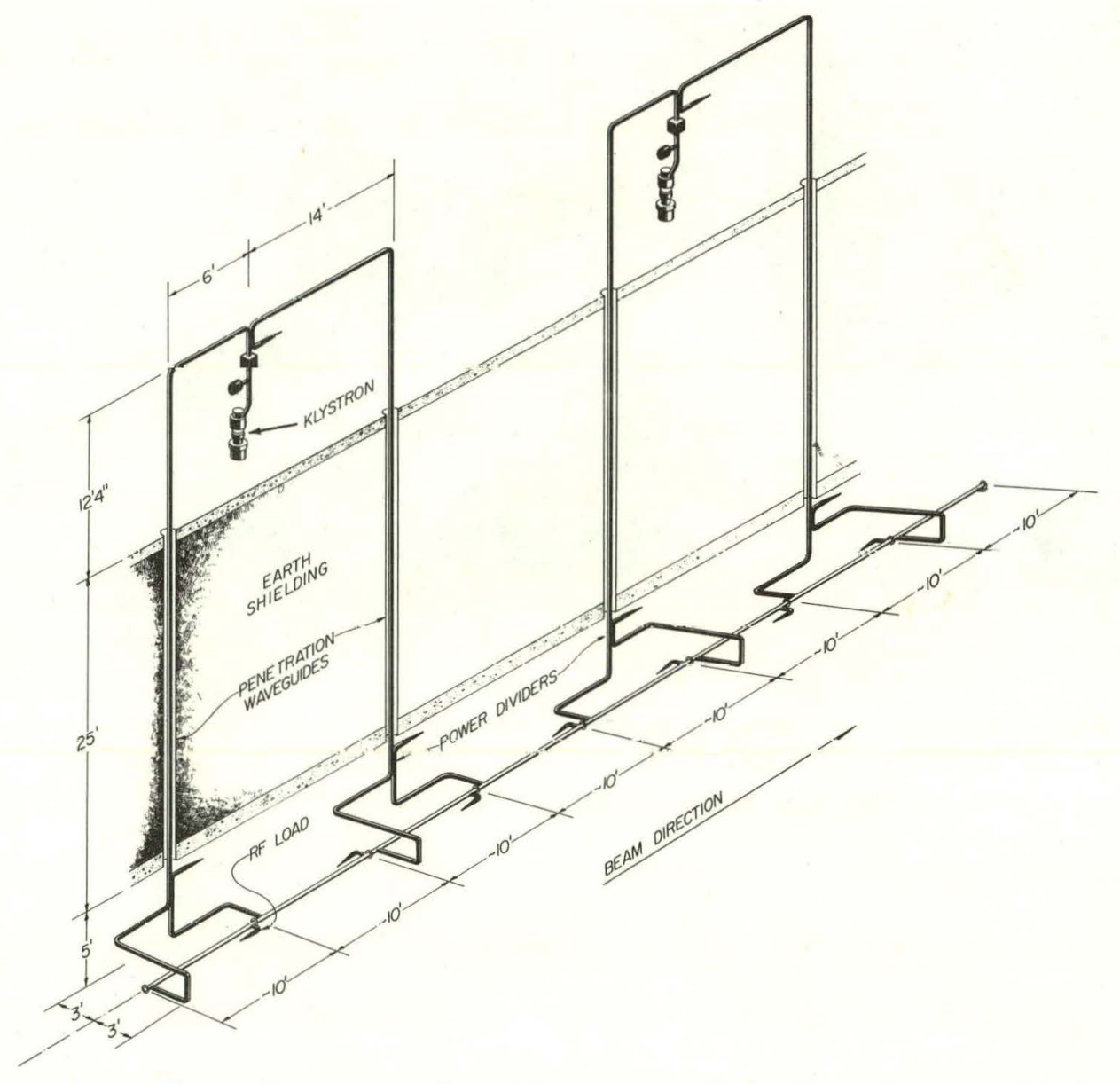

FIG. 38--Two of the 240 forty-foot-long accelerator stages. 
At the bottom of each penetration, the $\mathrm{rf}$ power is again divided in two so that 6 megawatts of power is available to feed each 10 -foot section of the accelerator. This high power radio wave enters the typical 10-foot accelerator section at its west end, via a coupler, and travels east through this section at the speed of light. The electron beam from the previous section of the accelerator enters this next section through a small hole. The electrons are caught on the crest of the radio wave and ride it for ten feet, absorbing energy.

After ten feet of acceleration, the radio wave has lost sufficient energy so that it is no longer economical to continue acceleration.(Most of this energy loss is caused by the traveling wave heating the copper walls of the accelerator pipe.) Therefore, what remains of the radio wave after ten feet of acceleration is taken out of the 10-foot section at its east end and is dumped into and dissipated by a water-cooled copper load. Meanwhile the accelerated electrons continue their easterly trek, again through a small terminal hole, and enter the next 10-foot length where a new radio wave receives them for another 10-foot acceleration.

This power splitting scheme serves the purpose of equipping the accelerator so that if in future it becomes desirable to increase the energy of the accelerator, all that need be done is the adding of klystrons. For instance, four klystrons could be placed where there is now one, and the entire 24-megawatt output of each could be delivered to just one 10-foot section. Such a possible future phase , has been referred to as "Stage II" (Fig. 39).

The actual accelerator itself is a four-inch-diameter tube assembled from over 80,000 copper cylinders interstacked with over 80,000 copper disks (Fig. 40). These cylinders and disks were fabricated by SLAC from extremely pure copper stock, the cylindrical pieces sliced from long copper cylinders, the disks cut from large pieces of copper plate. These pieces were then machined to tolerances 
within 0.0001 inch. To maintain such machining tolerances, cutting was done in an air conditioned room with a temperature-controlled (to within a quarter of a degree Centigrade) coolant oil flowing over the part during machining.
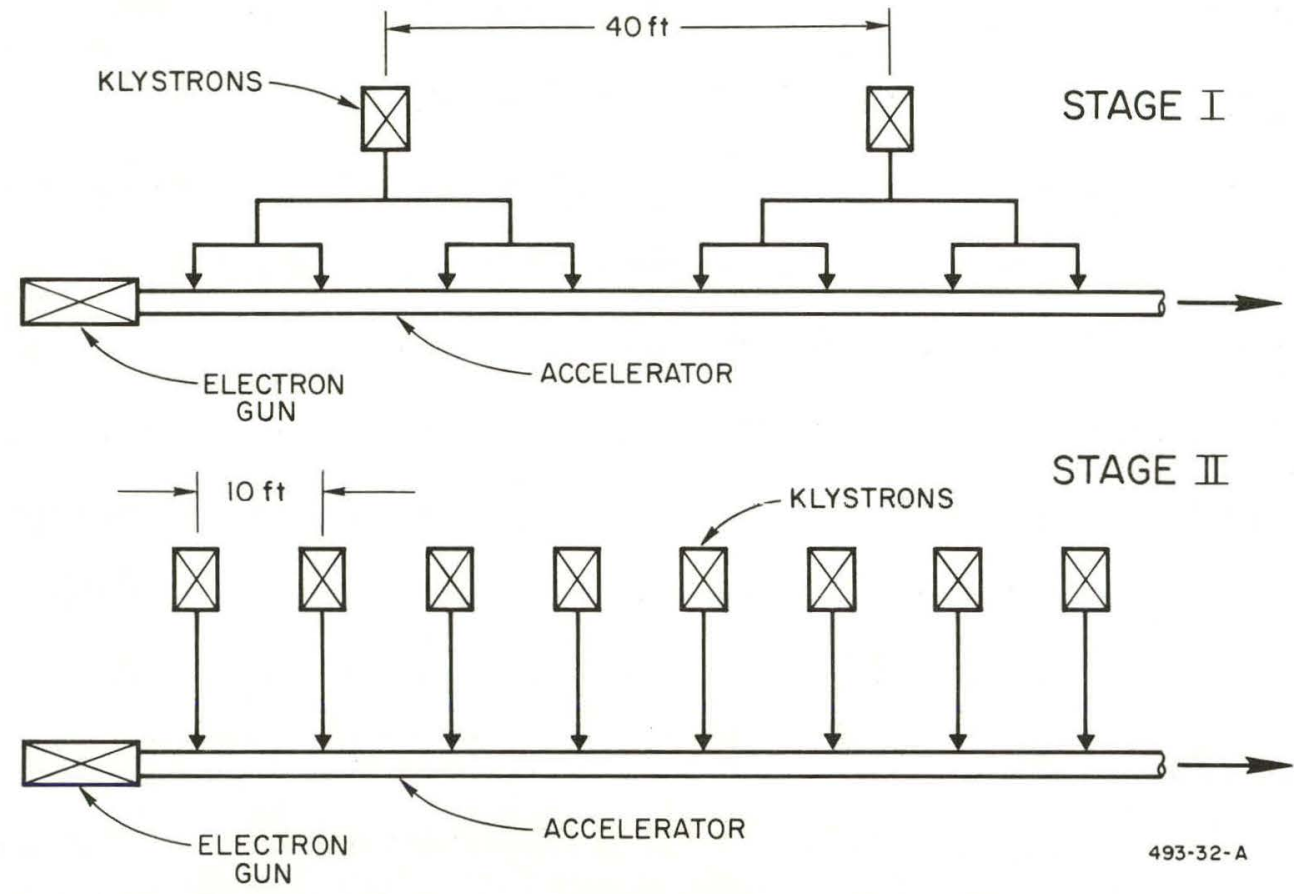

FIG. 39--Diagram of the present klystron-to-accelerator configuration (Stage I) and of the possible future configuration (Stage II).

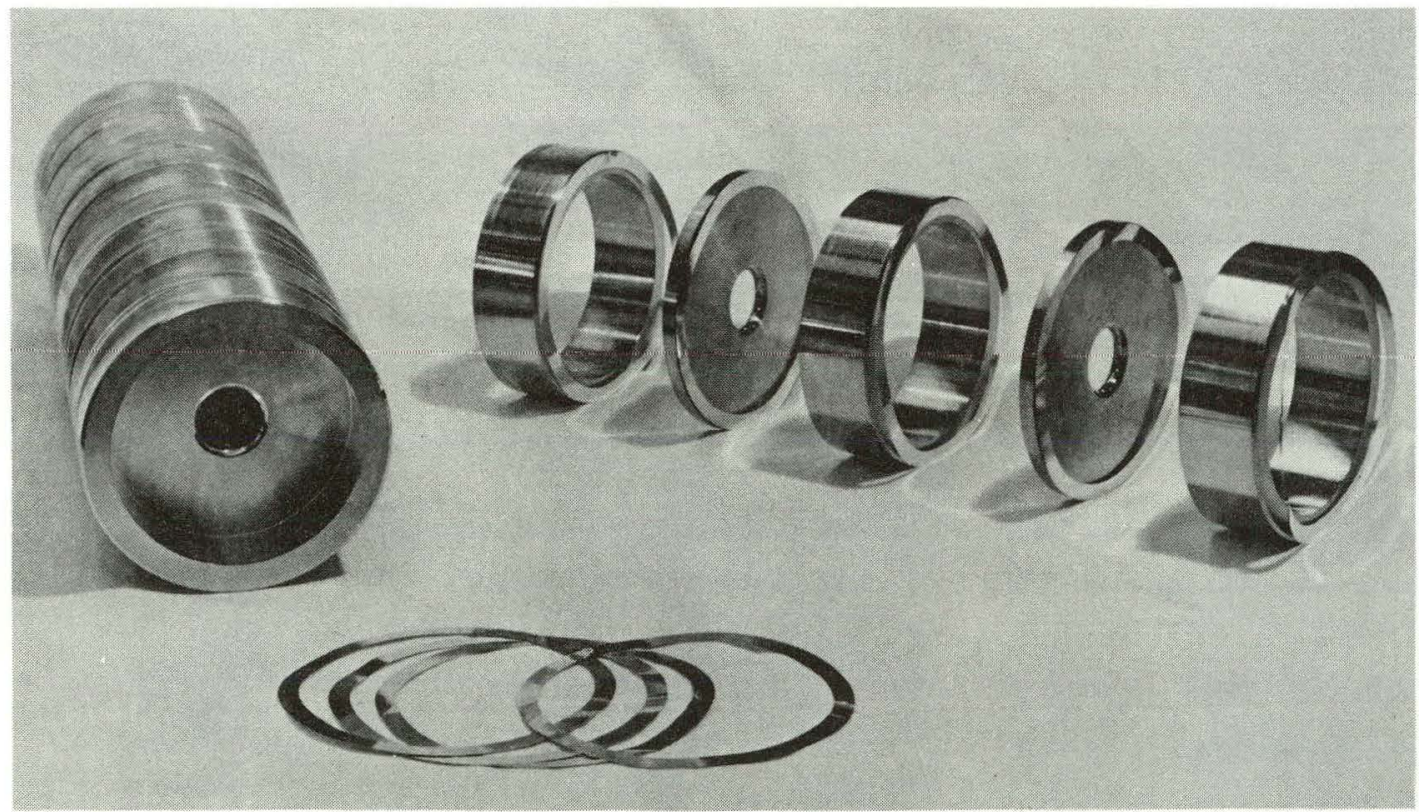

Fig. 40--Copper cylinders and disks making up the four-inch-diameter, two-mile-long accelerator structure. The thin wafers are alloy rings for brazing the cylinders and disks together. 
After sufficient disks and cylinders were machined, a stack ten feet high was assembled with brazing copper-silver alloy washers between each pair of pieces. Then the entire ten-foot section was brazed together to form a solid copper unit. The brazing was carried out using a split-ring burner which surrounded the stack of disks and cylinders. This ring burner, which was fired by an oxygen-hydrogen flame, was started at the top of the stack and moved slowly down. As the burner passed each joint, the brazing alloy washer melted and fused the pieces together. Following the burner down the stack was a water-cooled chamber in which the brazed section could cool.

The ten-foot section was completed when an array of small copper tubes had been brazed to the exterior of the section (Fig. 41) in a separate pit furnace. These small tubes are for passage of temperature-controlling water during operation.

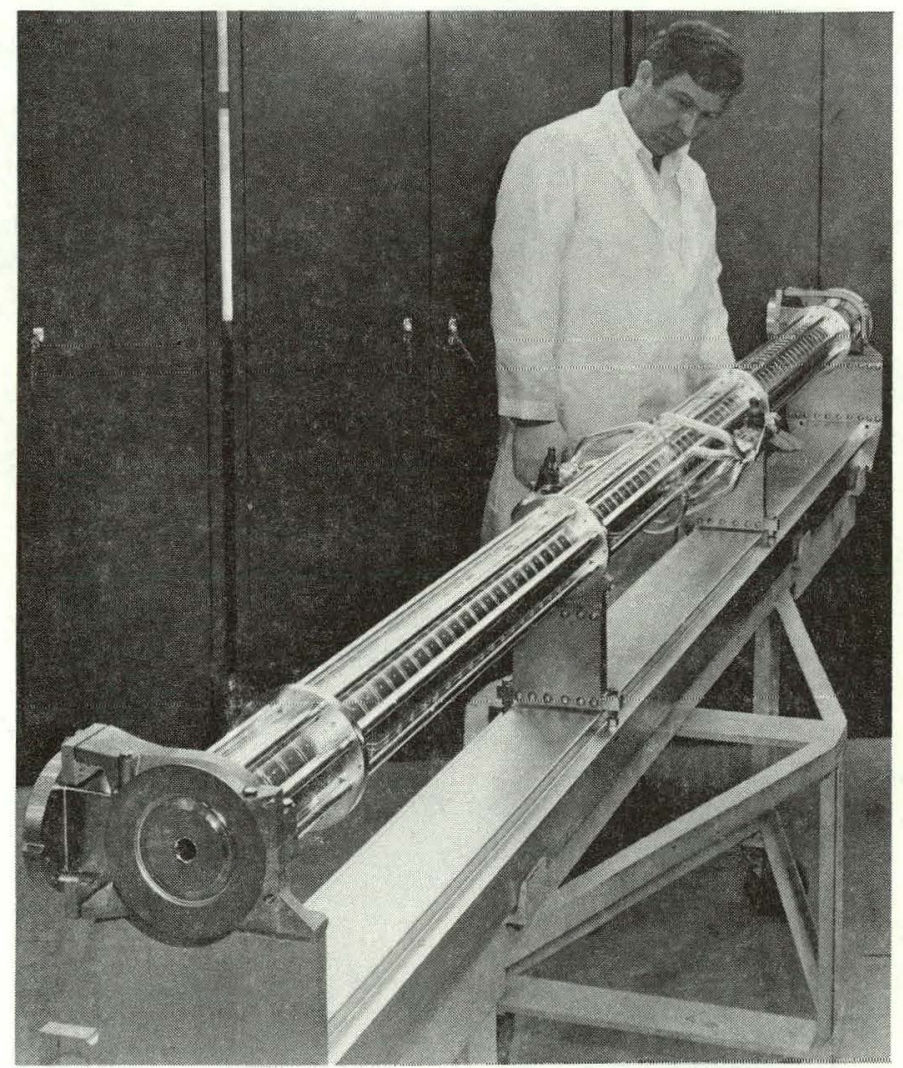

FIG. 41--One 10-foot section of the accelerator pipe showing the input and output rf couplers at each end and the small center-fed pipes forming the accelerator temperature control jacket. 
Every standard 10-foot section of accelerator tube is identical to every other. However, within each 10 -foot section, the disks and cylinders vary in dimension slightly. Thus the first cavity in each section is the same size as in all other sections, the second in each section is the same size as in all other sections, and so on. But along each 10-foot length, each succeeding cavity is smaller than its immediate predecessor. In all the early Stanford accelerators, all the cavities formed by the disks and cylinders were identical in size in the section. Calculations and experiments during the early stages of planning for the two-mile machine showed that improved pertormance would result by varying the cavitics within a 10 -foot length.

The transfer of energy from the rf wave to the electrons takes place along the entire length of the 10 -foot section, resulting in a decrease of $\mathrm{rf}$ energy along the pipe. The amount of energy transfer at any point depends upon the magnitude of the electric field of the $\mathrm{rf}$ wave along the axis at that point. As the wave travels through a uniform 10-foot section, the electric field strength decays. This means that further along the section, the field strength is less than the breakdown limit which the cavities would permit. However, with succeeding cavities made smaller, the electric field remains constant at its peak value, permitting a greater energy transfer to the electrons. In each 10 -foot section of the two-mile machine, the inside diameter of the last cylinder is a little over one percent smaller than that of the first cylinder. The diameter of the small hole in the last disk is nearly one-fourth smaller than that in the first disk. Sections employing this gradually tapered internal conical design ${ }^{1}$ are now installed in both the Mark III and the two-mile machine. The incorporation of these new sections in the Mark III resulted in as much as $20 \%$ more energy per foot being given to the electron beam.

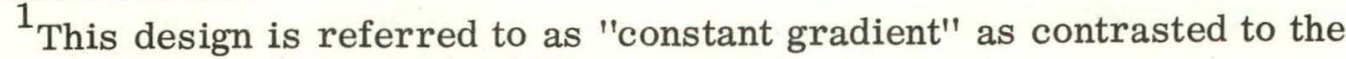
earlier "constant impedance" design.
} 
Some of the final dimensional tolerances of the cavities in the inside of the section must be held to \pm 0.00005 inch, better than can be achieved during machining . A final step in the fabrication of a 10-foot section, then, is a mechanical tuning. In the manufacture, the cavities are made just a little bit oversized to permit final sizing by deformation or squeezing. A radio wave is passed through the finished 10 -foot section. A plunger reaches into the section to measure the velocity of this wave through a cavity. If the internal dimensions of the cavity are not exact, the radio wave travels at the wrong velocity. Slow moving, automatically driven pneumatic plungers then gently press against that cavity at four equally spaced points on the outside. This begins to squeeze the cavity. When the radio wave is traveling at the exact velocity desired, the squeezing is stopped and that cavity is tuned. Each cavity in each 10-foot section was tuned in this manner.

Next, four 10-foot sections were assembled on top of a 40-foot-long aluminum pipe two feet in diameter (Fig. 42). The primary function of this larger pipe is to serve as a girder, providing rigidity and strength to the overall module. When all the auxiliary components had been assembled on the girder and after all laboratory adjustments and alignment had been performed, this 40 -foot modulc was slowly hauled out of the shop and down to the Accelerator Housing where it was placed on adjustable supports and flexibly coupled to the previously installed module. Over 240 modules were placed in the Housing in this way (Fig. 43). At the peak of fabrication and installation, SLAC was producing and installing one 40-foul module every working day. 


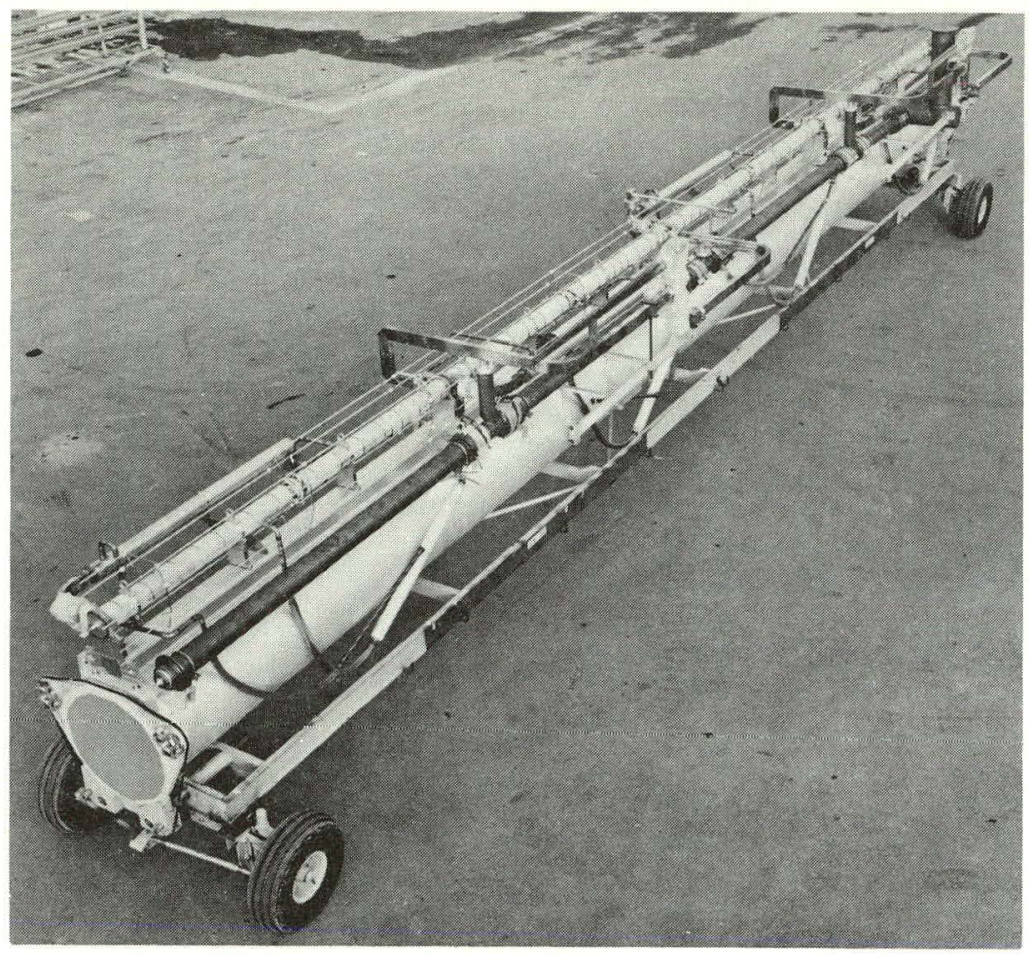

FIG. 42--A completed 40-foot module on the transporting rig ready to be taken to the Housing for installation. The accelerator is the smaller, uppermost tube. The large tube is the support girder. The small dark tube is a manifold for the vacuum system.

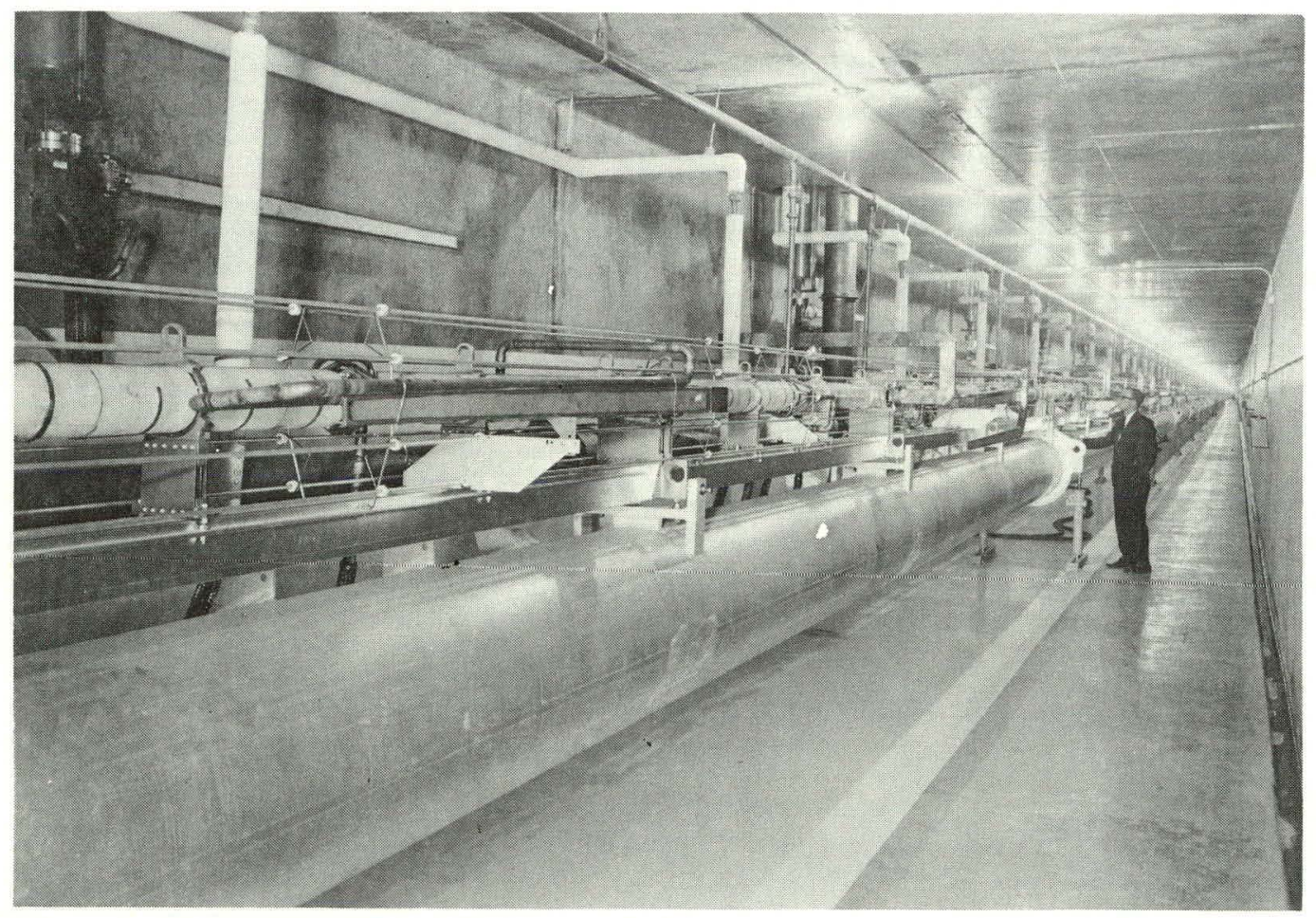

FIG. 43--The interior of the Accelerator Housing after installation of the accelerator. 


\section{AUXILIARY SYSTEMS}

A secondary, but not inconsequential, by-product of the development of such advanced devices as the two-mile accelerator is what the Federal Government refers to as "technological spinoff." To accomplish the formidable task of designing and building a complex installation requiring advancing the state of technology, many supporting systems and components must be developed which themselves are advances in modern techniques and capabilities. Each of these developments broadens the ability of industry and is usually applicable to other areas of endeavor. A great deal of research has gone into developing the several auxiliary systems required to make the accelerator a functioning reality. Most of these auxiliary systems and their components were supplied by industry. As a result, new techniques have become available to industry to apply to expansion of their capabilities.

\section{A. Injection}

Several requirements were placed on the design of the assembly which creates the electron beam in the first place and molds it into the proper form for acceptance by the accelerator. This assembly, the "injector," must first of all produce electrons in sufficient quantity to supply the required beam current. Then the injector must focus and aim the beam so that at least $80 \%$ of the inserted electrons reach the far end of the machine without striking the walls of the accelerator tube. This is because such striking would cause excessive radiation in the Housing and would thus necessitate reducing the beam current below the design requirement. Next the injector must bunch the beam; that is, the electrons must be speeded up and slowed down (as they are in a klystron) so that the appearance of bunches will coincide with the crests of the radio waves in the first accelerator section. Finally, the injector must preaccelerate the electrons up 
to a sufficient velocity where they are capable of being "caught" by the accelerating radio wave crests which travel at the speed of light.

The producer of the electrons is a relatively standard "electron gun." The electron gun is much like a triode vacuum tube. A hot-wire filament heats a surrounding cathode sleeve of some material, such as thoriated tungsten, which is a good emitter of electrons. The heat causes atomic electrons to "boil off" the cathode. These electrons form a cloud in space around the cathode. An anode (a plate having a positive voltage) attracts the electrons in the proper direction. Most of the electrons pass through an aperture in the anode and form a beam moving in the direction of the accelerator. A third element, called the "grid," lies between the cathode and the anode. This is a fine mesh screen which will allow the electrons to pass from the cathode to the anode unless a negative voltage is connected to it. Thus the grid can act as a switch, turning on and off the electron flow. In fact, this is done at SLAC to form the pulses of electrons. ${ }^{1}$ By controlling the amount of negative voltage applied to the grid and controlling the timing and direction of that application, the rate and direction of the electron beam pulses are controlled. This allows beams to be formed of various desired characteristics. In fact, alternate bunches can be made to differ from each other for varying applications.

The electrons from the electron gun have an energy of $80 \mathrm{keV}$. This beam then enters a "prebuncher," which is a oavity much like the first cavity in a klystron. ${ }^{2}$ Here initial rough bunching of the electrons takes place. This is

$1_{\text {The entire accelerator is "pulsed" so that electrons flow for a little over a }}$ millionth of a second between much longer dead times. During this millionth -ofa-second pulse, the electrons are formed into several thousand in-line bunches to coincide with the number of wave crests appearing during that time.

${ }^{2}$ Refer to Section VI-D: 
followed by a drift tube, again similar to that in a klystron, where the accumulation of bunching is allowed to proceed. Next the prebunched electrons enter a 10-centimeter-long buncher similar internally to an accelerator section, where a radio wave traveling at three-fourths the velocity of light further bunches the electrons and raises their energies to $250 \mathrm{keV}$. Finally, the electrons enter a standard 10-foot accelerator section where an accelerating wave is traveling at the velocity of light. Here final bunching takes place and electron energy is raised to $30 \mathrm{MeV}$.

The beam in the injector is focused to the proper spot size by a solenoid electromagnet, which surrounds the 10-centimeter buncher and the 10-foot accelerator section (Fig. 44), aided by various magnetic lenses and steering magnets along the injector. At the output of the injector, various devices monitor the characteristics of the electron beam as it is introduced into the accelerator proper.

B. The High Power Klystron

Over 240 high power klystron amplifier tubes are spaced along the two-mile Klystron Gallery to provide the radio waves to be inserted at regular intervals

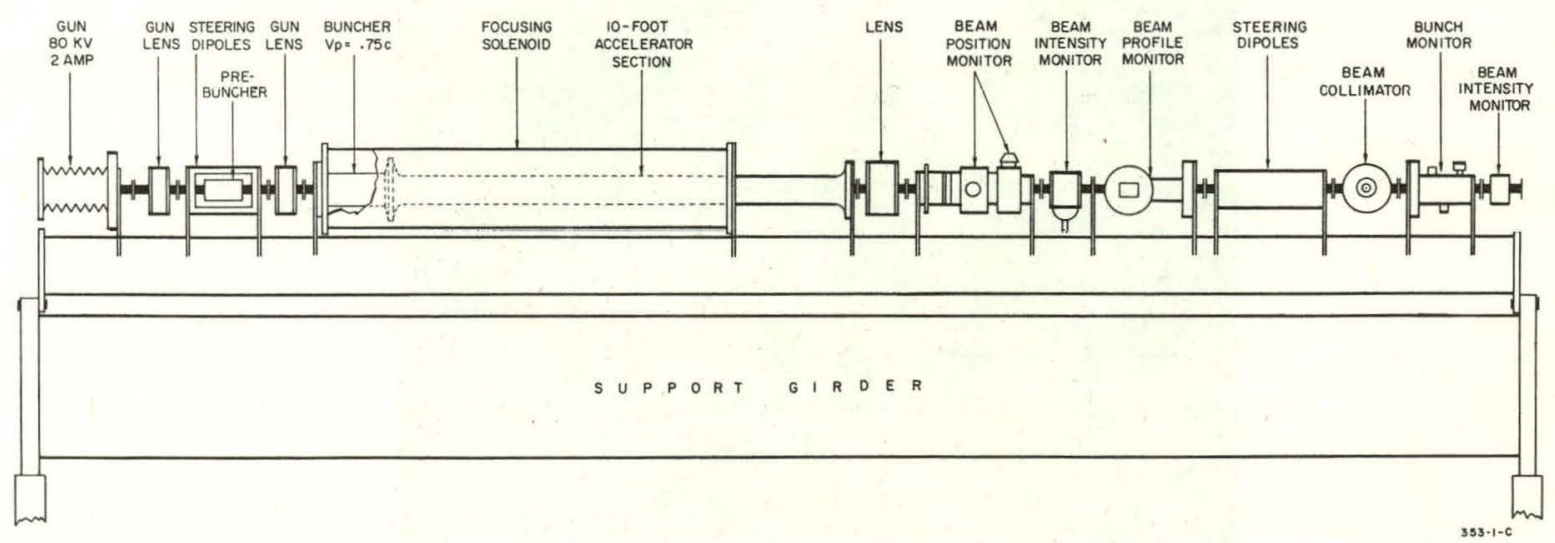

FIG. 44--Simplified diagram of the injector, showing major components. 
into the accelerator. These klystrons work on the same principle described earlier, in Section VI-D. However, instead of having just two resonant cavities, these klystrons have five. The three cavities between the buncher and the catcher refine the bunching of the electron stream. As the bunches reach the second cavity, this cavity is excited. Its oscillations narrow the bunches further. The third and fourth cavities do this again until the bunches reaching the catcher have been narrowed in space and time to result in a near single-frequency amplified output radio wave.

The high power klystron is installed in the Gallery in a vertical orientation. The cathode supplying the electrons is at the bottom (Fig. 45). The collector is

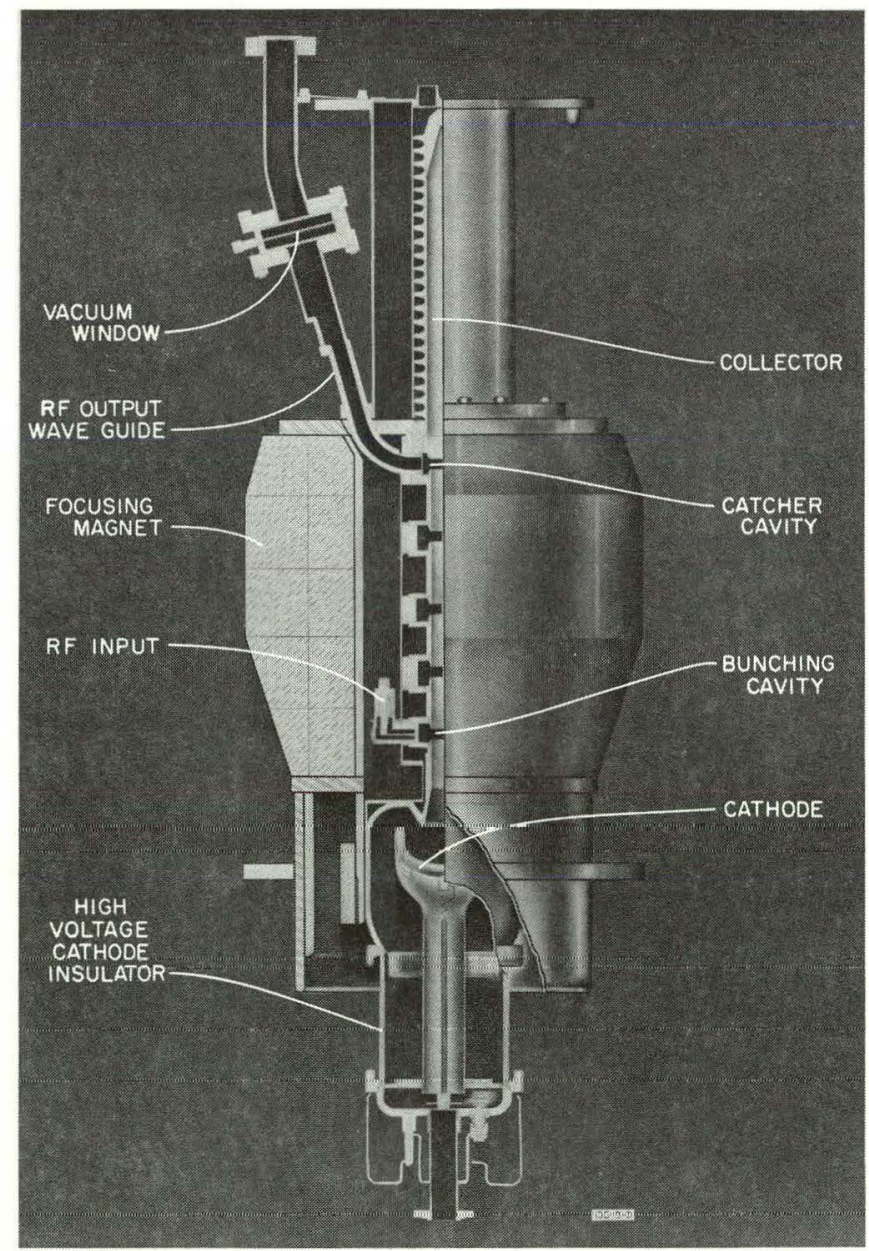

FIG. 45--Cutaway drawing of the SLAC high power klystron amplifier. 
at the top of the klystron. Surrounding the five cavities is a permanent magnet which serves to focus the electron stream to keep it from diverging from its narrow stream configuration. The klystron body and the collector are kept at ground potential. The high voltage $(-250$ kilovolts $)$ from the modulator, which switches the klystron on and off, is applied to the cathode at the bottom of the klystron via a connection through a ceramic high voltage insulator. The entire cathode structure is surrounded by an oil-filled tank to house the transformer which applies the high voltage pulses.

Because the vacuum inside the klystron is a permanently sealed one while that in the accelerator is continuously pumped, a "window" is required in the rf output line. This window permits the klystron to be evacuated by the manufacturer, shipped to SLAC, tested at the accelerator site, installed in the machine, and removed for maintenance or replacement without loss of vacuum. The window must maintain the vacuum in the klystron and yet permit the passage of $24-$ megawatt pulses of microwave power. The window is made of aluminum trioxide, sputter-coated with titanium. This has proved to be the best combination for lessening the probability of cracking of the window due to the passage of the pulses of radio power.

The design and fabrication of these klystrons was considered to be one of the most crucial tasks in the program. It was decided to undertake several development and manufacturing programs in parallel. Successful tubes meeting full specifications have been produced by four outside companies as well as by SLAC itself (Fig. 46). All of these tubes are electrically and mechanically interchangeable, amplifying a radio signal of 2856 megacycles per second to levels of between 21 and 24 megawatts. An installation of several klystrons in the Klystron Gallery is shown in Fig. 47. 


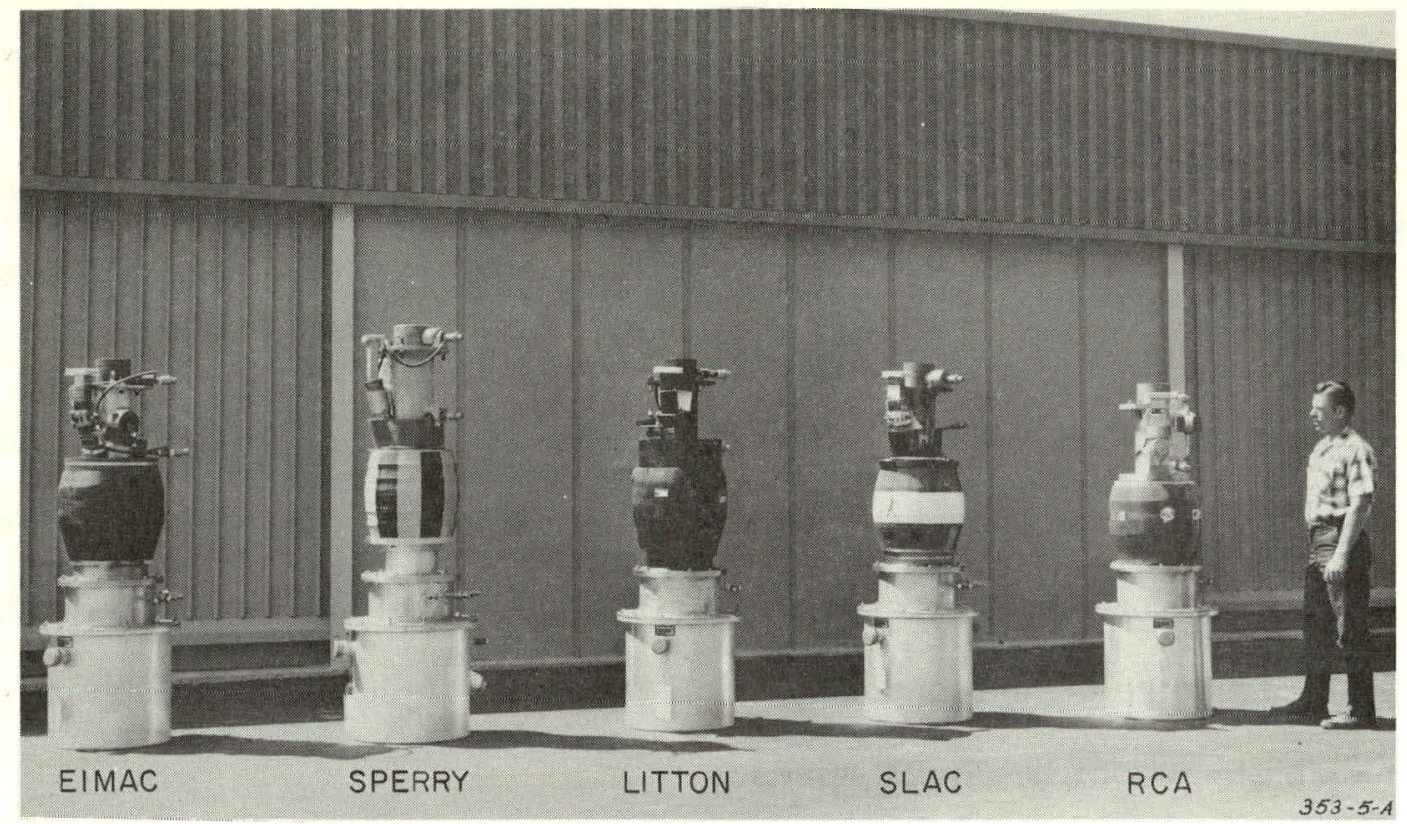

FIG. 46--Five of the high power klystrons, ready for installation, as manufactured by four different companies and by SLAC itself.

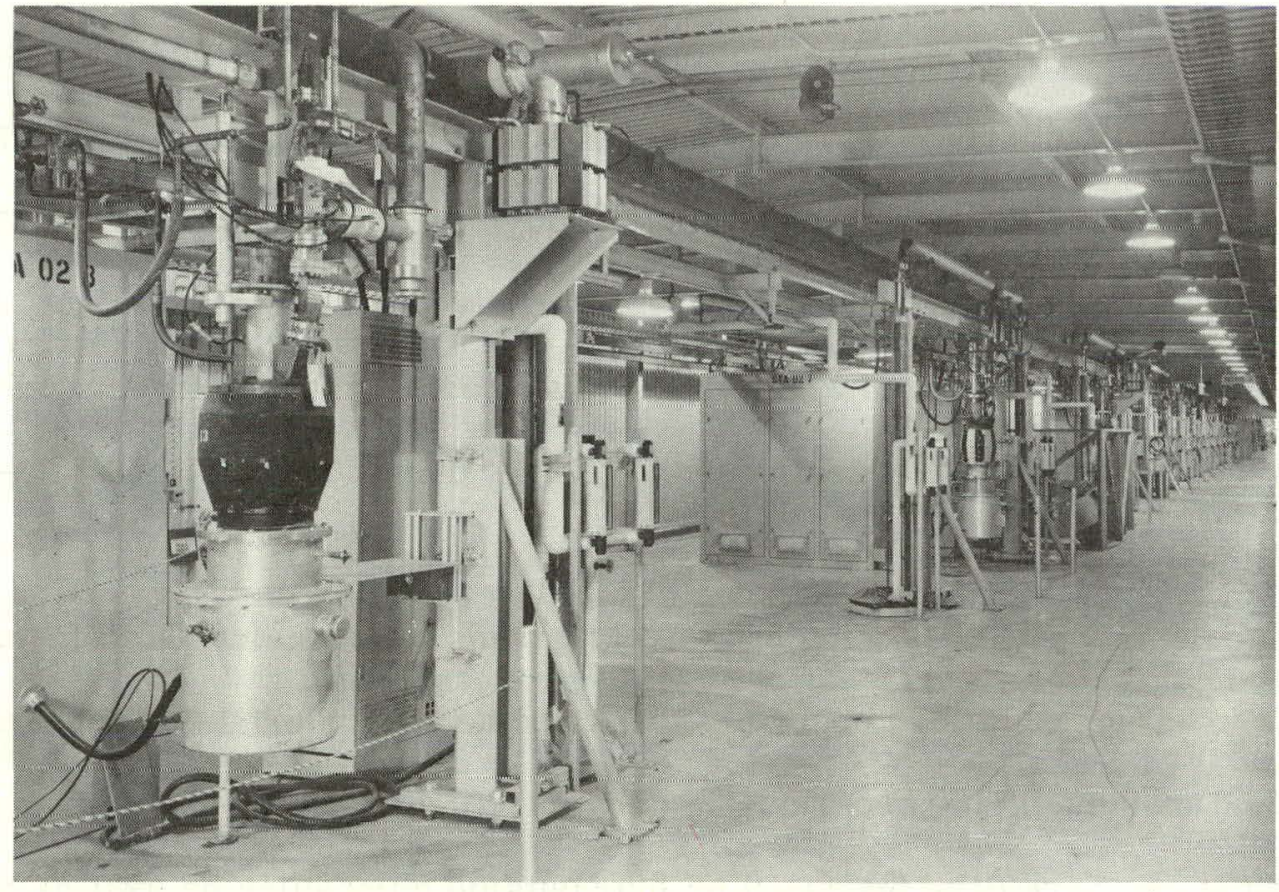

FIG. 47--The interior of the Klystron Gallery. The 40-foot installation, with its klystron, is repeated 240 times down the length of the machine. A vacuum pump is shown sitting on the small shelf above and to the right of the first klystron. The vacuum manifold is the long, dark pipe running along beneath the roof. 


\section{The High Voltage Mndulator}

Each high-power klystron must be turned on for 2.5 millionths of a second and then turned off. This occurs at a selectable rate of between 60 and 360 times per second. The device which accomplishes this switching is the high-voltage modulator. This is a large cabinet which houses the high current switching tubes, rectifiers to change the supplied alternating current to direct current, and the regulating circuits and components. There is one modulator associated with each klystron. The switching is done by the modulator alternately applying and removing the 250-kilovolt beam voltage at the klystron cathode.

\section{Trigger System}

To control the pulse rate of the accelerator, a master trigger signal is generated near the injector end of the accelerator. This 360-pulse-per-second signal is sent out to all stations in the machine, including the injector and the 30 control alcoves associated with the 30 sectors into which the accelerator is divided. Other separate control signals are sent from a central control room to each such station to tell each station which and how many of these signals to accept. Thus one sector may be operating at 360 pulses per second while another is operating, say, at 120 pulses per second. This means that some electron beam pulses can bc accelerated by more sectors than alternate beam pulses might be. In this manner, several different "interlaced" high-energy electron beams can be produced in the accelerator at the same time.

The trigger pulses which are delivered to the modulators to turn the kly- strons on and off last for 2.5 millionths of a second. The trigger pulses which turn the injector on and off are shorter. This permits each klystron to fill each

accelerator section with rf waves before the electrons in the beam start their trip.

Because the beam pulses are less than two millionths of a second long and because, through most of the accelerator, these pulses are traveling nearly at 
the speed of light, electrons are physically inside no more than about one-fifth of the length of the machine at any one time. This 2000-foot-long pulse of electron bunches moves down the machine, section by section. Therefore, the turning on of the klystrons must be accomplished in a sequence. This occurs almost naturally because the trigger pulses to activate the modulators also start at the injector end of the machine and travel at nearly the same velocity along the trigger line cable.

\section{E. Drive System}

The original rf signal which is to be amplified by all the high-powcr klystrons orginates in a single rf generator. The output of this oscillator is a 476-megacycleper-second radio wave. This is fed to a main booster amplifier which brings this signal up to a power level of 17.5 kilowatts. A coaxial cable distributes this rf power down the two-mile length of the machine.

Couplers in each of the 30 sectors of the accelerator remove about four watts of this rf power and deliver it to a frequency multiplier. These varactor frequency multipliers multiply the frequency of the $\mathrm{rf}$ wave to the final frequency of 2856 megacycles per second. At each sector, then, a pulsed sub-booster klystron amplifies this 2856 -megacycle signal to a power level of about 2400 watts. Another coaxial line distributes this power to the rf input connectors of the eight klystrons in that sector, resulting in about 300 watts of $\mathrm{rf}$ drive per high-power klystron.

\section{F. Phasing System}

The electrons in the beam arrive in each accelerator section, from the previous section, in bunches. In order for acceleration to take place in the new section, the radio wave from the klystron for that section must be so timed that its wave crests coincide (are "in phase") with the bunches of electrons. To assure that this is the case, a semi-automatic phasing system is associated with each klystron. 
Whenever it is deemed necessary to check or adjust the phase of the rf wave from a particular klystron, the pulsing of that klystron is delayed so that it appears after the beam pulse passes by. The bunches of electrons in the beam pulse themselves induce small oscillations in the accelerator section, much like those which are induced in the catcher of a klystron. These induced oscillations cause some loss of beam energy. The phase of these induced oscillations is determined by the timing of the bunches of the passing electron beam. The phase of this induced wave is compared with a reference phase, that of the rf wave in the main drive system. The relationship between the two is noted.

Next, the phase of the output of the klystron is compared to the same reference. The output of the klystron is then adjusted so that its relationship to the reference is exactly opposite to the relationship of the beam-induced wave to the reference. In direct opposition, the klystron output is properly adjusted to be most effective in making up the energy lost from the beam due to induced oscillations. When this is accomplished, the output of the klystron has been "phased" to produce the maximum acceleration in the beam in the accelerator.

\section{G. Beam Guidance}

Magnetic fields inside the Accelerator Housing could cause the electron beam to veer from pure linearity. Such fields result from the earth's magnetic field and from stray fields from mechanical and electrical sources. To compensate for these, each 333-foot sector of acclerator is surrounded by a set of vertical and horizontal degaussing coils. The degaussing currents in these wires are independently adjustable for each sector. The currents are programmed to counteract (or "buck out") existing magnetic fields with opposing fields. Then, to reduce cven further the difference between the natural fields and the counter field, the accelerator tube is wrapped in a magnetic shielding made of molypermalloy material, which reduces the remaining difference by a factor of 10 . 
At the end of each 333 -foot sector there is a 10 -foot special drift section containing special devices to locate and to guide the electron beam. This drift section includes a magnetic focusing lens, a set of steering magnets, a set of beam-position monitors, a beam-current monitor, a beam-profile monitor, a beam scraper, and two vacuum valves.

The beam-position monitors provide information regarding any horizontal and vertical displacement of the beam. The beam-current monitor measures the number of electrons per second in the passing beam. The beam profile monitor is remotely insertable in the beam path and measures the relative concentration of electrons at each point in the beam's cross-section. The beam scraper permits only the proper central portion of the beam to pass and stops the diverging electrons at the edges; this protects the accelerator itself from eventual bombardment by these diverging electrons and localizes radiation to the scraper area. The two vacuum valves, one at each end of the dift section, permit the isolation of one sector from the next if desired.

\section{H. Support and Alignment}

As described earlier, each rigid accelerator module is 40 feet long and is connected to the next module via flexible bellows -like couplings (Fig. 48).

One end of each module rests upon three adjustable worm-screw supports, two bolted to the floor of the Housing and one to a wall (Fig. 49). The other end of this module rests in roller bearing pin-sockets in the supported end of the next module. Thus each 40-foot joint can expand, be raised, bo lowered, be moved to one side, or be rotated.

In order to be able to determine the relative straightness of all 240 such modules, a beam of optical light is used as a reference. This beam of optical light is transmitted from one end of the accelerator to the other. The accelerator 


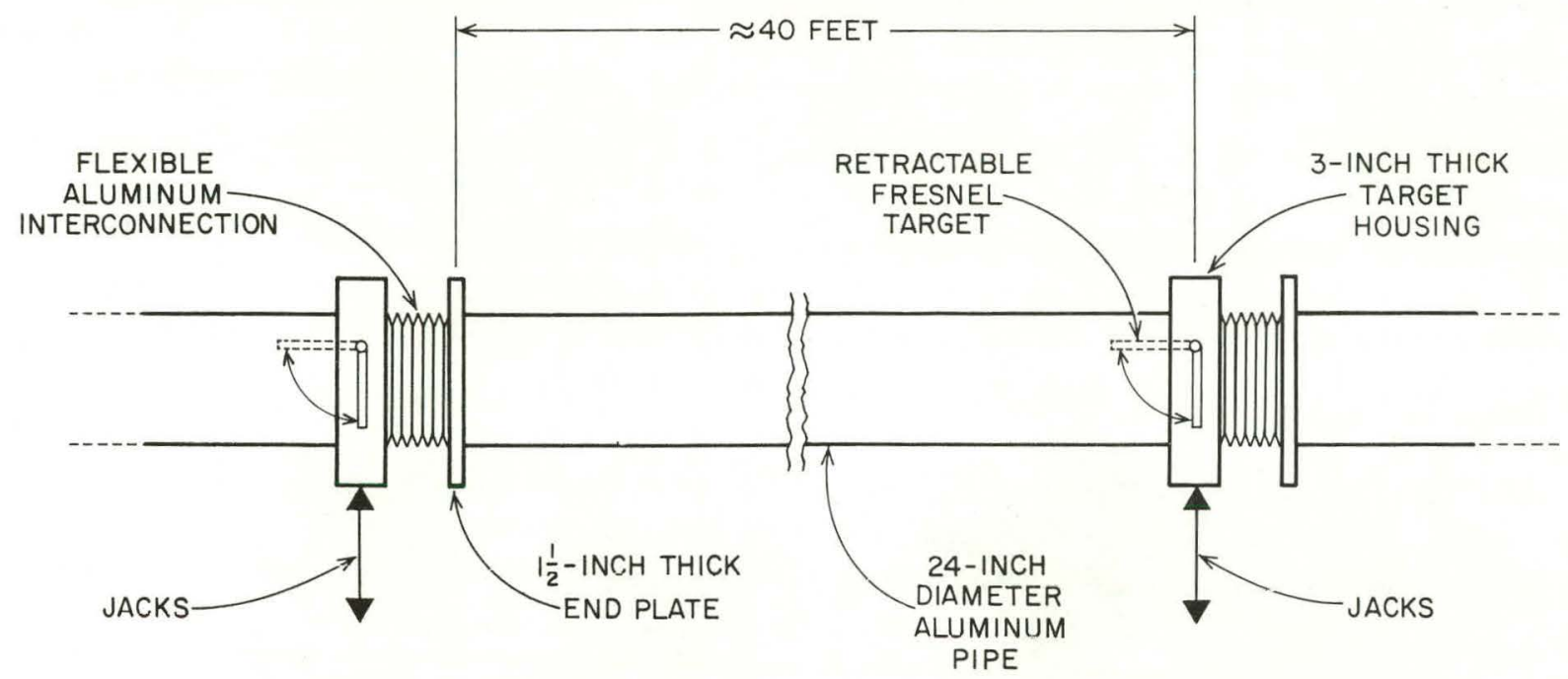

FIG. 48--Each 40-foot-long accelerator girder is loosely coupled to the next with a flexible bellows arrangement.

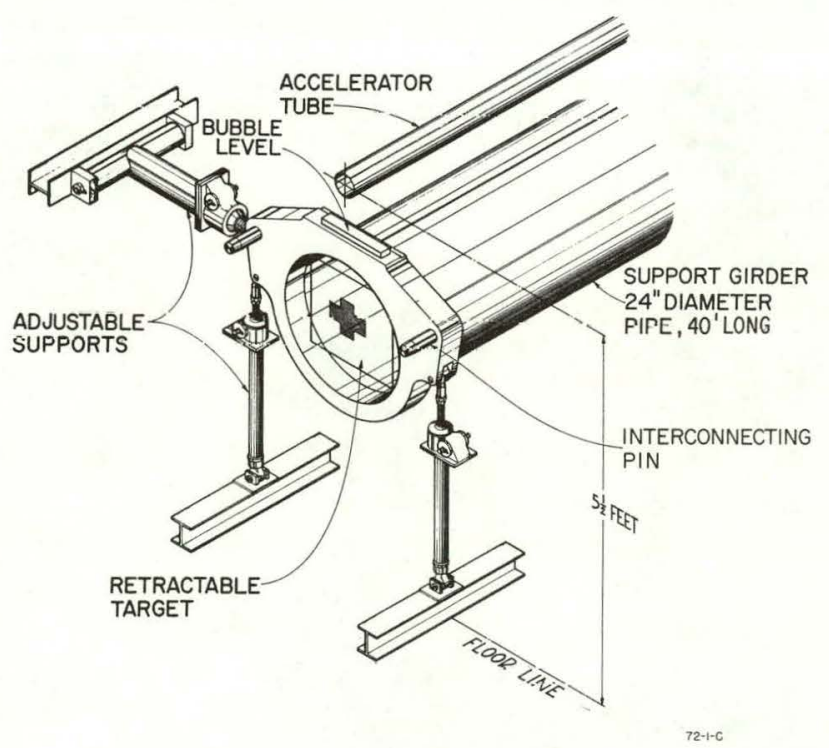

FIG. 49--One end of each 40-foot long girder rests upon three adjustable worm-screw supports.

pipe itself could not be used to transmit this light beam, first because its small diameter would produce diffraction effects in a beam of light, and second because the mechanical alignment monitoring devices needed would burden the accelerator pipe's primary function. 
It was decided to utilize the two-foot-diameter support girder for the transmission of the reference optical light beam. Visible light from a gas laser "point" light source is admitted to the 24 -inch pipe at one end of the two-mile-long assembly. An observation system is located at the other end of the assembly, two miles away. Near each 40-foot coupling point and support set, an etched grating target plate is housed inside the 24 -inch pipe (Fig. 50). This target is hinged at

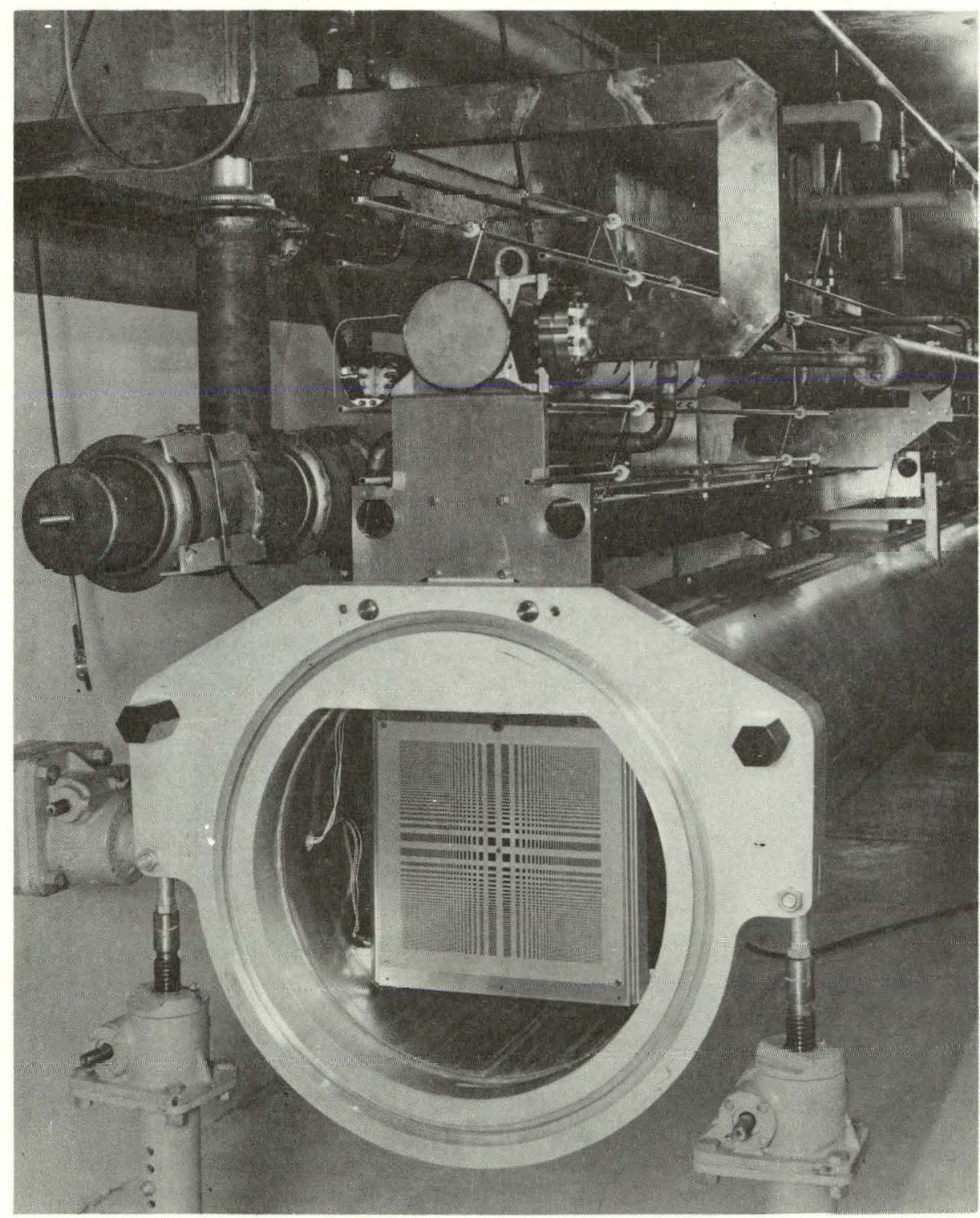

FIG. 50--A retractable Fresnel zone plate target is housed within each 40-foot-long girder to intercept the laser light beam and provide alignment indication. 
the top and is normally stowed in a horizontal position. When alignment is underway, this target can be swung into the vertical position in the path of the laser light beam. Observation of the diffraction-interference phenomena produccd by the grating in the path of the light provides minute indication of the alignment of the accelerator at that point. By dropping one target at a time and adjusting the supports under that target, alignment of the accelerator is achieved in a stepby-step fashion.

The above procedure aligns all the girders in the accelerator. The accelerator tube sections themselves have been previously optically aligned to the girders during assembly in the laboratory.

\section{Vacuum System}

In order to perform its function unimpeded, an electron beam must be permitted to travel through as good a vacuum as possible. Air molecules and other residual gases in the way would result in collisions, radiation, and a degraded beam. For instance, the electron beam inside the klystrons which amplify the accelerating radio waves passes through a vacuum of $10^{-8} \mathrm{~mm} \mathrm{Hg}$. This vacuum. is pumped in the klystrons after manufacture and then the klystrons are permanently sealed against the incursion of air. In fact, one of the causes of breakdown in a klystron, as in any vacuum tube, is outgassing from the materials inside the tube.

For the same reasons, the interior of the accelerator must also be evacuated. However, this four-inch-diameter, two-mile-long cylinder is a little more difficult to evacuate and to maintain under the required vacuum of better than $10^{-6} \mathrm{~mm} \mathrm{Hg}$. For this reason the accelerator is continuously pumped; that is, once a vacuum is attained, the vacuum pumps are kept pumping to keep removing airs and gases which might appear inside the tube. 
To accomplish this, the accelerator has been divided into 30 sectors, each served by an independent vacuum subsystem. The 30 subsystems are interconnected only via the open accelerator itself. The following paragraph describes just one of these thirty subsystems.

Alongside the accelerator itself, there extends a five-inch-diameter cylindrical manifold, 330 feet long (Fig. 42). This manifold exhausts the accelerator by tapping into it at each ten-foot $\mathrm{rf}$ feed point. Air drawn from these points thus evacuates both the accelerator and the waveguides delivering the radio energy from the klystrons, all of which cumprise a continuous vacium envelopo. Air drawn into the vacuum manifold at these points is carried upstairs to the Klystron Gallery via four 8-inch-diameter cylindrical "fingers," spread roughly equally apart. These four fingers then exhaust to an 8-inch-diameter horizontal cylindrical manifold running along the sector of the Klystron Gallery (Fig. 47). This manifold is also connected to the rf output waveguides above each klystron to aid in the evacuation of the system at this upper reach. Four getter-ion type vacuum pumps, rat.er at 500 liters per'second and $10^{-9} \mathrm{~mm}$ Hg at their input ports, exhaust this manifold to air.

The getter-ion pumps begin their pumping after a portable rough pumping system has evacuated the accelerator down to between $10^{-3}$ and $10^{-4} \mathrm{~mm} \mathrm{Hg}$. This same rough pumping system is also used to re-evacuate the connecting waveguide between the output window of a newly replaced klystron and the temporily valved-off waveguide of the accelerator system.

The 24-inch-diameter alignment girder must also be evacuated so that the laser beam will not be degraded by refraction. A set of vacuum pumps in the Klystron Gallery, connected to the girder interior via a 24 -inch pipe, maintains a vacuum in the alignment passage of about 100 microns. 
A separate vacuum system has been installed above the beam switchyard to maintain a vacuum in the many large vacuum chambers therein of about $10^{-4} \mathrm{~mm} \mathrm{Hg}$.

\section{J. Temperature Control System}

A great deal of electric power is used in the accelerator and generates a great deal of heat in the components through which it passes. Three areas in particular are sensitive to this power dissipation.

The cavities inside each 10 -foot accelerator pipe section must be held to very strict dimensional tolerances, some to within 50 millionths of an inch, in order to control the velocity of the accelerating radio wave. If these sections change temperature because of varying heat dissipation, the natural expansion and contraction of copper under temperature changes would violate the requirement for dimensional stability.

The radio waves from the master oscillator, through the booster klystrons and the high power klystrons, and through the penetrating waveguides down to the accelerator, must arrive at the accelerator in the proper phase to match the bunching of electrons. The radio wave through each high power klystron is carefully adjusted to accomplish this. Should the lines and waveguides carrying the radio waves change dimensions with temperature changes, the radio waves will change velocity and arrive at an improper phase.

The collectors in each klystron must dissipate as much as 74 kilowatts of power as the internal klystron electron beam terminates at the collector. If this heat were allowed to build up, the collector would become damaged.

To remove the heat from these components before temperatures can build up, 70 independent water cooling subsystems have been installed in the Klystron Gallery. Each of these subsystems includes a return header to receive heated 
water from the cooled components, a surge tank to supply extra water for smooth flow as necessary, a pump to circulate the water, a filter and a demineralizer to purify the water, a heater ${ }^{1}$ to permit heating of the water to the initial design temperature if necessary, a heat exchanger to permit cooling of the water by transfer of heat to a second water system feeding a cooling tower, a blending valve to control the temperature of the water to be resupplied to the components, and a supply header to feed the supply lines (Fig. 51).

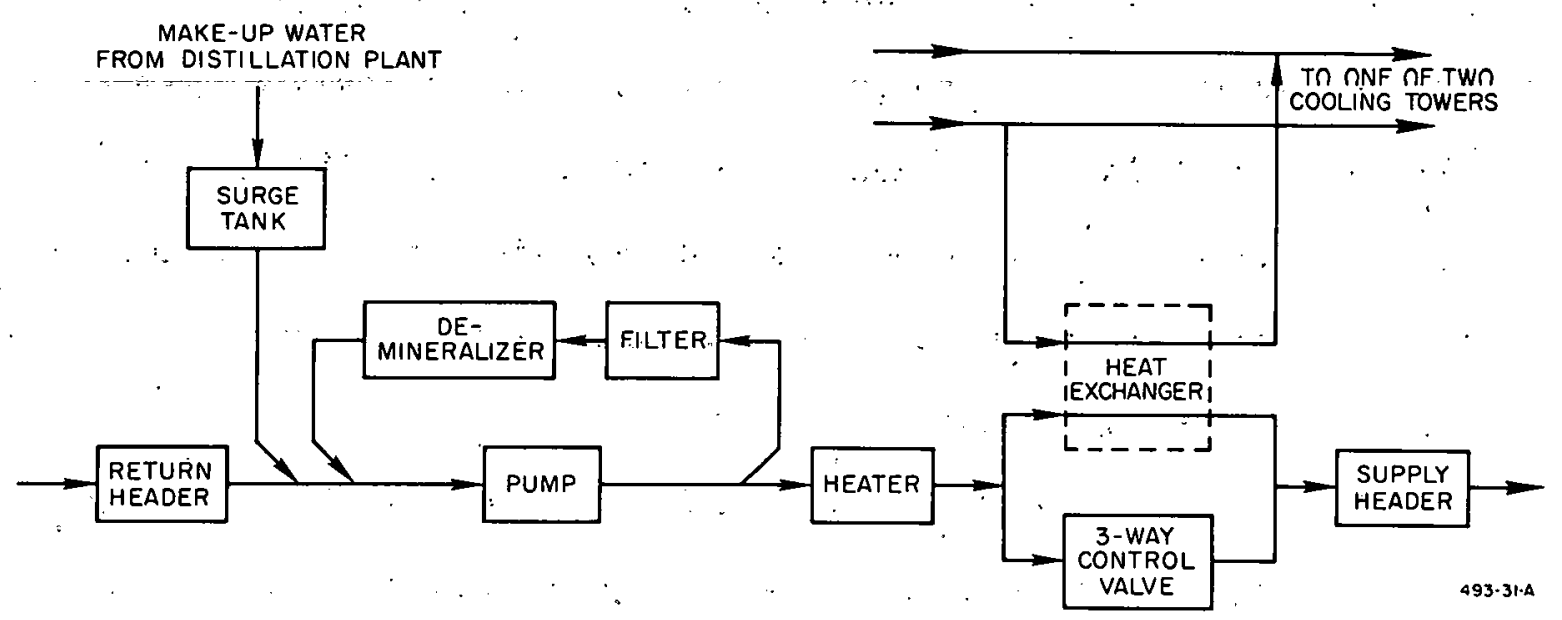

FIG. 51--Typical block diagram of one of the 70 closed-loop recirculating water.systems for the accelerator and its components.

$\therefore{ }^{1}$ The heater is not included in the water subsystems controlling klystron temperature. 
On the south side of each sector of the Klystron Gallery, an equipment alcove has been built to house these components of these subsystems. Each of these 30 sector alcoves contains one of these water subsystems to supply cooling water to the accelerator section water jackets (Fig. 41) in that sector at a nominal temperature of $110^{\circ} \mathrm{F} \pm 0.2^{\circ} \mathrm{F}$ but adjustable over the range of $95^{\circ} \mathrm{F}$ to $120^{\circ} \mathrm{F}$. Each of these 30 sector alcoves also contains a second of these water subsystems to supply water at $112^{\mathrm{O}} \mathrm{F} \pm 1^{\mathrm{O}} \mathrm{F}$ to control the temperature of the rf lines and waveguides in that sector.

Every third sector alcove also contains a third such water subsystem. This subsystem supplies cooling water to the 24 klystrons in the associated three sectors to maintain klystron temperature no higher than $158^{\circ} \mathrm{F}$. Thus 20 of the sectors contain two water subsystems and 10 of the sectors contain three.

The water system is the double closed-loop type. Water brought up from the cooled components is treated, restored to temperature, and returned to the components to repeat the job. The heat from this water is transferred via a shell-and-tube heat exchanger to a second loop of water which circulates through an extcrnal cooling tower and back. There are two cooling towers, one serving all the subsystems in the eastern half of the machine and one serving the western half. 1

Some water will be lost from these systems due to natural evaporation, leakage, etc. Make-up water to each surge tank is supplied from a distillation plant on the site which in turn is supplied by thelocal metropolitan water system.

\section{K. Electrical System}

When the accelerator was under construction, it was supplied electricity over a temporary 60,000-volt transmission line. After beam turn-on and in

\footnotetext{
${ }^{1}$ There are two more cooling towers at SLAC, one serving a water system in the laboratory buildings and one serving the beam switchyard and end station area.
} 
order to operate the beam at its full capabilities, more electricity was required than could be supplied by that line, as much as 80,000 kilowatts. In addition, as experiments with the beam become more complex in years to come and larger experimental apparatus is required, it is estimated that eventually as much as 300,000 kilowatts of electric power may be required.

To supply this electricity, a very high voltage (220,000 volts) transmission line has been constructed to a nearby high capacity transmission line. This power line has been constructed using a relatively new design of pole structure, single tubular poles averaging seventy feet high and painted to match the landscape (Fig. 52). Because this new type of pole is capable of bearing only one 3 -wire circuit, instead of the two carried by conventional four-legged towers, the original temporary 60,000 -volt line is being retained to supply emergency power in case of an outage on the main line.

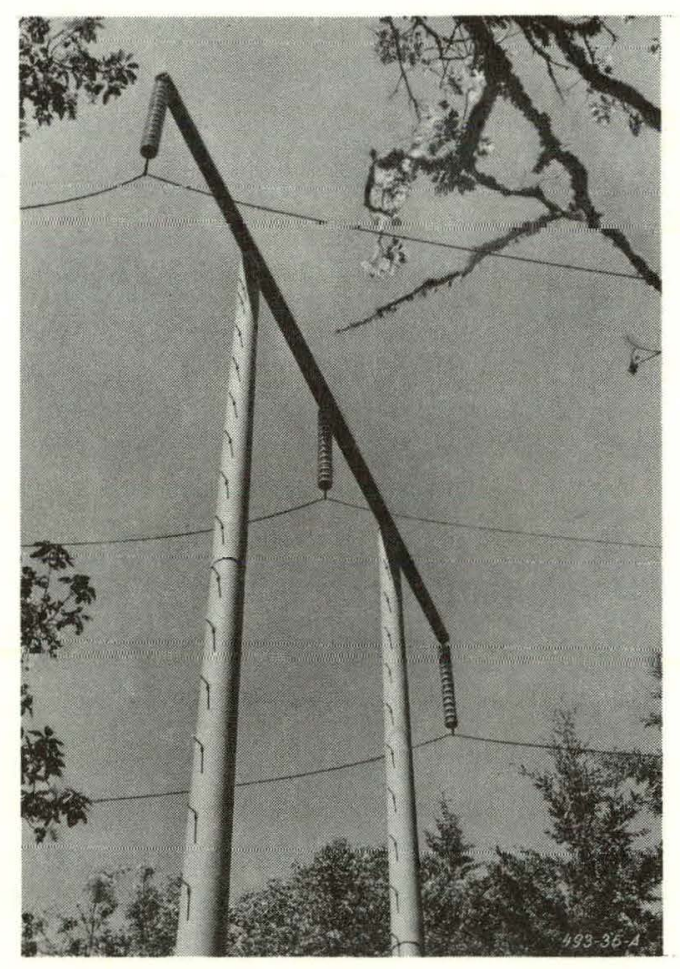

FIG. 52--One of the pole structures in the SLAC highvoltage transmission line. 
This high voltage power is brought to a substation near the output end of the accelerator, where its voltage is stepped down to about 12,000 volts for distribution over the site. All these distribution lines have been placed underground.

\section{Instrumentation and Control}

Along the north side of the Klystron Gallery, at each of the 30 sectors, an alcove has been built to contain various instrumentation and control devices for that sector. In this alcove, initital setting up and adjustments of the components in the sector are made. Also here, from time to time, maintenance and operating adjustments can be performed. However, in normal satisfactory steady operation of the accelerator, these control alcoves will not be manned.

All essential instrumentation and control information is transmitted to a Central Control Building near the east end of the accelerator. Monitoring and control of the accelerator and the beam switchyard are performed in this building remotely. In case of necessity, the engineer-in-charge can dispatch operators and maintenance personnel to Klystron Gallery sectors requiring attention. Thus the operation of the entire machine is supervised from the one control point. The job of the people in this building is to assure that the proper desired beam is delivered to the end station area. 


\section{USING THE ACCELERATOR}

The beam from the two-mile machine exits at the east end of the accelerator and enters a 1000-foot-long "beam switchyard" (Figs 4 and 53). The beam switchyard is an extension of the underground Accelerator Housing and lies in the same horizontal plane as the end of the Housing. In order to direct the accelerated beam to any of selected research areas, the beam switchyard gradually becomes wider toward its output end. In this beam switchyard, huge electromagnets process and direct the beam into experimental areas located in two target buildings. Because processing of a curved electron beam results in more radiation than does the motion of a linear beam, the beam switchyard is covered with 40 feet of shielding earth and concrete.

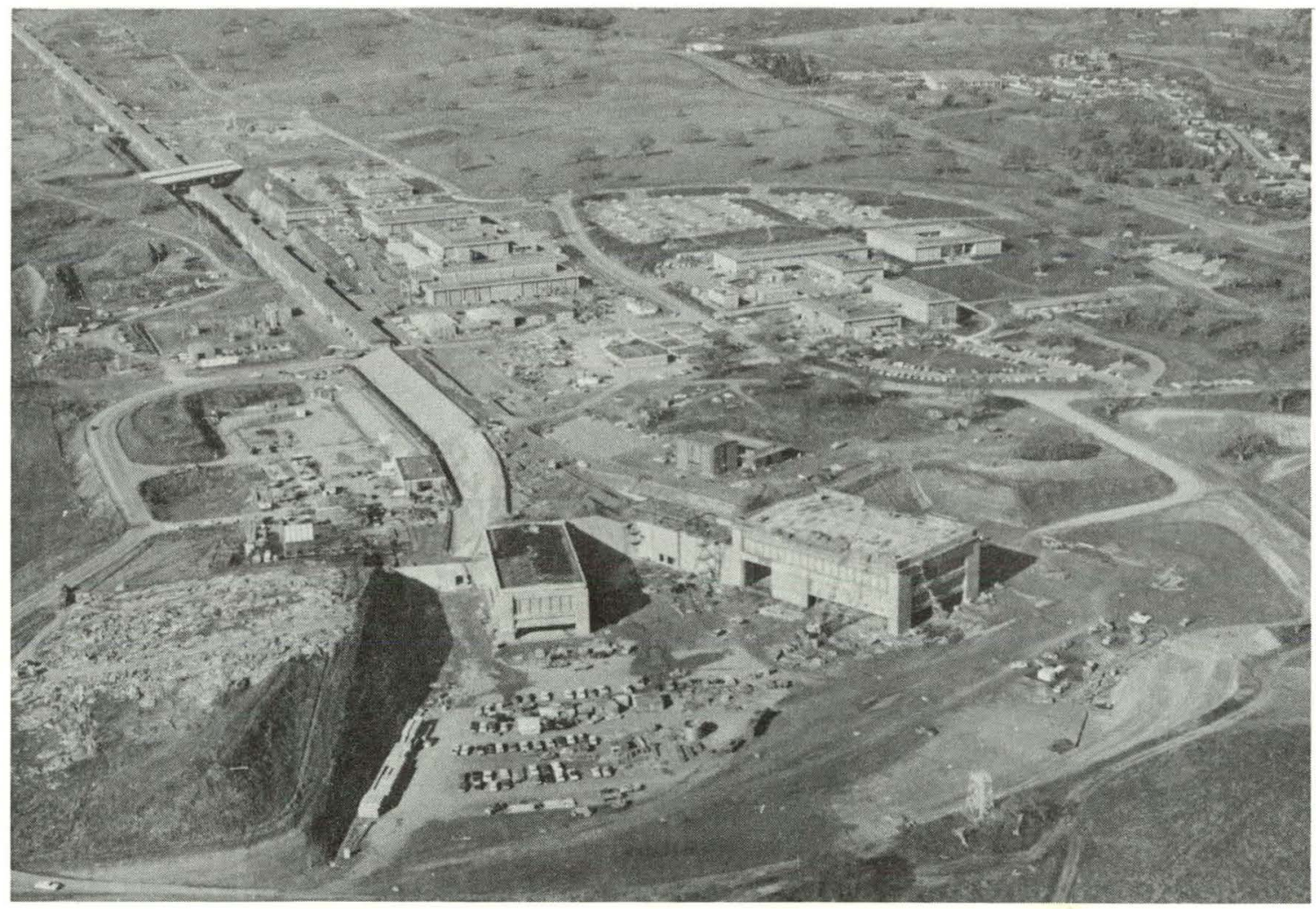

FIG. 53--The research end of the accelerator. The fork-shaped beam switchyard, under 40 feet of earth shielding, directs the accelerator beam to the desired experimental area in the two end station target buildings. 
The larger of the two target buildings is a single room with 25,000 square feet of floor space. Its concrete walls are over 70 feet high. It is in these two target buildings, and in an auxiliary 20 -acre open area behind these buildings, that the results of directing the electron beam on a nuclear target are studied.

When a high energy electron is caused to travel through some target material and passes within nuclear dimensions of a target nucleus, one of two things can happen. An electromagnetic interaction between the electron and the nucleus can cause the electron to veer off in its path at some angle while the interacting nucleus recoils at a different angle. This phenomenon is called "elastic scattering. "The other thing that can happen is similar except that during the interaction, some of the kinetic energy of the bombarding electron is lost and some new and different elementary particles eventually emanate from the point of interaction. This phenomenon is called "inelastic scattering."

The smaller of the two target buildings, End Station B, was designed to specialize in the analysis of the "secondary" particles produced from such inelastic interactions. In this target building, the accelerated electron beam is used to produce secondary beams of new particles for observation and study. The variety_ of secondary particles created in this way depends upon the energy of the approaching electron. The quantity of secondary particles produced in a given time depends in addition upon the number of electrons (the current) in the bombarding beam. The Stanford two-mile beam is unique in the combination of these two parameters. Its $20-\mathrm{GeV}$ electrons have three times the energy of those from the next highest energy electron accelerator. The beam current is 300 times higher. In light of these advantages, some of the first experiments planned for use of the two-mile beam involve creation and study of secondary particles. For instance, in one'series of experiments the electron beam will bombard a thick 
copper target at the entrance of End Station B. The interactions in the target will cause all kinds of secondary particles to be produced. Magnet systems will direct these into a separation system which will stop all particles except one kind called "muons." The muon is a short-lived secondary particle which appears to be much like an electron only heavier. The resultant muon beam will then be directed into a cylinder of liquid hydrogen surrounded by a large spark chamber assembly. The spark chamber assembly itself is contained within a gigantic 200ton electromagnet.

When the muons approach the hydrogen nuclei, they produce interactions and are scattered off in all directions. As these scattered muons pass through the spark chamber, they create high-voltage lightning-like discharge sparks along their paths which can be photographed. The surrounding magnet serves to curve the path of the scattered muons by an amount which depends on their energies. Analysis of the photographs of the curved trajectories thus provides knowledge of both the direction of motion and of the energy of the scattered particles. This in turn leads back to further understanding of the interaction of the muon and the hydrogen nucleus responsible for the scattering.

Some of the same apparatus is used to investigate the possibility that accompanying the muons there are other as yet unknown elementary particles which are similar to the muon, differing perhaps only in mass.

Another team of experimenters from the University of California plans an investigation aimed at the achieving, by special separation processes, of a beam made up exclusively of particles known as $\mathrm{K}$-mesons, one of the family of "strange" particles. The University of California is modifying and enlarging its 72-inch-diameter bubble chamber for installation in this $\mathrm{K}$-particle beam. As $\mathrm{K}$-mesons pass through the liquid hydrogen of the bubble chamber, they leave 
behind fine tracks of bubbles. Similar tracks are produced by other particles if the K-meson suffers a violent collision with a hydrogen nucleus. Photographs of these bubble tracks then give a graphic record of the nuclear event. Analysis of millions of such photographs provides detailed information about the interaction processes, leading to further understanding of the $\mathrm{K}$-meson and its progeny.

SLAC is building another bubble chamber to be installed behind End Station $B$ to receive a beam of high-energy $\mathrm{x}$-rays produced by the electron beam and to study the interactions between $x$-rays and the nuclei of the hydrogen in this bubble chamber.

Other research to be carried out with the new accelerator will extend measurements of nuclear size and structure carried out during the past fifteen years at Stanford with the University's 300-foot-long, 1-GeV Mark III. To perform this analysis, the larger of the two target buildings, End Station A, is equipped with three huge spectrometers. The largest of the three is over 150 feet long and weighs over 3000 tons. These spectrometers can be swung around an axis and are set at various angles from the line of the bombarding beam in order to accept particles scattered at particular angles. Magnets in the spectrometer then separate out all particles except those having a particular energy and electric charge. By electronic means, particles of a particular energy are then identified with respect to their mass. The result in each spectrometer is a tally of the number of particles of a unique kind scattered at a unique angle.

The three spectrometers are of different sizes and thus cover different ranges of scattering energies. With these three each covering a wide arc and analyzing many scattering angles successively, a complete picture of the results of an interaction can be obtained. In the process of elastic scattering, the electrons scatter off at each angle with a unique energy for that angle. This energy, 
which of course also depends upon the energy given the electron by the accelerator, can be calculated. In inelastic scattering, because energy has gone into creation of other kinds of particles, total interaction energy is reduced. This means that inelastically scattered electrons can have different amounts of energy at a particular angle and that those energies are always less than the energy of an elastically scattered electron.

Setting a spectrometer to receive only particles having the energy permitted with elastic scattering provides data for understanding that kind of action. Setting a spectrometer to discriminate againstparticles having the energy of elastic scattering provides information about the inelastic scattering process. Not only can the scattered electrons be studied, but so can the secondary particles produced.

In the study of elastic scattering, in order to be able to relate the experimental results just to the characteristics of the little-known nucleus and not to those of the better understood electrons, the process will be repeated using a beam of positrons, which are electrons of positive charge. To do this, a "positron source" has been placed in the path of the two-mile electron beam at a point about one-third of the way down the machine. Electrons accelerated in the first third of the accelerator strike a target. Among the secondary particles which emanate from inelastic collisions there are many positrons. These positrons are then accelerated down the remaining two-thirds of the accelerator. The resulting high-energy positron beam is delivered to the target in End Station A and the spectrometers are set to monitor the elastic scattering of the positrons. Comparison of this data with that obtained from elastic scattering of electrons permits the scientist to separate the experimental effects of the bombarding particle from the experimental effects of the nucleus being studied.

Not only will large spectrometers be used to study the yield of secondary particles resulting from inelastic collisions, but also a huge spark chamber is 
being constructed for similar purposes. By directing the electron beam into a thin metallic sheet, a copious beam of high-energy $x$-rays is produced. These $\mathrm{x}$-rays will be directed to a gaseous hydrogen target cylinder located inside the special spark chamber. The $\mathrm{x}$-rays interact with the hydrogen nuclei and produce violent events from which emerge several secondary particles. As these secondary particles emanate from the collision target they spread through the spark chamber leaving momentary visible lightning-like tracks. Three cameras are used to photograph these tracks in three dimensions, resulting in a stereo presentation of the complete interaction.

These are just a few of the types of experiments planned for the new accelerator for the first year of its use. Scheduling cannot be done much more than a year in advance. "Elementary particle physics" is still in a dynamic state. Each year new discoveries mean re-oriented thinking. This in turn requires the design of newer experiments previously not imagined.

One of the excitements of this new science is that the future is so unknown. Throughout the short history of accelerator development, many accelerators have often turned out to be the most dramatically effective in areas not even known about at the time of their original conception. Elementary particle physics stands at the fruntier of man's knowledge. As Professor W.K.H. Panofsky, Director of the Stanford Linear Accelerator Center, has said, "All other physical sciences, and probably all life sciences, must ultimately rest on the findings of elementary particle physics. It would indeed violate all our past experience in the progress of science if nature had created a family of phenomena which governs the behavior of elementary particles without at the same time establishing any links between these phenomena and the large-scale world which is built from those very particles . . . We cannot afford to be ignorant of the most fundamental type of structure on which everything else depends." 


\section{BIBLIOGRAPHY}

\section{Books}

1. Borghi, R. P., et al., "Design and Fabrication of the Accelerating Structure for the Stanford Two-Mile Accelerator," in Advances in Microwaves, ed. L. Young (Academic Press, New York, 1966).

2. Ford, K. W., The World of Elementary Particles (Blaisdell Publishing Co., New York, 1963).

3. G. Gamow, The Atom and Its Nucleus (Prentice-Hall, Englewood Cliffs, New Jersey, 1961).

4. Heckman, H. H. and P. W. Starring, Nuclear Physics and the Fundamental Particles (Holt-Rinehart-Winston, New York, 1963).

5. Livingston, M. S. and J. P. Blewett, Particle Accelerators (Mc Graw-Hill Book Company, Inc., New York, 1962 ).

6. Panofsky, W.K.H. , "Particle Accelerator," McGraw-Hill Encyclopedia of Science and Technology (McGraw-Hill Book Company, Inc., New York, 1960).

7. Wilson, R. R. and R. Littauer, Accelerators: Machines of Nuclear Physics (Doubleday-Anchor Books, Garden City, New York, 1960).

\section{Journal Articles}

1. Alvarez, L. W., et al. , "Berkeley Proton Linear Accelerator," Review of Scientific Instruments $\underline{26}, 111$ (1955).

2. Becker, G. E. and D. A. Caswell, "Operation of a Six-MeV Linear Electron Accelerator, "Review of Scientific Instruments 22, 402 (1951).

3. Chodorow, M. , et al., "Stanford High-Energy Linear Electron Accelerator (Mark III)," Review of Scientific Instruments 26, 134 (1955).

4. "Contractor Casts 2-Mile Tunnel With 80-Foot-Long Ganged Forms," Engineering News Record 172, 82 (June 18, 1964). 
5. Dupen, D. W. , "SLAC's Tiny Universe," Stanford Review LXVI (No. 2), $18(1964)$.

6. Dupen, D. W. , "Stanford's Long, Long Beam," New Scientist $\underline{30,} 296$ (1966).

7. Ginzton, E. L., W. W. Hansen, and W. R. Kennedy, "A Linear Electron Accelerator," Review of Scientific Instruments 19, 89 (1948).

8. Ginzton, E. L. and W. Kirk, "The Two-Mile Electron Accelerator," Scientific American 205, 49 (November 1961).

9. "High Energy Accelerators," Atomics Magazine, Vol. 15, No. 3 (1962), Vol. 16, No. 3 (1963), and Vol. 17, No. 4 (1964).

10. Neal, R. B., "Design of Linear Electron Accelerators With Beam Loading," Journal of Applied Physics 29, 1.019 (1958).

11. Page, B. M. and L. L. Tabor, "Chaotic Structure and Décollement in Cenozoic Rocks Near Stanford University, California, "Bulletin of the Geological Society of America (in press).

12. Panofsky, W.K.H., "Experimental Techniques," Springer Tracts in Modern Physics 39, 138 (1965).

13. Post, R. F. and N. S. Shiren, "The Stanford Mark II Linear Accelerator," Review of Scientific Instruments $\underline{26}, 205$ (1955).

14. Rose, B. F.," Atom Smasher for Nuclear Physics Research," Military Engineer $\underline{56}, 2$ (1964).

15. "Stanford Linear Accelerator," Western Construction Magazine 39 (No. 2), 64 (February 1964).

16. Varian, R. H. and S. F. Varian, "A High Frequency Oscillator and Amplifier," Journal of Applied Physics 10, 321 (1939).

17. Wilson, R. R., "Particle Accelerators," Scientific American 198, 64 (March 1058). 


\section{Conference Proceedings}

1. Ballam, J., et al. , "Status of Design, Construction, and Research Programs at SLAC," Proceedings, Fifth International Conference on High-Energy

Accelerators, Frascati, Italy, September 9-16, 1965.

2. Blewett, M. H., Proceedings of the 1961 International Conference on HighEnergy Accelerators (U. S. Government Printing 'Office, Washington, 1961).

3. Chodorow, M. , "Design and Performance of a High Power Pulsed Klystron," Proceedings of the I. R. E. $\underline{41}, 1584$ (1953).

4. Hermannsfeldt, W. B. , "Linac Alignment Techniques," Proceedings, IEEE

Particle Accelerator Conference, Washington, D. C. , March 10-12, 1965.

5. Loew, G. A. , "Progress Report on the Stanford Linear Accelerator Center," Proceedings, 1.964 Linac Conference, MURA, Madison, Wisconsin, July 1964.

6. Neal, R. B., "The Two-Mile Linear Accelerator," Proceedings of the 75th Anniversary Symposium, Georgia Institute of Technology, Atlanta, Georgia, 57 (1963).

7. Neal, R. B. , "The Stanford Two-Mile Linear Accelerator," Proceedings, American Vacuum Society Symposium, Chicago, Illinois, September 30 October 2, 1964.

8. Merdinian, G. K., J. H. Jasberg, and J. V. Lebacqz, "High Power, Permanent Magnet Focused, S-Band Klystron for Linear Accelerator Use." Prodeedings, 1964 Electron Devices Meeting, Washington, D. C.

October 29-31, 1964.

9. Miller, R. H., R. F. Koontz and D. D. Tsang, "The SLAC Injector," Proceedings, IEEE Particle Accelerator Conference, Washington, D. C. , March 10-12, 1965. 
10. Osgood, E. W. and J. M. Keith, "Construction of the Accelerator Housing at the Stanford Linear Accelerator Center," Presented at Annual American Concrete Institute Convention (1965).

\section{$\underline{\text { Reports }}$}

1. Atchley, F. W., "Preliminary Geological Investigation of the Sand Hill and Felt Lake Linear Accelerator Sites, Stanford University," Private Report to John A. Blume and Associates (1960).

2. DeStaebler, H. , "Average Radiation Levels Inside the Accelerator When The Machine is Off," SLAC Internal Report, Stanford Linear Accelerator Center, Stanford University, Stanford, California (1962).

3. DeStaebler, H. , "Radioactive Gas in the Tunnel," SLAC Internal Report, Stanford Linear Accelerator Center, Stanford University, Stanford, California (1962).

4. DeStaebler, H. , "Transverse Radiation Shielding for the Stanford Two-Mile Accelerator," SLAC Report No. 9, Stanford Linear Accelerator Center, Stanford University, Stanford, California (1962).

5. "Geologic Site Investigation for Stanford Linear Accelerator Center," Aetron-Rlume-Atkinson Report No. ABA-88 (1965).

6. Neal, R. B. , "A High Energy Linear Electron Accelerator," M. L. Report No. 185, Microwave Laboratory, Stanford University, Stanford, California (1953).

7. Neal, R. B., and W. K. H. Panofsky, "The Stanford Mark III Linear Accelerator and Speculations Concerning the Multi-BeV Applications of Electron Linear Accelerators," HEPL Report No. 80, High Energy Physics Laboratory, Stanford University, Stanford, California (April 1956). 
8. Trask, P. D. , "Engineering Geology, Proposed Linear Electron Accelerator Sand Hill Site, Stanford University," Private Report to Aetron-BlumeAtkinson (1961).

\section{Government Documents}

1. Accelerators: "Understanding the Atom," (U.S. Atomic Energy Commis.sion, Division of Technical Information Extension, Oak Ridge, Tennessee, 1963).

2. Background Information on the High Energy Physics Program and the Proposed Stanford Linear Electron Accelerator Project, Report to the Joint Committee on Atomic Energy, Congress of the United States (U.S. Government Printing Office, Washington, D. C. , 1961).

3. Report of the Panel on High Energy Accelerator Physics of the General. Advisory Committee to the Atomic Energy Commission and the President's Science Advisory Committee, TID-18636 (U.S. Atomic Energy Commission, Division of Technical Information, Washington, D. C. , April 26, 1963) .

4. Stanford Linear Accelerator Center, Hearings Before the Subcommittee on Research and Development and the Subcommittee on Legislation of the Joint Committee on Atomic Energy, Congress of the United States, July 14 and 15, 1959 (U.S. Government Printing Office, Washington, D. C. 1959). 


\section{LEGAL NOTICE}

This report was prepared as an account of Government sponsored work. Neither the United States, nor the Commission, nor any person acting on behalf of the Commission:

A. Makes any warranty or representation, expressed or implied, with respect to the accuracy, completeness, or usefulness of the information contained in this report, or that the use of any information, apparatus, method, or process disclosed in this report may not infringe privately owned rights; or

B. Assumes any liabilities with respect to the use of, or for damages resulting from the use of any information, apparatus, method, or process disclosed in this report.

As used in the above, "person acting on behalf of the Commission" includes any employee or contractor of the Commission, or employee of such contractor, to the extent that such employee or contractor of the Commission, or employee of such contractor prepares, disseminates, or provides access to, any information pursuant to his employment or contract with the Commission, or his employment with such contractor. 